\title{
Application of Nano Fluids in Changing Reservoir Rock and Fluid Properties for Enhanced Oil Recovery
}

\author{
Mohammad Ehtemam Haghighi
}

Follow this and additional works at: https://researchrepository.wvu.edu/etd

\section{Recommended Citation}

Ehtemam Haghighi, Mohammad, "Application of Nano Fluids in Changing Reservoir Rock and Fluid Properties for Enhanced Oil Recovery" (2014). Graduate Theses, Dissertations, and Problem Reports. 5530.

https://researchrepository.wvu.edu/etd/5530

This Thesis is protected by copyright and/or related rights. It has been brought to you by the The Research Repository @ WVU with permission from the rights-holder(s). You are free to use this Thesis in any way that is permitted by the copyright and related rights legislation that applies to your use. For other uses you must obtain permission from the rights-holder(s) directly, unless additional rights are indicated by a Creative Commons license in the record and/ or on the work itself. This Thesis has been accepted for inclusion in WVU Graduate Theses, Dissertations, and Problem Reports collection by an authorized administrator of The Research Repository @ WVU. For more information, please contact researchrepository@mail.wvu.edu. 
Application of Nano Fluids in Changing Reservoir Rock and Fluid Properties for

Enhanced Oil Recovery

\section{Mohammad Ehtemam Haghighi}

Thesis submitted to the

Benjamin M. Statler College of Engineering and Mineral Resources

At West Virginia University

In partial fulfillment of the requirements for the degree of

Master of Science in

Petroleum and Natural Gas Engineering

Khashayar Aminian, Ph. D., Chair

Samuel Ameri, M.S.

Daniel E. Della-Giustina, Ph.D.

Department of Petroleum and Natural Gas Engineering

Morgantown, West Virginia

July 2014

Keywords: Water Flooding, Enhanced Oil Recovery, Interfacial Tension, Wettability Angle, Nano Fluid

Copyright 2014 Mohammad Ehtemam Haghighi 


\section{Abstract \\ Application of Nano Fluids in Changing Reservoir Rock and Fluid Properties for Enhanced Oil Recovery}

\section{Mohammad E. Haghighi}

In conventional oil reservoirs after drilling a well, the hydrocarbon starts to produce by the natural force of the reservoir. After a period of production the reservoir energy declines and the secondary recovery methods are used to keep the production rate constant. The most common secondary method is water flooding in which by injecting water into the reservoir, trapped oil is pushed toward the producing wells. Water flooding is not a long term method for producing oil and as soon as the water finds its path to the producers, water cut goes up and injection is not economical anymore. Therefore tertiary methods or EOR methods are introduced. In these methods by injecting special kind of fluid, rock and/or fluid properties are changed and another portion of trapped oil can be produced. Nano particles are one of the popular new EOR agents that can attract petroleum engineers' attention in recent years. In this work, two types of nano particles were used for studying the effect of nano particles on additional oil recovery. In the first step different concentration of nano fluids were prepared and the effect of each concentration on IFT and wettability angle was determined. After specifying the optimum concentration of nano fluid for each two types of nano particles, two sand stone samples were first flooded by four pore volume of brine and then with three pore volume of nano fluid and the volume of produced oil for calculating the recovery factor was recorded. The results show hydrophobic and neutral wet nano particles can bring in additional recovery factor of $23.8 \%$ and $29.9 \%$ in sandstone core samples respectively. This improvement in sandstone samples can be recognized due to interfacial tension reduction and wettability alteration. 
To my lovely parents; my brothers and my sister for all their unwavering support and motivation 


\section{Acknowledgements}

I would like to acknowledge all of those who have educated, inspired, guided, influenced and not least supported me during my years of studies.

I would also like to express my sincere thanks and gratitude to my advisor, Dr. Khashayar Aminian for all his guidance and support. I feel honored to have been a student of Dr. Aminian, and thank you for challenging me all the time to bring out the best. I am highly grateful to Prof. Samuel Ameri for insightful conversations and his useful suggestions for this research. I cannot thank him enough for all his encouragement and support. Special thanks to Dr. Daniel E. Della-Giustina for his remarkable advice for doing this research and being my committee member.

I am also thankful to Schlumberger and Chevron companies' engineers and petrophysicists, Zeyn Safarkhanlu, Mojtaba Khadem and Vahid Haghighi for their training, advice, suggestion and assistance.

My sincere thanks to family and friends for their unconditional love, patience and support. 


\section{Table of Content}

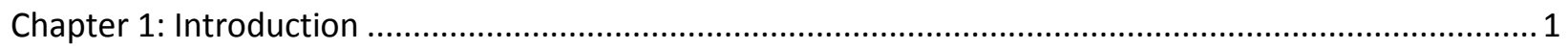

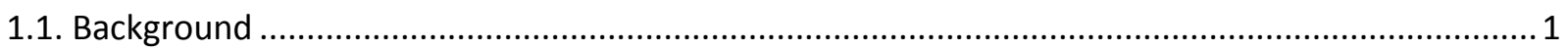

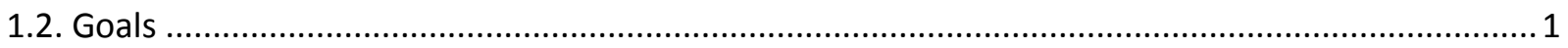

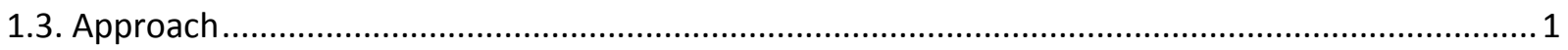

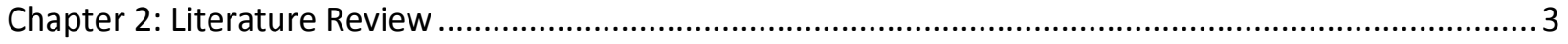

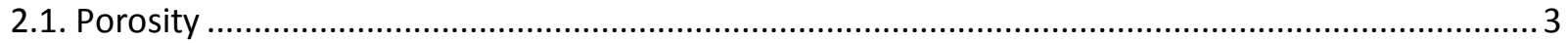

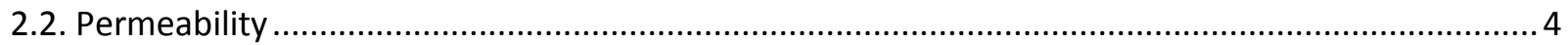

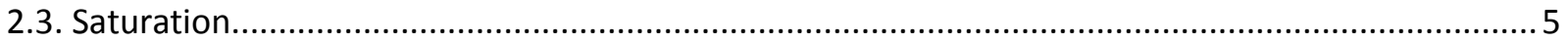

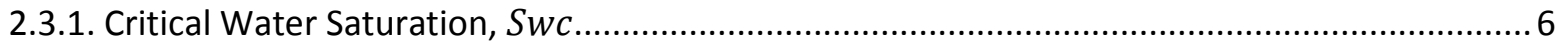

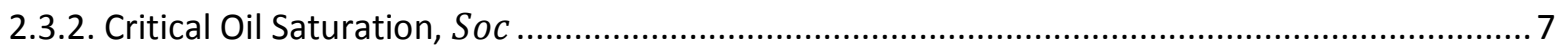

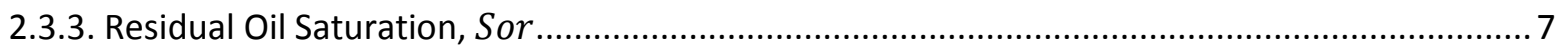

2.3.4. Moveable Oil Saturation, Som ........................................................................................ 7

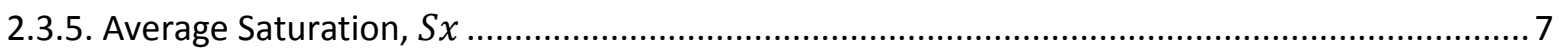

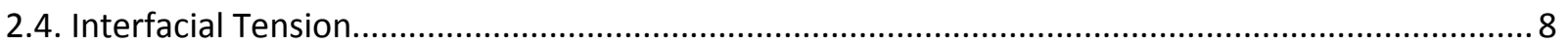

2.4.1. Laboratory Measurement of Interfacial Tension ..................................................................... 9

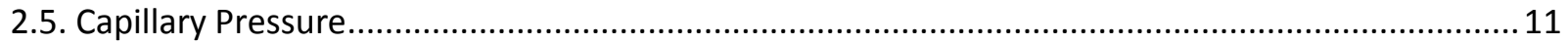

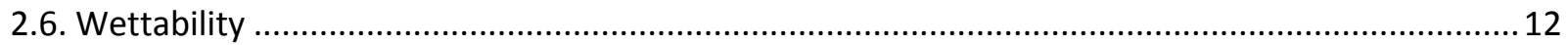

2.6.1. Classification of Reservoir Rock Wettability ...................................................................... 13

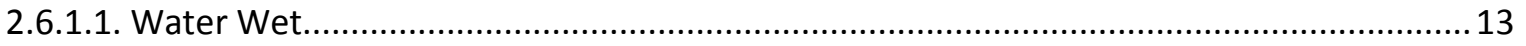

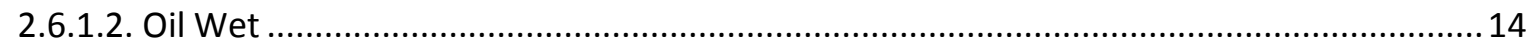

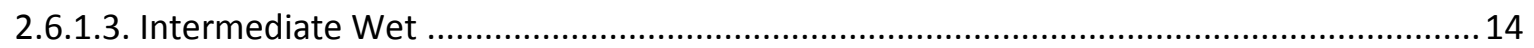

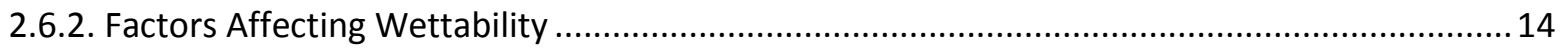

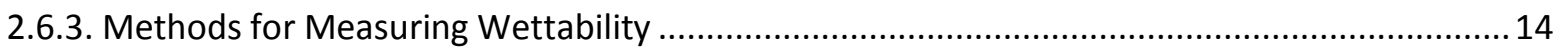

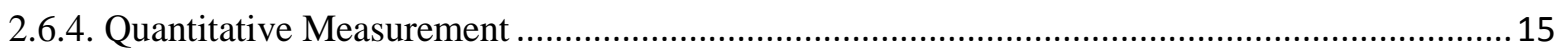

2.6.4.1. Contact Angle Measurement Method ......................................................................... 15

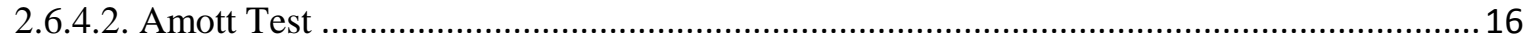

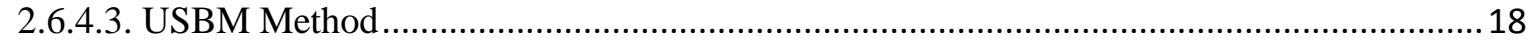

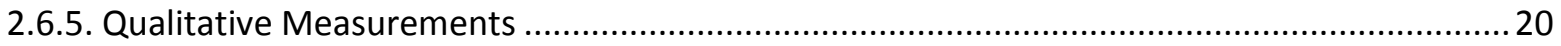

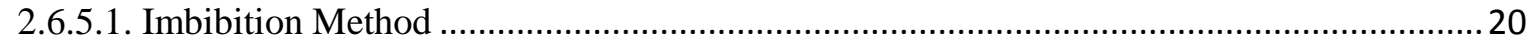

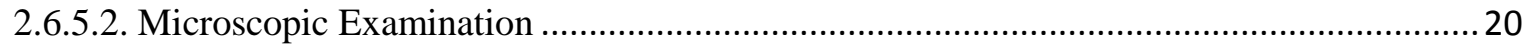

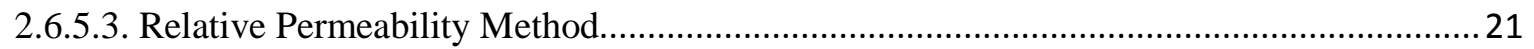


2.6.5.4. Permeability/Saturation Relationship Method .............................................................. 22

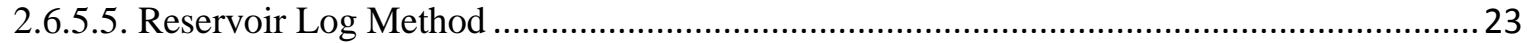

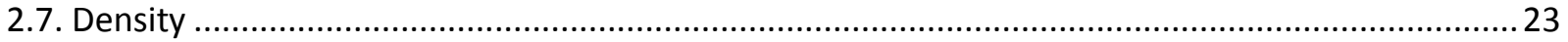

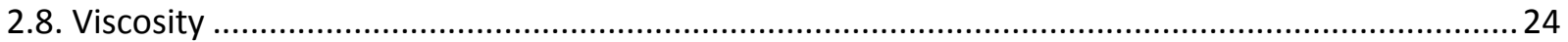

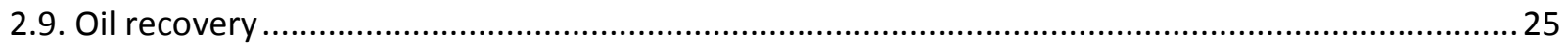

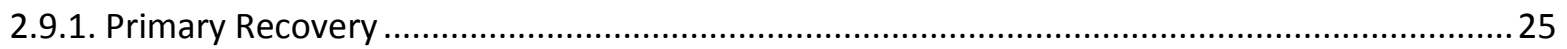

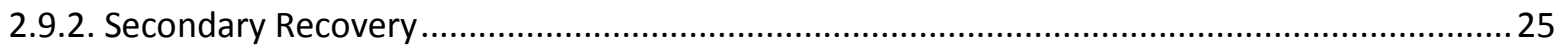

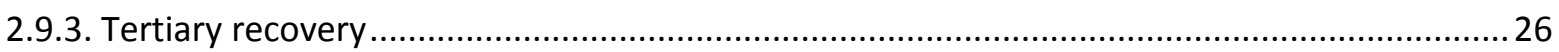

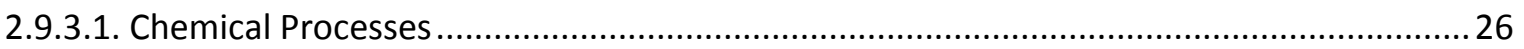

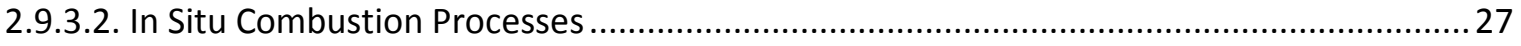

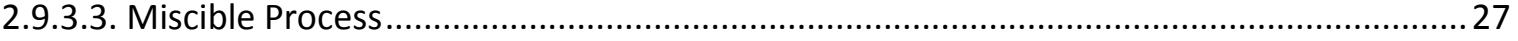

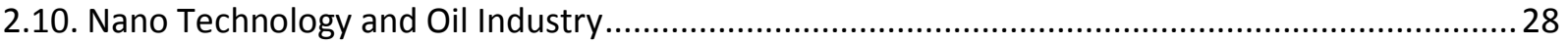

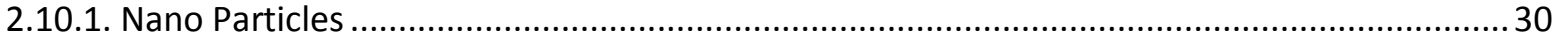

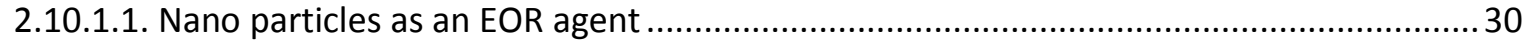

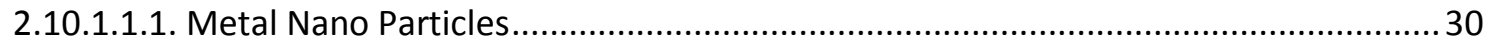

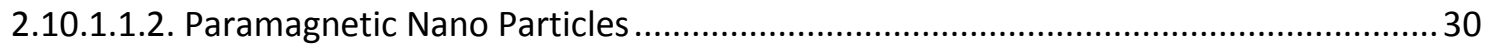

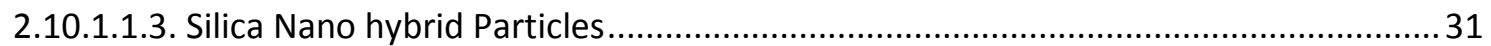

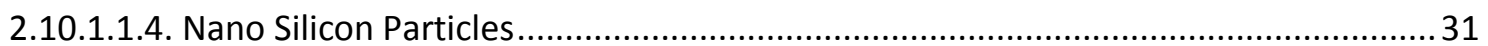

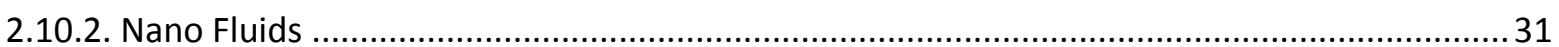

Chapter 3: Experimental Procedures and Apparatuses ........................................................................... 32

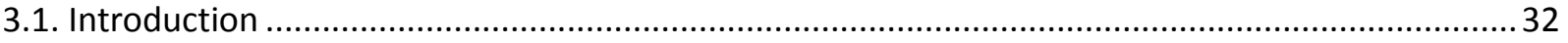

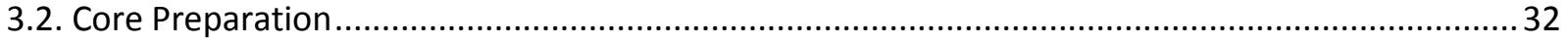

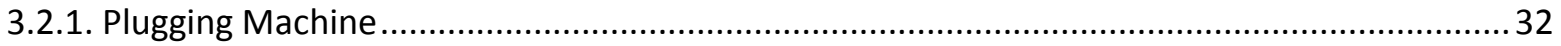

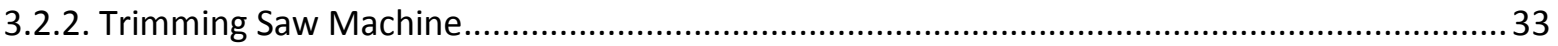

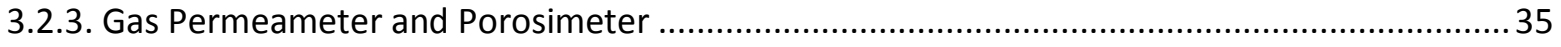

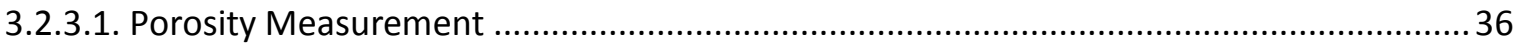

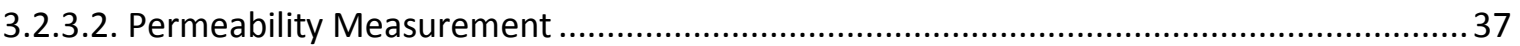

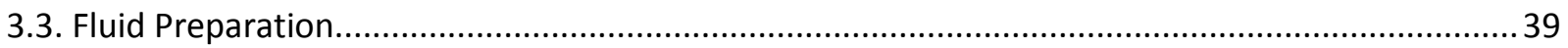

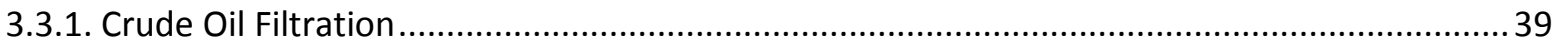

3.3.2. Synthetic Formation Water Preparation …......................................................................... 40

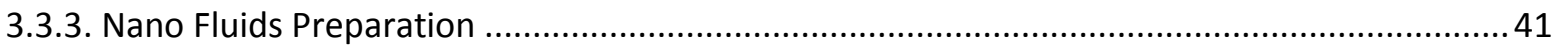

3.4. Contact Angle Measurement ……............................................................................................... 43 


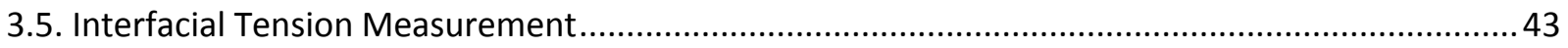

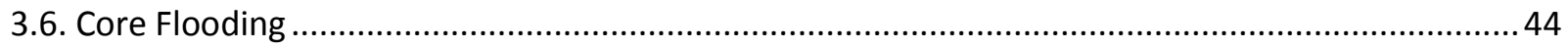

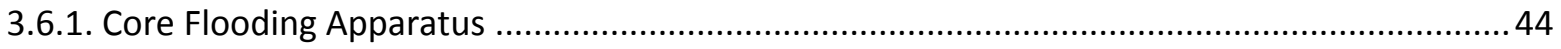

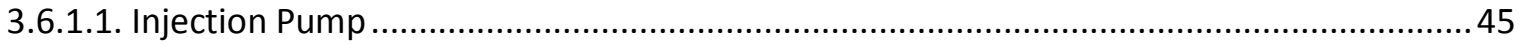

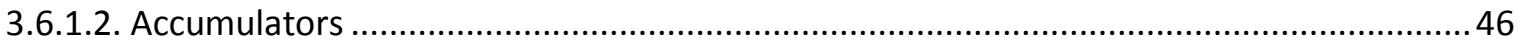

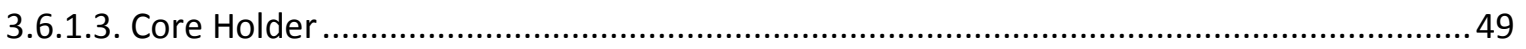

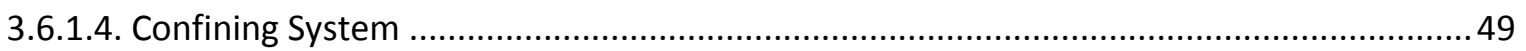

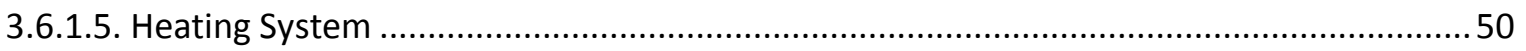

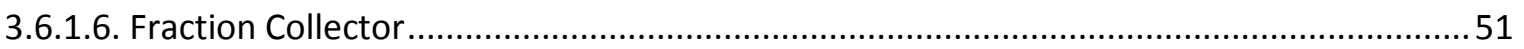

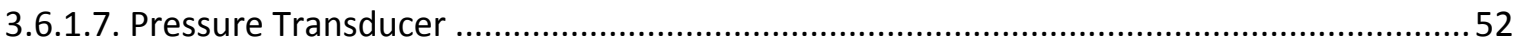

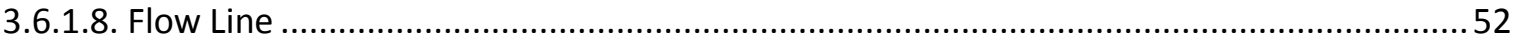

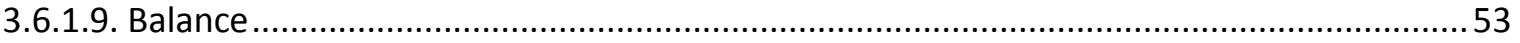

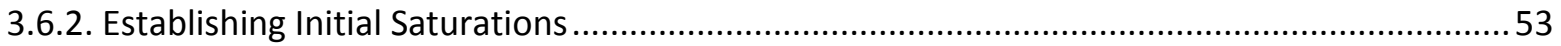

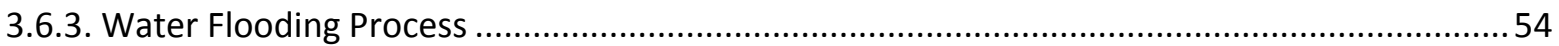

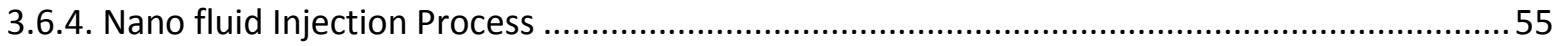

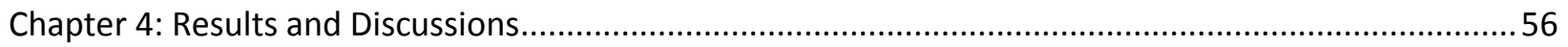

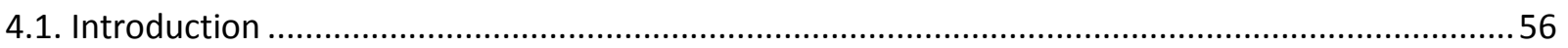

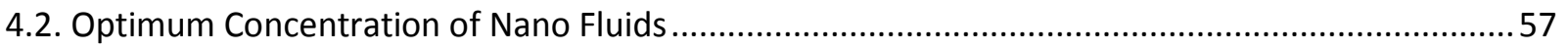

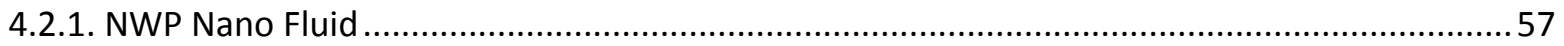

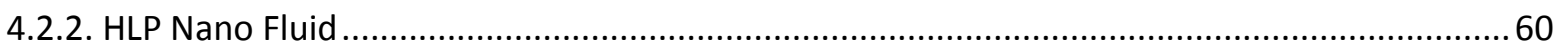

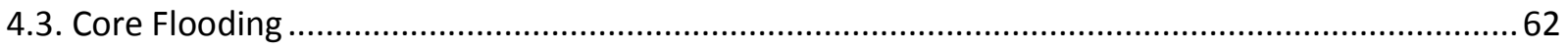

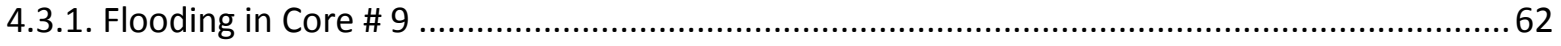

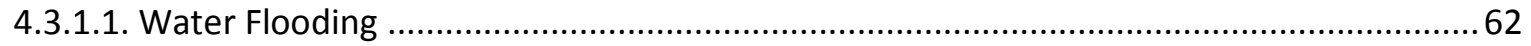

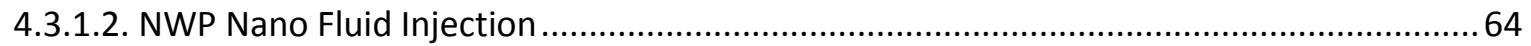

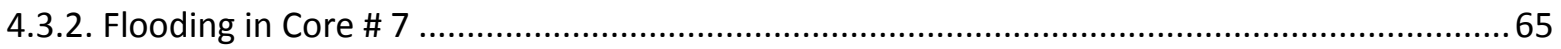

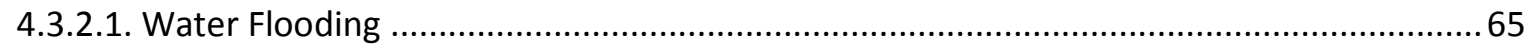

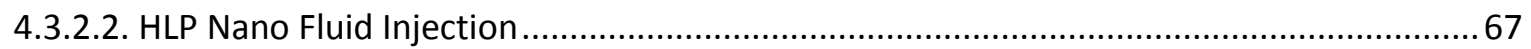

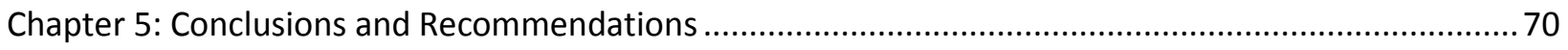

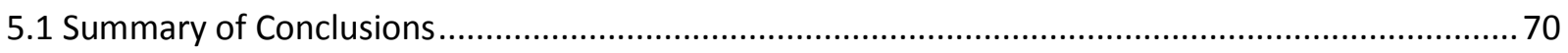

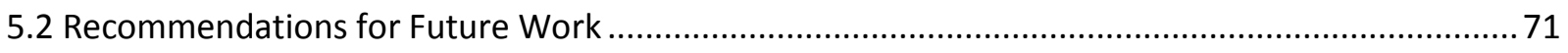

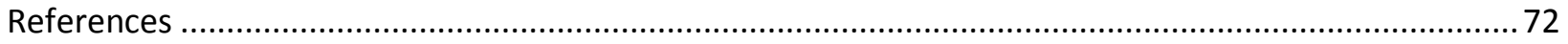




\section{List of Tables}

Table 2 - 1 Relationships between Wettability and Amott Wettability Indices.......................................18

Table 2 - 2 Craig's Rules of Thumb Relating Wettability and Relative Permeability................................22

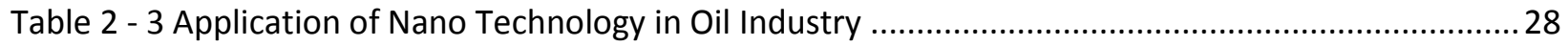

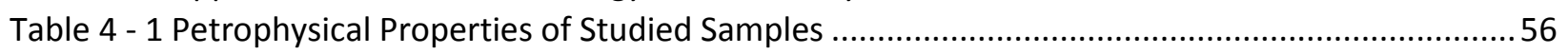

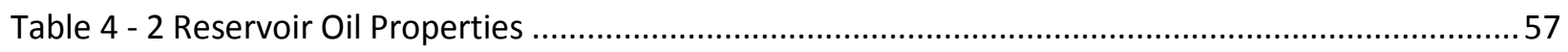

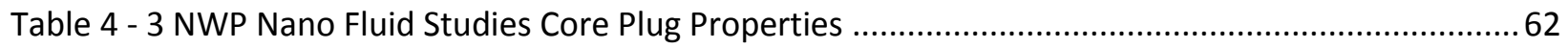

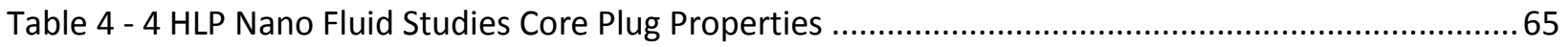




\section{List of Figures}

Figure 2 - 1 Interconnected pores and Isolated Pores ........................................................................ 4

Figure 2 - 2 Good Permeability and Poor Permeability ................................................................... 4

Figure 2 - 3 Definition of Porosity and Water, Oil and Gas Saturation ................................................ 5

Figure 2 - 4 Schematic Representation of Irreducible Water Saturation in a Reservoir ............................ 6

Figure 2 - 5 The Concept of Interfacial Tension Between Two Immiscible Liquids .................................... 9

Figure 2 - 6 Schematic of Pendant Drop Method Setup, Brine is Suspended in Clear Oil ........................ 10

Figure 2 - 7 Schematic of a System of Two Immiscible Liquids (Oil and Water) in Contact with Mineral

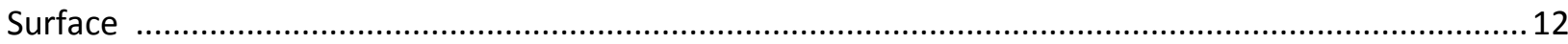

Figure 2 - 8 Schematic of Water Wet Rock, Grains are Covered by Water and Oil is at the Center of Pores

13

Figure 2 - 9 Schematic of Oil Wet Rock, Grains are Covered by Oil and Water is at the Center of Pores.. 14

Figure 2 - 10 Determining Contact Angle by Drawing Tangent Line ..................................................... 15

Figure 2 - 11 Contact Angle Measurement in Modified Sessile Drop Method ........................................16

Figure 2 - 12 Oil and Water Displacement Setup for the Amott Wettability Test ...................................17

Figure 2 - 13 Centrifuge Tube Cross Section in USBM Setup ................................................................. 18

Figure 2 - 14 Effective Pressure Versus Average Water Saturation for Wettability Determination in USBM

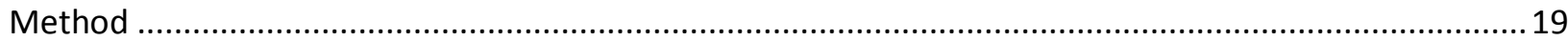

Figure 2 - 15 Wettability Determination by Using Relative Permeability Curve ..................................... 21

Figure 2 - 16 Wettability Determination Based on Air Permeability and Water Saturation .....................22

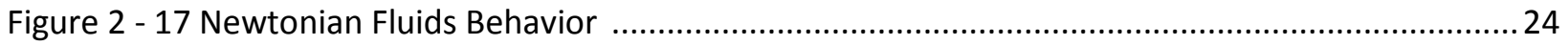

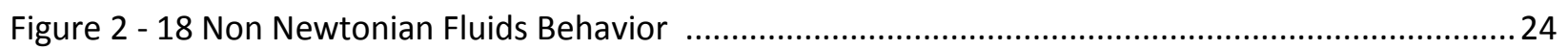

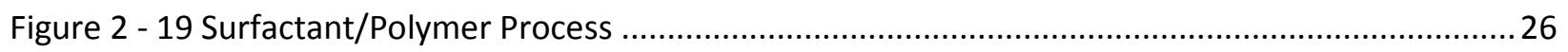

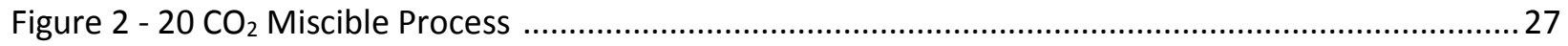

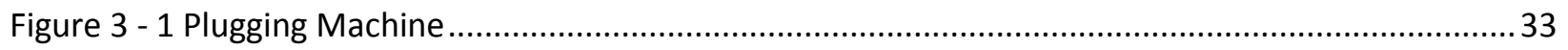

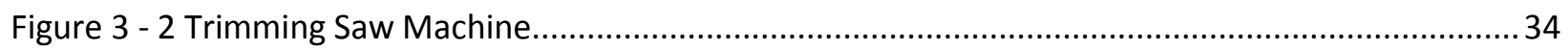

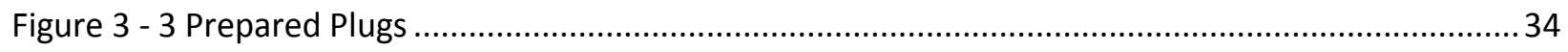

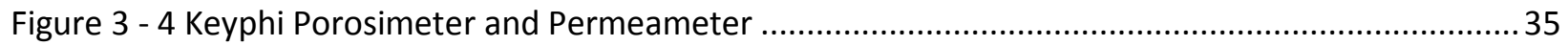

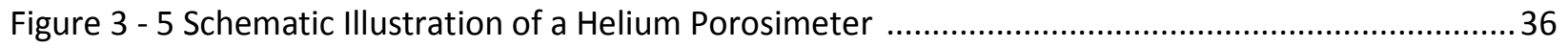

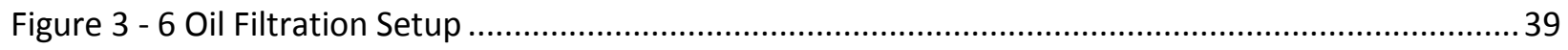

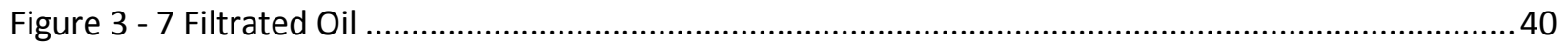

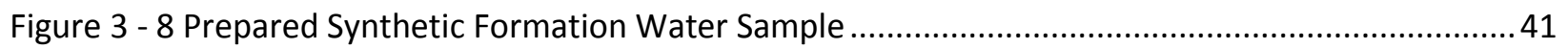

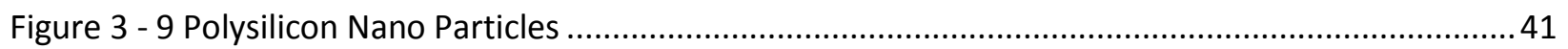

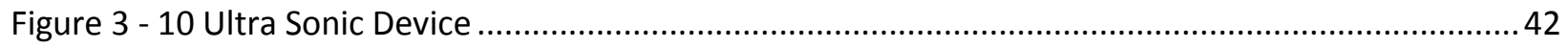

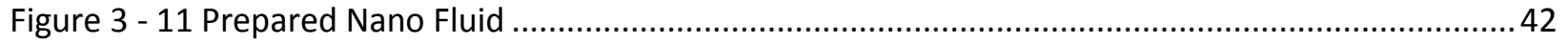

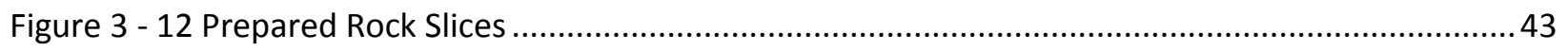

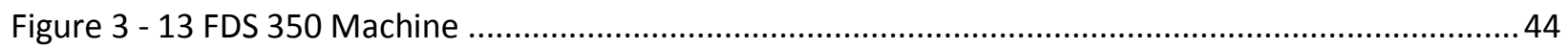

Figure 3 - 14 FDS 350 Program Environment and Piping Schematic .................................................... 45

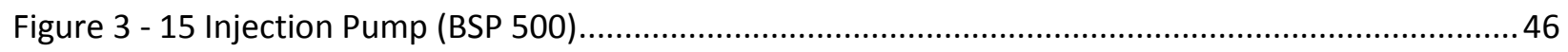

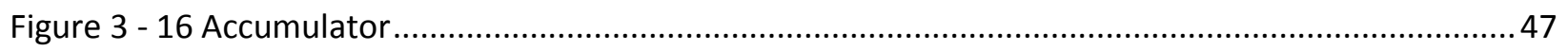

Figure 3 - 17 Plastic Cylinder for Refilling the Accumulator in Indirect Method ......................................48

Figure 3 - 18 Air Compressor for Pushing the Fluid into the Accumulator ............................................. 48 


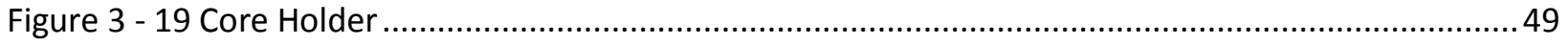

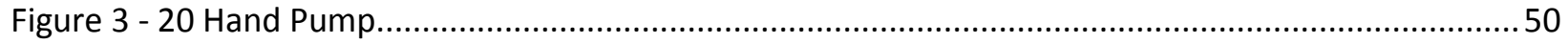

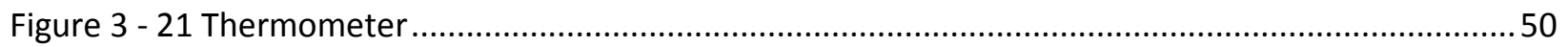

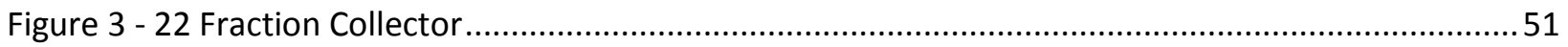

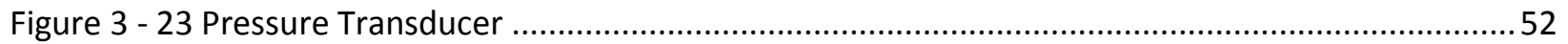

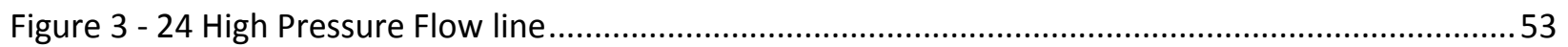

Figure 4 - 1 IFT Changes versus Different Concentration of NWP Nano Fluid............................................58

Figure 4 - 2 Wettability Angle Changes versus Different Concentration of NWP Nano Fluid ....................59

Figure 4 - 3 Comparing the Effect of Different Concentration of NWP Nano Fluid on IFT and Wettability

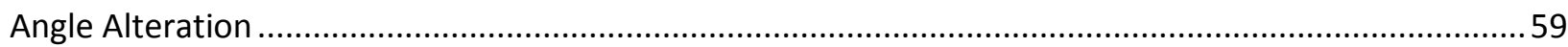

Figure 4 - 4 IFT Changes versus Different Concentration of HLP Nano Fluid.........................................60

Figure 4 - 5 Wettability Angle Changes versus Different Concentration of HLP Nano Fluid ..................... 61

Figure 4 - 6 Comparison the Effect of Different Concentration of Nano Fluid on IFT and Wettability Angle

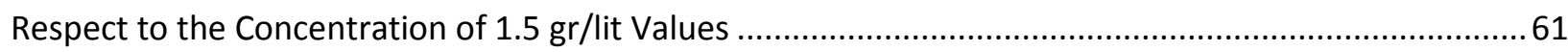

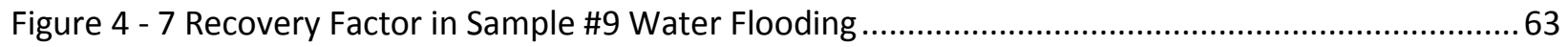

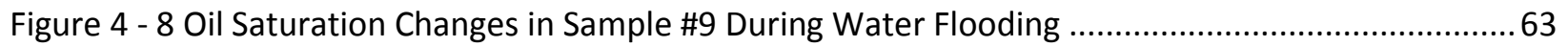

Figure 4 - 9 Recovery Factor Changes in Sample \#9 During NWP Flooding...............................................64

Figure 4 - 10 Oil Saturation Changes in Sample \#9 During NWP Flooding ................................................65

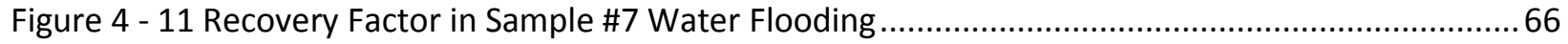

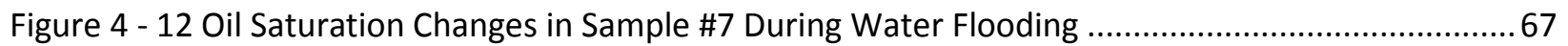

Figure 4 - 13 Recovery Factor Changes in Sample \#7 During HLP Flooding............................................6 68

Figure 4 - 14 Oil Saturation Changes in Sample \#7 During HLP Flooding ...............................................69 


\section{Chapter 1: Introduction}

\subsection{Background}

The global demand of energy in recent years has been increased significantly. In order to provide enough oil and gas for other industries consumption as well as people daily life more production is required from conventional and non-conventional resources. This demand can be fulfilled by exploring new hydrocarbon fields and drilling wells or by improving the production from the current producing fields. Since most of the easy accessible reservoirs have been explored and drilled, petroleum engineers prefer to focus on improving the production from the current fields by using different IOR methods. One of the main and common IOR methods is water flooding which can help to produce additional portion of initial oil in place by injecting water into the reservoir and pushing oil toward producing wells. But after water break through especially in sandstone reservoirs due to high water oil ratio this method is not economical anymore; therefore tertiary methods or EOR methods are used to produce another portion of trapped oil by changing rock and/or fluid properties. Currently surfactant and $\mathrm{CO}_{2}$ flooding are the most common EOR methods which are used in upstream oil industry. Scientists and researchers have introduced several new methods for EOR that can improve oil recovery significantly. Nano technology is the one that could show a great progress and attention in oil industry in the last couple of years. Nano technology is kind of applied science and technology which focuses on the material within the size of atom or molecule (100 nm or smaller) and also designing and producing the devices within this range. Nano technology has broad range of application in upstream, midstream and downstream in oil industry.

\subsection{Goals}

The goal of this experiment is to study the effect of two types of nano particles on interfacial tension and wettability angle and improving oil recovery after conducting the primary and secondary recovery by the means of water flooding in sandstone samples.

\subsection{Approach}

To conduct this experiment, different concentrations of three two of nano fluids are prepared and their effect on changing IFT value and wettability angle was determined. After finding the optimum concentration of 
nano fluid for each type of polysilicon, core flooding apparatus was loaded with core sample, oil, brine and studying nano fluid. The sample was first flooded with brine to mimic primary and secondary recovery for four pore volume and then by three pore volume of nano fluid. The volume of produced oil was recorded at specific intervals for determining recovery factor. In the next step a graph of recovery factor versus injection pore volume was plotted for each of the flooding tests. By analyzing the graphs the optimum concentration of injection fluid for each test was determined. 


\section{Chapter 2: Literature Review}

\subsection{Porosity}

One of the main parameters in reservoir studies is porosity which has to be determined as accurate as possible. Porosity is defined as the capacity of the rock to store a fluid or in another words the fraction of bulk volume which is occupied by pores. [1]

$$
\text { Porosity }(\varphi)=\frac{V_{p}}{V_{b}} \times 100 \%=\frac{V_{p}}{V_{p}+V_{g}} \times 100 \%=\frac{V_{b}-V_{g}}{V_{b}} \times 100 \%
$$

Where:

$V_{P}:$ Pore or void volume

$V_{b}:$ Bulk volume of rock

$V_{g}$ : Grain volume

Porosity value is affected by grain size, compaction, clay content, cementation, packing, sorting, granulation and crushing. Based on the sedimentation environment and the mentioned parameters, porosity is classified in two groups, total porosity and effective porosity. In total porosity whole of the pore volumes are considered while in effective just those that are connected to each other. [2]

$$
\begin{gathered}
\text { Total Porosity }\left(\varphi_{t}\right)=\frac{\text { Total Pore Volume }}{\text { Bulk Volume }} \\
\text { Effective Porosity }\left(\varphi_{e}\right)=\frac{\text { Interconnected Pore Space }}{\text { Bulk Volume }}
\end{gathered}
$$

In very clean sand stone usually total porosity is equal to effective porosity while in highly cemented rock and/or when significant amount of clay minerals are present the total porosity is greater than effective porosity. [2] As Figure 2-1 shows on the left side most of the pores are interconnected so the total is approximately equal to effective porosity while on the right one most of them are isolated so these two are not equal to each other. 

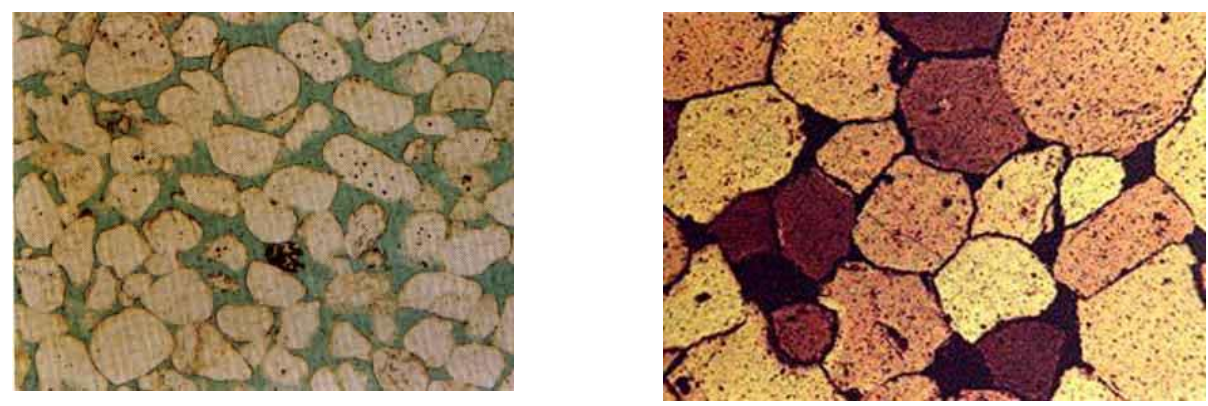

Figure 2 - 1 Interconnected pores (Left), [3]; Isolated Pores (Right), [4]

\subsection{Permeability}

Permeability is defined as the ability of the rock to pass the fluid. Permeability is the function of how well the pore spaces are interconnected. [1] As the Figure 2-2 shows on the left side since the pores are interconnected and pore throats are large enough to pass the fluid the permeability is greater than the right one.
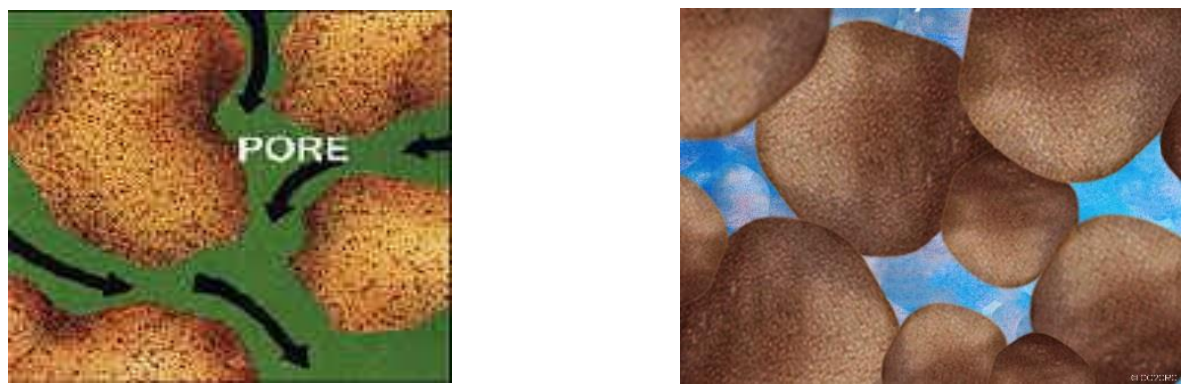

Figure 2 - 2 Good Permeability (Left), [5]; Poor Permeability (Right), [6]

Henry Darcy was the first person whom by conducting different experiments on beds of packed sand and their abilities to pass different kind of fluid understood that flow rate is proportional to pressure difference, cross section area and inverse of length, so by combining them the following formula was driven [7]:

$$
q=C \frac{A \Delta P}{L}
$$

Where:

$q:$ Fluid flow rate in porous medium, $\frac{\mathrm{cm}^{3}}{\mathrm{~s}}$

$\Delta P:$ Pressure difference between inlet and oulet of medium, atm 


\section{$L:$ Lenght of medium, $\mathrm{cm}$}

\section{$A:$ Cross section of medium open to flow, $\mathrm{cm}^{2}$}

By running more tests it was found constant $\mathrm{C}$ is proportional to inverse of fluid viscosity so the formula was modified to:

$$
q=K \frac{A}{\mu} \frac{\Delta P}{L}
$$

Where:

\section{$\mu:$ Fluid viscosity, $c p$}

Constant $\mathrm{K}$ is known as the permeability and its unit is Darcy. On the basis of this formula the porous medium permeability is 1 darcy if the pressure difference between inlet and outlet is $1 \mathrm{~atm}$ and the cross section area and length are $1 \mathrm{~cm}^{2}$ and $1 \mathrm{~cm}$, respectively and the viscosity of passing fluid is $1 \mathrm{cp}$.

1 darcy is equal to $9.869 \times 10^{-9} \mathrm{~cm}^{2}$ but since the field units are different the following Darcy's law is used for calculating the flow rate in linear flow system:

$$
q=1.127 K \frac{A}{\mu} \frac{\Delta P}{L}
$$

Where $\mathrm{q}, \mathrm{K}, \mathrm{A}, \Delta \mathrm{P}$ and $\mathrm{L}$ units are bbl/day, darcy, $\mathrm{ft}^{2}$, cp, psi and $\mathrm{ft}$ respectively.

\subsection{Saturation}

Pore volume is always filled with gas, oil, water or combination of them, so the fraction of pore volume that has been occupied by any of them is called saturation respect to that fluid. [7]
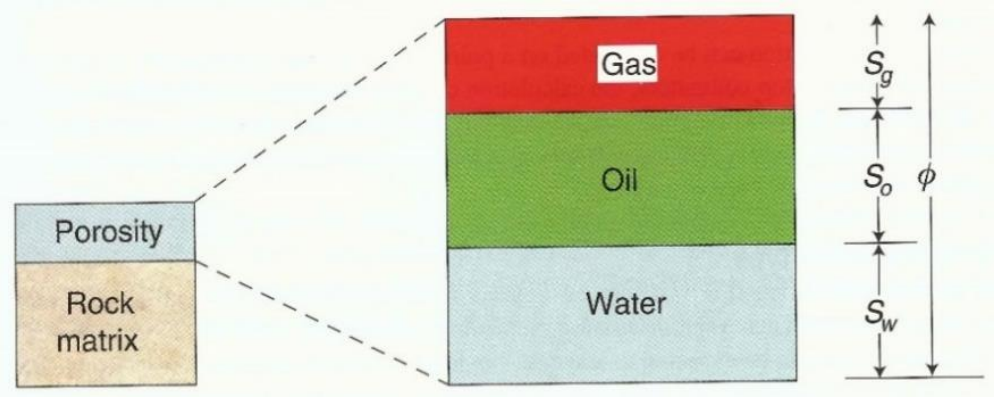

Figure 2 - 3 Definition of Porosity and Water, Oil and Gas Saturation [8] 
In equation form saturation is defined as:

$$
S_{x}=\frac{V_{f}}{V_{p}}
$$

Where:

$S_{x}:$ Fraction of fluid, fraction or percent

$V_{p}:$ Total pore volume, $\mathrm{cm}^{3}$

$V_{f}$ : Total volume of studying fluid (water, oil, gas), $\mathrm{cm}^{3}$

The summation of fluid saturations is always equal to one.

$$
S_{o}+S_{w}+S_{g}=1
$$

Where $S_{\mathrm{o}}, S_{\mathrm{w}}, S_{\mathrm{g}}$ are oil, water and gas saturation, respectively.

\subsubsection{Critical Water Saturation, $S_{w c}$}

The maximum water saturation in porous medium which the water is still immobile is called critical water saturation. Connate water saturation, irreducible water saturation are another terms that can be used. [9] Figure 2-4 shows irreducible water saturation distribution in a reservoir.

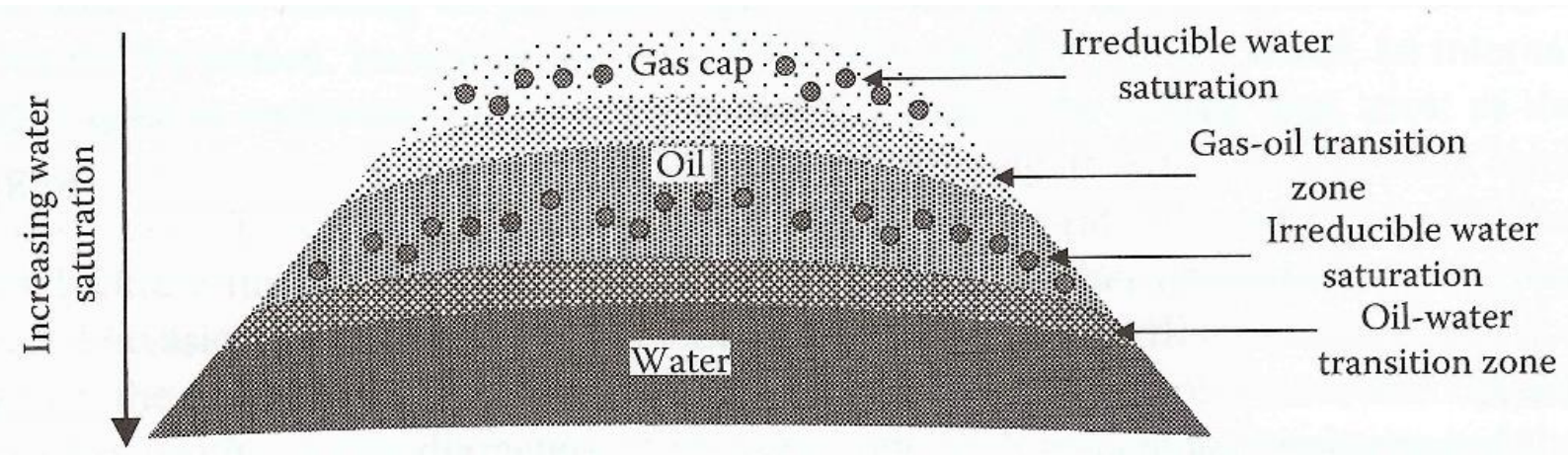

Figure 2 - 4 Schematic Representation of Irreducible Water Saturation in a Reservoir [10] 


\subsubsection{Critical Oil Saturation, $S_{o c}$}

As the oil saturation decreases with production it reaches to the point that the oil traps in the pores and cannot flow any more, this saturation is called critical oil saturation, $S_{o c}$. [9]

\subsubsection{Residual Oil Saturation, $S_{\text {or }}$}

During displacing the oil by secondary or tertiary methods a portion of oil is not swept and remains in pore spaces, this value which is larger than critical oil saturation, is called residual oil saturation. The term residual oil saturation is usually refers to non-wetting phase when it is being displaced by wetting phase. [9]

$$
S_{o r}=\frac{(P V-\text { cummulative volume of produced oil })}{P V}=\frac{\text { trapped oil in the sample }}{P V}
$$

Where:

PV : Pore volume, $c c$

\subsubsection{Moveable Oil Saturation, $S_{\text {om }}$}

Moveable oil saturation is defined as the portion of oil saturation that can be produced and it is expressed by the following equation [9]:

$$
S_{o m}=1-S_{w c}-S_{o c}
$$

Where:

$S_{w c}:$ Connate water saturation

$S_{o c}:$ Critical oil saturation

\subsubsection{Average Saturation, $\bar{S}_{x}$}

Understanding of reservoir fluids saturation and distribution is a critical factor in reservoir studies. Different methods are used for calculating average saturation but the most common ones are those which 
assign a weight to different involving parameters and calculate the average saturation. [10] The following equations can be used for calculating average reservoir fluids saturation:

$$
\begin{gathered}
\bar{S}_{o}=\frac{\sum_{i=1}^{n} \Phi_{i} h_{i} S_{o i}}{\sum_{i=1}^{n} \Phi_{i} h_{i}} \\
\bar{S}_{w}=\frac{\sum_{i=1}^{n} \Phi_{i} h_{i} S_{w i}}{\sum_{i=1}^{n} \Phi_{i} h_{i}} \\
\bar{S}_{g}=\frac{\sum_{i=1}^{n} \Phi_{i} h_{i} S_{g i}}{\sum_{i=1}^{n} \Phi_{i} h_{i}}
\end{gathered}
$$

Where:

$\Phi_{i}:$ Porosity of layer $i$

$h_{i}$ : Thickness of layer $i$

$S_{o i}, S_{w i}, S_{g i}:$ oil,water, gas saturation of layer $i$

\subsection{Interfacial Tension}

When two immiscible fluids are in contact with each other, they are separated by a very thin interface $\left(10^{\circ} \mathrm{A}\right)$ due to the underbalanced forces in their boundary. As Figure 2-5 shows, in oil/water system the resultant forces on oil or water molecules which are remote from the interface are zero while those present at oil/water interface are under tension force due to different force magnitudes from the upper oil and lower water molecules which in turn leads to forming of thin membrane. This boundary tension at an interface of two immiscible liquids is called interfacial tension (IFT) and for gas/liquid system is known as the surface tension (ST); its dimension is force per unit length and is usually expressed as $\mathrm{mN} / \mathrm{m}$ or $10^{-3} \mathrm{~N} / \mathrm{m}(\mathrm{dyn} / \mathrm{cm})$ and the Greek symbol of $\sigma$ is used for showing it. [10]

Studying of interfacial and surface tension is very important since it has a direct effect on wettability, relative permeability and capillary pressure which are playing a significant role in oil and gas recovery. 


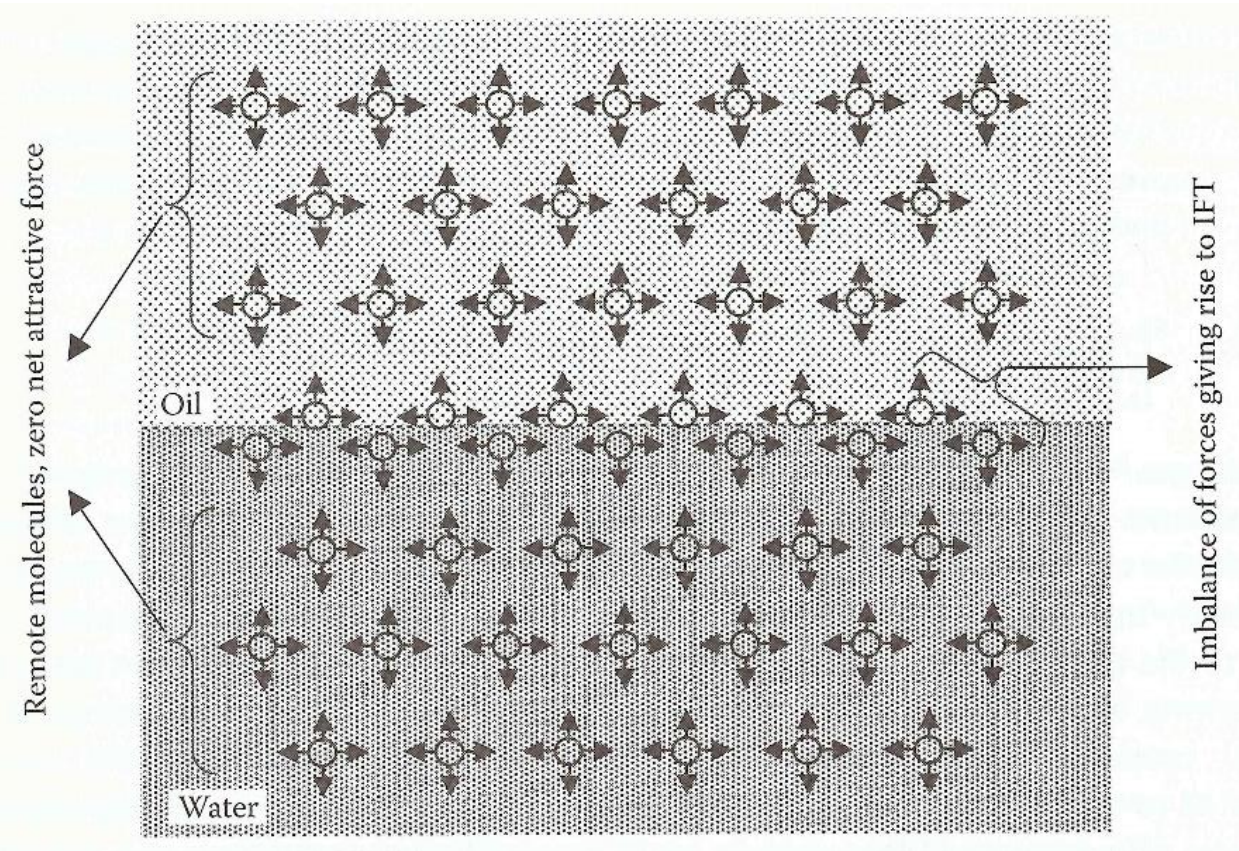

Figure 2 - 5 The Concept of Interfacial Tension Between Two Immiscible Liquids [10]

\subsubsection{Laboratory Measurement of Interfacial Tension}

For measuring IFT and ST different methods are available such as Wilhelmy plate, du Noüy ring, spinning drop, and the maximum pull force method but the most common one in oil industry in pendant drop method. All of these methods are measuring tension force.

The pendant drop method is based on suspending a droplet of denser liquid in adjacent of lighter one by using a narrow tube, syringe or spout for IFT measurement; and for ST the liquid droplet is suspended in the gas cell that has reservoir pressure and temperature to remodel the reservoir condition to increase the accuracy of measurements. Since the shape and size of droplet has a direct relationship with IFT/ST properties a video system is capturing droplet image during the test. As Figure 2-6 shows, IFT/ST determination is based on the assumption of droplet symmetry around a central vertical axis. After the system reaches to equilibrium the final image is taken and by enlarging it two diameters are measured, $d_{e}$ and $d_{s} \cdot[10]$ 


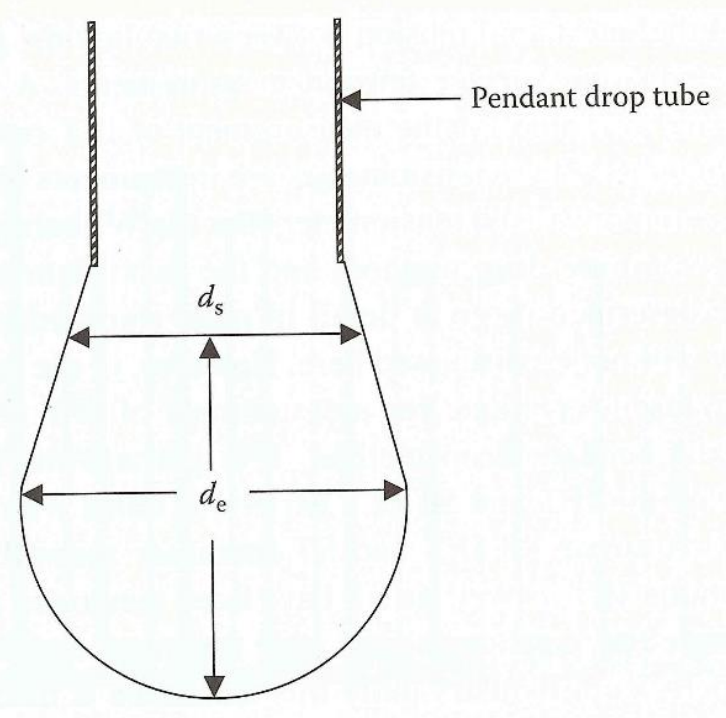

Figure 2 - 6 Schematic of Pendant Drop Method Setup, Brine is Suspended in Clear Oil [10]

Having diameters and density difference, IFT/ST can be determined by the equation which developed and published by Andreas et al. at 1938 .

$$
\sigma=\frac{\Delta \rho g d_{e}^{2}}{H}
$$

Where:

$\sigma:$ Interfacial tensio/ Surface tension, $\frac{N}{m}$

$\Delta \rho:$ Density difference between the two immiscible phases (e.g., gas - liquid or liquidliquid), $\frac{\mathrm{kg}}{\mathrm{m}^{3}}$

$g:$ Gravity accelartion, $\frac{m}{s^{2}}$

$d_{e}:$ Maximum horizontal diameter after doing magnify correction, $m$

$H:$ Drop - shape factor as a function of $S=\frac{d_{s}}{d_{e}}$

$d_{s}:$ Diameter of droplet measured at distance $d_{e}$ above the tip of droplet, $m$ 


\subsection{Capillary Pressure}

Capillary pressure is defined as the pressure difference that exists at the interface of two immiscible fluids in the pore space under the capillary equilibrium. [11] Capillary pressure can be shown mathematically as follow:

$$
P_{c}=P_{n w}-P_{w}
$$

Where

$P_{c}:$ Capillay pressure, $p$ si

$P_{n w}:$ non wetting phase pressure (e.g.oil in oil/water system), psi

$P_{w}:$ Wettingh phase pressure (e.g.water in oil/water system), psi

Capillary pressure is the function of IFT, wetting characteristics, pore size distribution and chemical composition of hydrocarbon. Tiab and Donaldson proved that it has a direct relationship with interfacial tension and reverse relationship with pore size distribution by the following equation

$$
P_{c}=\frac{2 \sigma \cos \theta}{r}=\sigma\left(\frac{1}{R_{1}}-\frac{1}{R_{2}}\right)
$$

Where:

$\sigma:$ Interfacial tension force between to immiscible liquids, $\mathrm{N} / \mathrm{m}$

$\theta:$ Contact angle between two immiscible liquids

$r:$ Capillary radius, $m$

$R_{1}, R_{2}$ : Principal radii of curvature of the interface, $m$

One of the main applications of capillary pressure is in flowing of two immiscible fluid phases in porous media under the control of gravity and external pressure differential. Drainage and imbibition are the most common phenomena in dynamic problems. Drainage is defined as the process of displacing of wetting phase by non-wetting phase such as gas pushing down oil in gas/oil transition zone and imbibition is an opposite of drainage process in which non-wetting phase is displaced by wetting phase, e.g. aquifer pushes hydrocarbon upwards in an anticline reservoir. [10] 


\subsection{Wettability}

The concept of wettability is introduced when two immiscible fluids are in contact with a mineral grain. There are different definitions for wettability but in general wettability is the relative ability of a fluid to spread on a solid surface in the presence of another fluid, or in another words the tendency of mineral surface to be wet by one fluid phase. The knowledge of reservoir rock wettability is very crucial since it provides information about water, oil and gas distribution, capillary pressure, relative permeability characteristics and especially in secondary and tertiary recoveries since the type of wettability has a huge effect on selecting improved recovery method as well as determining the amount of additional recovered oil. [10]

The relation between spreading tendency and surface tension is expressed as an adhesion tension which is defined by

$$
A_{T}=\sigma_{S O}-\sigma_{S W}
$$

Where:

$\sigma_{S O}:$ the surface tension between lighter liquid and solid surface (here oil and mineral grain surface)

$\sigma_{S W}:$ the surface tension between denser liquid and solid surface (here water and mineral grain surface)

Wettability is measured as a contact angle, $\theta$. As Figure 2-7 Shows $\theta$ is measured through the denser liquid relative to rock surface. Where the angle can vary from 0 to 180 degrees, if the angle is smaller than $90^{\circ}$ the surface has more affinity to be wet by denser liquid while for large $\theta$ lighter liquid plays the main role in wetting the surface.

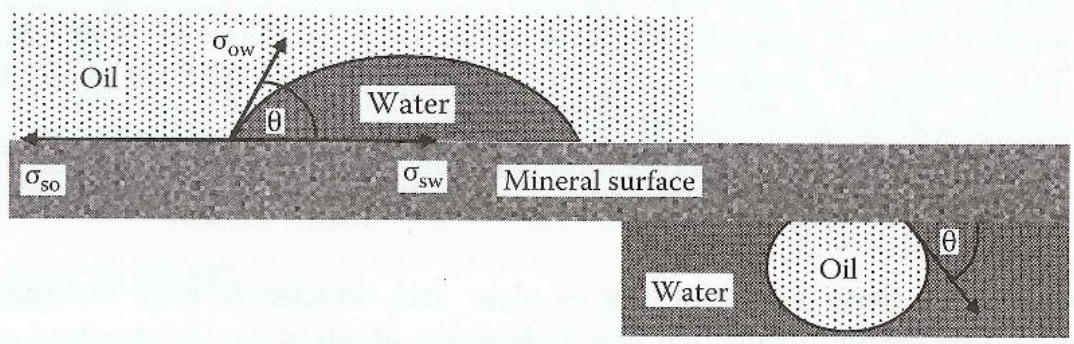

Figure 2 - 7 Schematic of a System of Two Immiscible Liquids (Oil and Water) in Contact with Mineral Surface [10] 
Wettability angle can also be driven from interfacial and surface tension forces between immiscible fluids and rock surface. [10]

$$
\operatorname{Cos} \theta_{O W}=\frac{\sigma_{S O}-\sigma_{S W}}{\sigma_{O W}}=\frac{A_{T}}{\sigma_{O W}}
$$

According to this equation positive adhesion tension value shows the preference of surface to be wet by the denser liquid while the negative value indicates a wetting preferably by lighter liquid. In the case where the adhesion tension is approximately zero the both phases have the same affinity to wet the surface.

Wetting index (WI) is another term which is used for expressing the wetting preferences of the surface. The range of WI is varied from -1 to +1 , which positive values shows the affinity of the surface to the denser liquid such as water rather than oil and for negative values it is reverse and WI of 0 shows neutral or intermediate wet system. [10]

\subsubsection{Classification of Reservoir Rock Wettability}

Reservoir rocks are classified in three groups, water wet, oil wet and intermediate wet. Which water wet and oil wet has their own sub division, strongly water wet, water wet and strongly oil wet, oil wet.

\subsubsection{Water Wet}

In this type of wettability mineral surface grain has been coated by water or in another words the grain surface shows more tendency to be wet by water. As Figure 2-8 shows oil or/and gas droplets are at the center of pore spaces. [10]

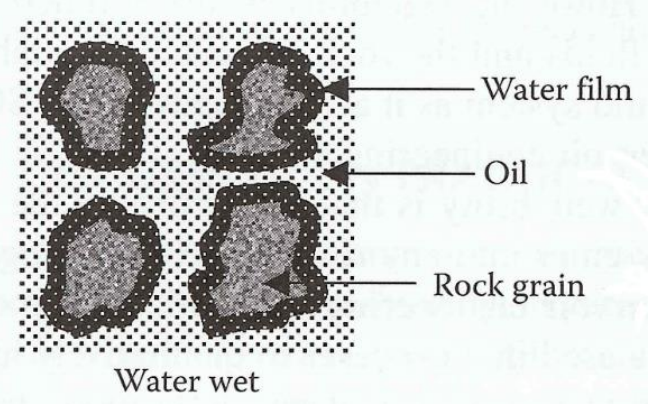

Figure 2 - 8 Schematic of Water Wet Rock, Grains are Covered by Water and Oil is at the Center of Pores [10] 


\subsubsection{Oil Wet}

This scenario in completely the opposite of water wet systems. In oil wet rock, oil occupies smaller pores and coats the surface of larger pores as Figure 2-9 shows. Due to chemical and physical reasons heavy components of oil such as asphalten are deposited on the surface of grain and change its wettability from water wet to oil wet. Carbonate rocks are the best example of oil wet rocks. [10]

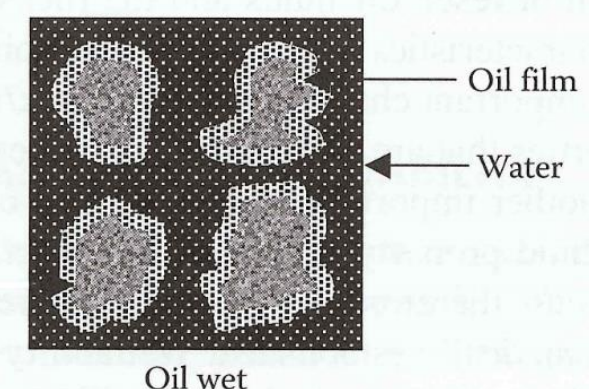

Figure 2 - 9 Schematic of Oil Wet Rock, Grains are Covered by Oil and Water is at the Center of Pores [10]

\subsubsection{Intermediate Wet}

If the grain's surface shows the same tendency to be wet by both liquids such as oil and water then it may be termed as intermediate wet.

\subsubsection{Factors Affecting Wettability}

Studies show reservoir wettability is strongly controlled by fluid properties such as composition of crude oil especially amount of presence asphalten as well as salinity of brine and mineral types which have been dissolved in it, and also reservoir rock lithology which shows the tendency of rock to adsorb especial elements due to electrical forces. But some other factors have minor effects on it such as pressure, temperature, drilling mud filtrate invasion which has to be considered during wettability analysis. [10]

\subsubsection{Methods for Measuring Wettability}

Wettability can be evaluated by qualitative and quantitative methods. In qualitative method, wettability angle cannot measured accurately and it can be estimated on the basis of other reservoir data such as capillary pressure and relative permeability curves, glass slide method, permeability-saturation relations, 
well logs like nuclear magnetic resonance (NMR) and dye adsorption. In quantitative methods contact angle is measured directly by conducting different tests on rock sample in the presence of reservoir oil and water. There are different quantitative methods but the most commons are contact angle measurement method, Amott test and USBM wettability method. [10]

\subsubsection{Quantitative Measurement}

\subsubsection{Contact Angle Measurement Method}

There are different methods of contact angle measurement but the simplest and cheapest one which is used in oil industry is sessile drop method. In this method a droplet of water is placed on the grain's surface in the presence of reservoir oil. If the water droplet spreads over the surface, the rock is water wet but if doesn't and remains as the spherical from it shows oil wet affinity and in the case of between these two is intermediate water wet. For determining the exact angle a photo is taken from the system and by drawing a line from rock surface tangent to the droplet surface, $\theta$ can be determined as it is shown in Figure 2-10. On the basis of Anderson table for contact angle if $\theta$ is less than $60^{\circ}-75^{\circ}$ the rock is considered as water wet and if it is greater than $105^{\circ}-120^{\circ}$ is called oil wet and between these two ranges is intermediate water wet.
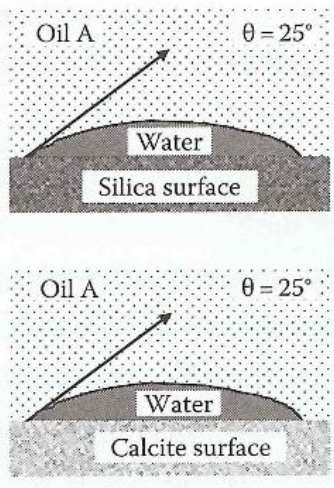
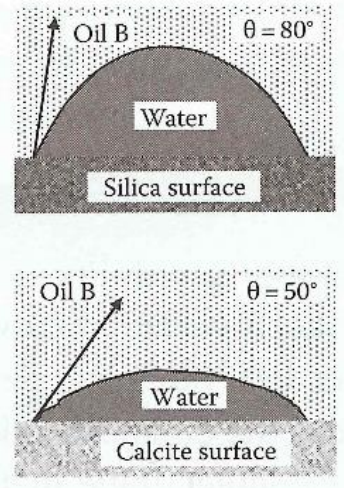
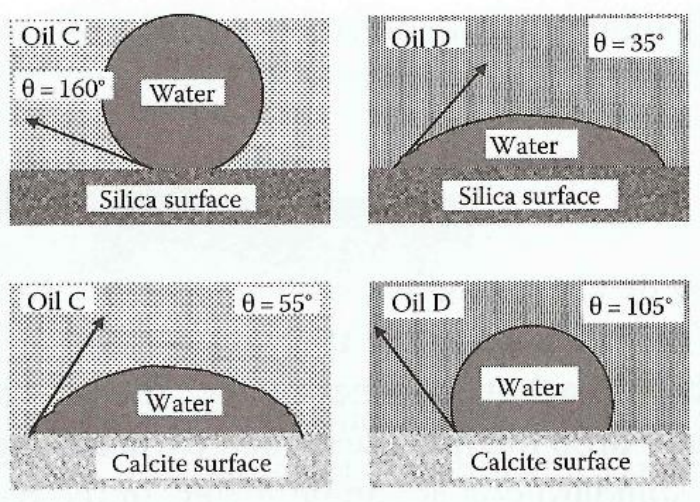

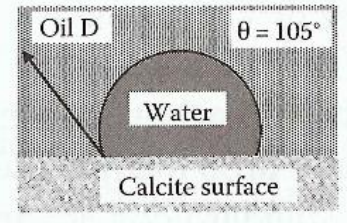

Figure 2 - 10 Determining Contact Angle by Drawing Tangent Line [10]

In modified sessile drop method, two slabs of studying rock are polished and are mounted parallel to each other and a droplet of oil is placed between them in the presence of water. After waiting on the system for a short while the mobile plate is pulled a little, therefore the droplet shape is changed by extending, and portion of water is replaced with the part that was covered with the oil previously as Figure 2-11 shows. 
The measured contact angle in this method is called water-advancing contact angle which is very common in water flooding studies. [10]

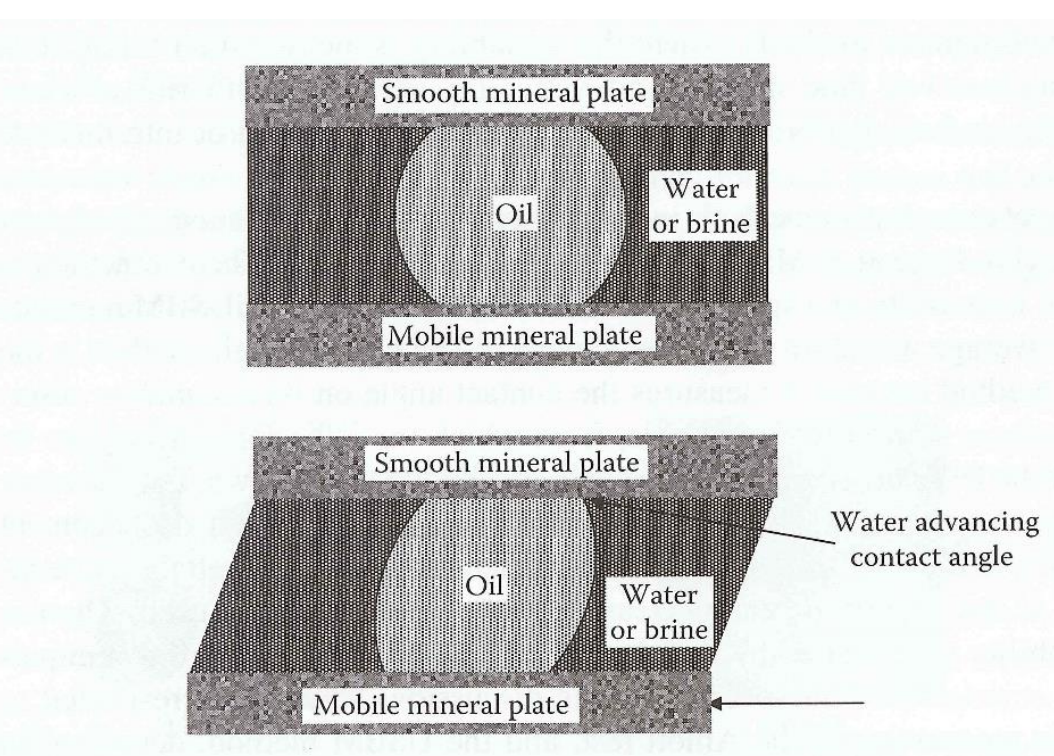

Figure 2 - 11 Contact Angle Measurement in Modified Sessile Drop Method [10]

\subsubsection{Amott Test}

The Amott wettability test is one of the common methods for determining average wettability of reservoir sample. This method is based on displacement properties of oil and water in porous medium. To conduct the experiment five steps should be followed:

1. Displacing the oil by water until the residual oil saturation is achieved.

2. Placing the core sample inside the oil chamber and leave it for couple of hours so that drainage process takes place on it (Figure 2-12).

3. Displaced water by oil by applying high pressure displacement by using core flood or centrifuge.

4. Placing the core sample in water and leave it for a couple of hours to imbibition process takes place (Figure 2-12).

5. Displaced oil by water the same as step 3 . 


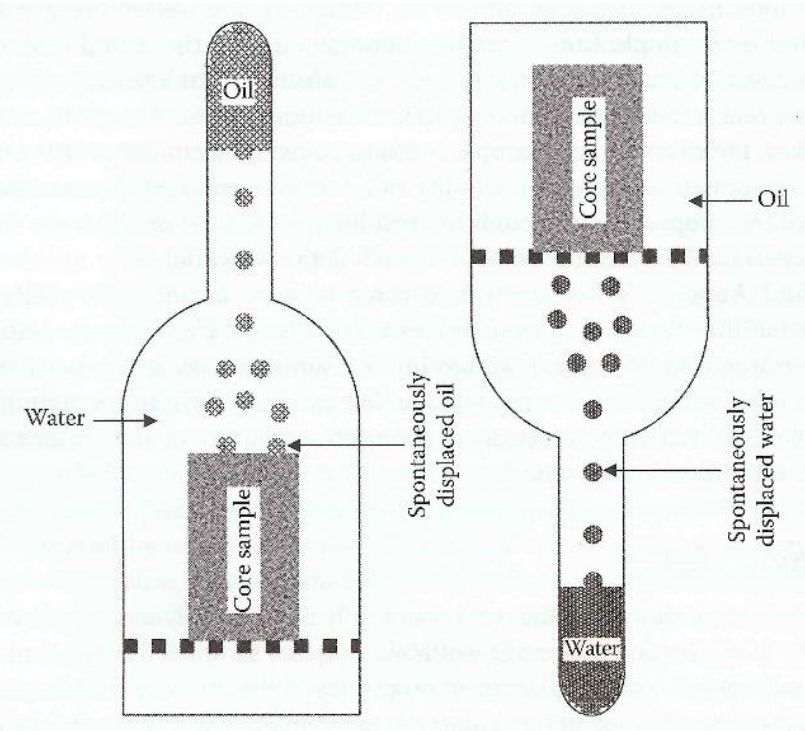

Figure 2 - 12 Oil and Water Displacement Setup for the Amott Wettability Test [10]

Oil and water volumes is measured at each stages and are called $V_{w s}, V_{w f}, V_{o s}$ and $V_{o f}$.

$V_{w s}$ is the volume of water displaced by oil in stage $2, V_{W f}$ is the volume of water displaced by high pressure in stage $3, V_{o S}$ is the volume of oil displaced spontaneously by water in stage 4 and the volume of oil which is moved out due to high pressure at stage 5 is called $V_{o f}$. Based on these volumes two equations are introduced which are named displacement ratios. [10]

$$
\begin{gathered}
\delta_{o}=\frac{V_{w s}}{V_{w t}} \\
\delta_{w}=\frac{V_{o s}}{V_{o t}}
\end{gathered}
$$

Where:

$\delta_{o}:$ Displacement by oil ratio

$\delta_{w}:$ Displacement by water ratio

$V_{w t}=V_{w s}+V_{w f}$

$V_{o t}=V_{o s}+V_{o f}$ 
The wetting preference of a rock is determined by using Table 2-1 which has been tabulated by Amott. Based on the tabulated values as $\delta_{o}$ approaches to 1 , rock shows strongly oil wet tendency, while values close to 0 show weak preference for oil wet. Similarly this is true for $\delta_{w}$, value close to 1 shows high water wet preferential, however as it approaches to zero indicates weak preference for water wet.

Table 2 - 1 Relationships between Wettability and Amott Wettability Indices [10]

\begin{tabular}{|c|c|c|c|}
\hline Displacement Ratio & Water Wet ${ }^{\mathrm{a}}$ & Neutral Wet & Oil Wet \\
\hline$\delta_{o}$ & Zero & Zero & Positive $^{b}$ \\
\hline$\delta_{w}$ & Positive $^{b}$ & Zero & Zero \\
\hline \multicolumn{4}{|c|}{ a Amott refers to this as preferentially water wet and preferentially oil wet. } \\
\hline \multicolumn{4}{|c|}{$\begin{array}{l}\text { b Although this is characterized as positive in Amott's paper, what it actually means is a value } \\
\text { approaching one. }\end{array}$} \\
\hline
\end{tabular}

\subsubsection{USBM Method}

The USBM method is another common and popular methods of determining average wettability which developed by Donaldson et al. in 1969. Whole of the test is conducted in centrifuge. Figure 2-13 shows the cross section of instrument, core is placed at the middle and displacing and displaced fluids are on top and bottom of the core respectively.

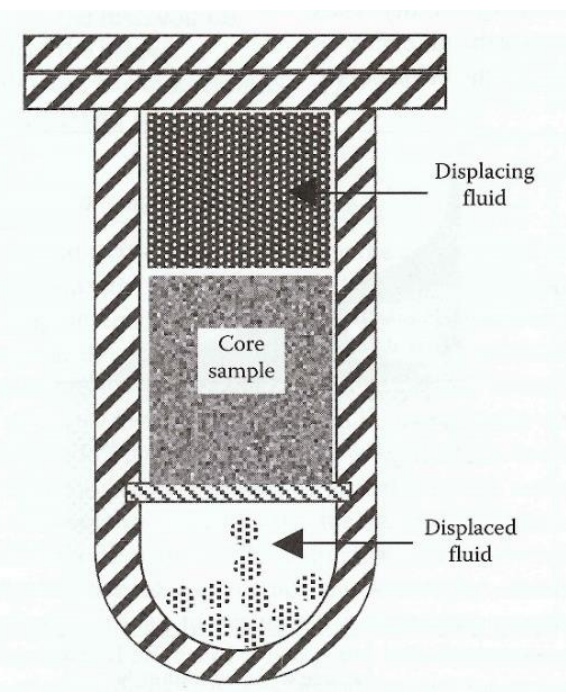

Figure 2 - 13 Centrifuge Tube Cross Section in USBM Setup [10] 
The test is started by placing the core sample inside the centrifuge working at high rotating speed and displacing water by oil till irreducible water saturation is achieved. Once no more oil comes out of the sample the wettability determination is started by placing the core in brine and try to push out the oil by displacing force of centrifuge which increases in specific incremental intervals by the time that the pressure difference of two phases gets $-10\left(P_{\text {effective }}=P_{\text {water }}-P_{\text {oil }}\right)$, which is called effective pressure. During this step effective pressure is recorded as well as changes in fluids volume. After the equilibrium state is achieved the test is conducted another time but this time oil is displacing water and the final effective pressure is $+10\left(P_{\text {effective }}=P_{\text {oil }}-P_{\text {water }}\right)$. By plotting effective pressure versus water saturation Figure 2-14 is achieved. [10]

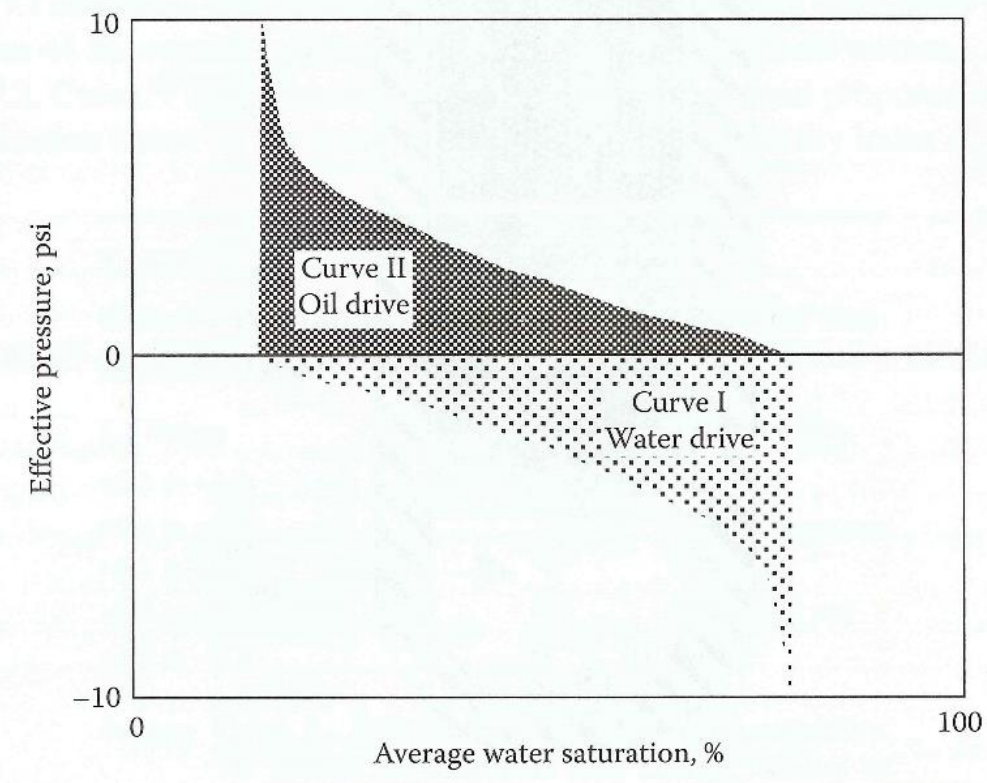

Figure 2 - 14 Effective Pressure Versus Average Water Saturation for Wettability Determination in USBM Method [10]

By finding the area of oil drive and water drive curves the USBM wettability index can be calculated.

$$
I_{U S B M}=\log \left[\frac{A_{1}}{A_{2}}\right]
$$

Where:

$I_{U S B M}:$ The USBM wettability index 
$A_{1}:$ Area under the oil curve

$A_{2}:$ Area under the brine curve

When $I_{U S B M}>0$ the core is water wet and if $I_{U S B M}<0$ the core is oil wet and for wettability index close to zero the sample shows neutral wettability.

\subsubsection{Qualitative Measurements}

Qualitative methods are used for getting a general idea about reservoir rock wettability. Different methods are used for wettability estimation such as imbibition, microscopic examination, flotation, glass slide, relative permeability curves, capillary pressure curves, capillarimetric method, displacement capillary pressure, permeability/saturation relationship and reservoir logs. Nuclear Magnetic Resonance log and dye adsorption are methods for measuring fractional wettability. [12] In follow some of qualitative methods will be discussed.

\subsubsection{Imbibition Method}

This method is one of the most common and cheapest methods for wettability determination. To conduct this experiment a core sample with initial water saturation in submersed in water, volume and rate of displaced oil is measured. If the volume of oil which is pushed out of the core sample is large it can be concluded that the rock sample is strongly water wet and if just few droplet comes out of it, the rock has more affinity to oil and it is oil wet and if no water is imbibed the rock shows neutral tendency to oil and water. In the next step oil saturation of non-water wet rock are driven to residual oil saturation and by placing the sample in the oil chamber the rate and volume of displacing water is measured. High rate and volume of displaced brine shows strongly oil wet characteristic of rock sample. [12]

\subsubsection{Microscopic Examination}

In microscopic examination method the fluid flow on single pore level porous medium is studied. In water rocks the a film of water surround grains while oil is lying on the water film at the center of large pores while in oil wet system the situation is opposite and grains are covered with thin layer of oil and water is at the center of large pores. In intermediate wetting system some grains are covered by water and some with oil. [12] 


\subsubsection{Relative Permeability Method}

Determination of wettability based on relative permeability is another qualitative method which introduced by Ehrlich and Wygal based on Craig's rule of thumb which is saying

1. Rock with connate water saturation of less than $10 \% \mathrm{PV}$ is an oil wet rock and greater than $20-25 \%$ PV is water wet rock.

2. If water saturation at the point which oil and water relative permeability are equal, is greater than $50 \%$ the sample is water wet and if it is less than that the sample shows more affinity to be wet by oil, Figure 2-15. Big divergence from water saturation of 50\% shows strongly water wet and strongly oil wet feature, respectively.

3. In water wet rocks the relative permeability of water at flood out is usually less than $30 \%$, while in oil wet rocks it is between 50 to $100 \%$

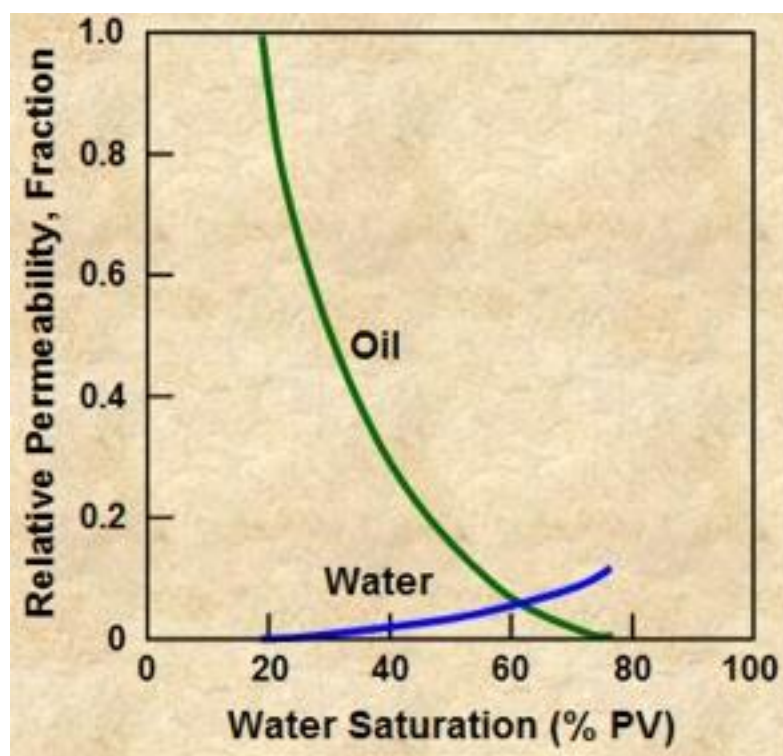

Strongly Water-Wet Rock

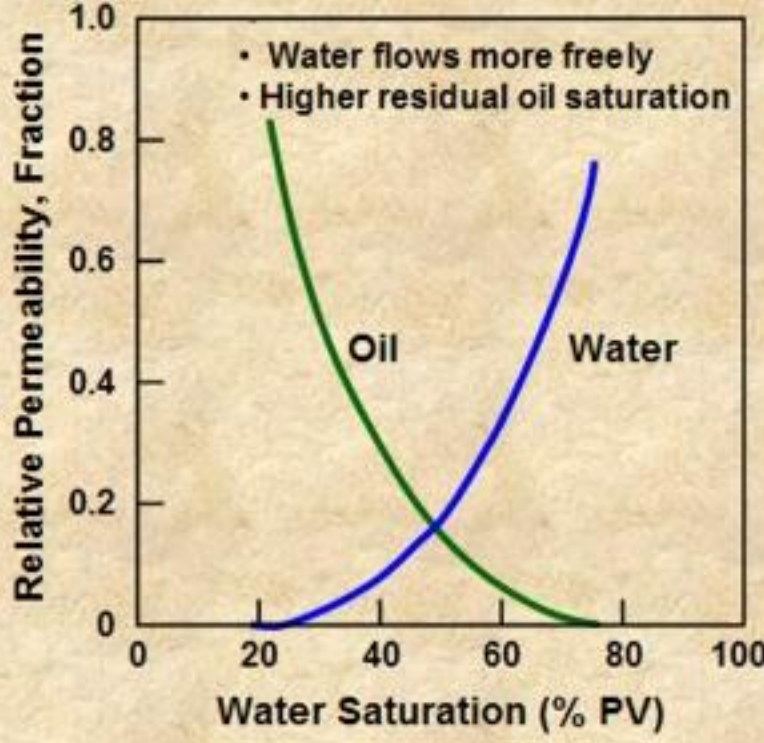

Strongly Oil-Wet Rock

Figure 2 - 15 Wettability Determination by Using Relative Permeability Curve [13]

Table 2-2 summarize Craig's rules of thumb relating wettability and relative permeability. 
Table 2 - 2 Craig's Rules of Thumb Relating Wettability and Relative Permeability [12]

\section{Characteristics}

Initial water saturation, $S_{w i}$

$S_{w}$ at which $K_{r o}=K_{r w}$

$K_{\text {ro }}$ at $1-S_{o r}$; based on $K_{e o} @ S_{w i}$ as base permeability

\section{Water Wet}

Greater than $20-25 \%$

Greater than $50 \%$

Generally less than $30 \%$

\section{Oil Wet}

Generally less than $15 \%$

Less than $50 \%$

Greater than $50 \%$

\subsubsection{Permeability/Saturation Relationship Method}

This method is according to Raza et al. proposal which is based on connate water saturation and air permeability. After the core sample is retrieved from OBM drilling fluid well, connate water saturation is determined and in core analysis air permeability is measured. As Figure 2-16 shows by plotting air permeability values versus connate water saturation of different samples from oil reservoir it can be understood in oil wet reservoir the correlation line is near vertical and is around small connate water saturation values, while in water wet rocks the line has a gentle slope and the samples show high connate water saturation values. [12]

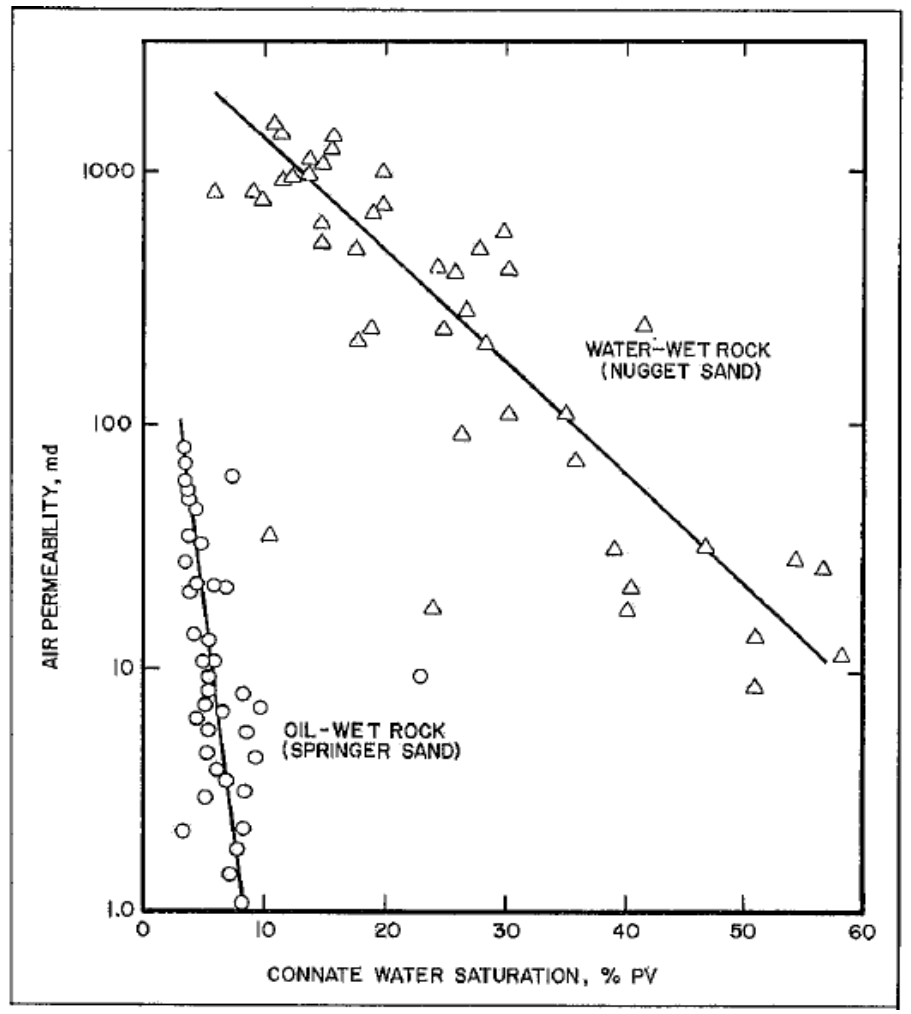

Figure 2 - 16 Wettability Determination Based on Air Permeability and Water Saturation [12] 


\subsubsection{Reservoir Log Method}

A method was introduced by Graham for estimation of in situ wettability based on resistivity log data. Oil wet rocks show higher resistivity values rather than water wet rocks with the same water saturation content. Based on this fact after brine injection to formation, resistivity log is run for measuring formation resistivity. Next time brine with reverse wetting agent which is changed water wet rock to oil wet one is injected into the formation and resistivity log reads the value again. If the resistivity values of second logging were increased it shows the rock wettability has been changed from water wet to oil wet but if the formation was oil wet, no change in resistivity will be noticed. [12]

\subsection{Density}

Density $(\rho)$, is defined as mass $(\mathrm{m})$, per unit volume $(\mathrm{V})$. Pressure and temperature are the parameters that have a significant effect on density. The SI unit for density reporting is $\mathrm{kg} / \mathrm{m}^{3}$. [16]

$$
\rho=\frac{m}{V}
$$

For simplicity sometimes density is reported by specific gravity. For liquids, specific gravity is the ratio of liquid density over pure water density and for gas is the ratio of gas density over the air density. In both scenarios densities are measured at standard condition in which pressure is 1 atmosphere and temperature is $60^{\circ} \mathrm{F}$. [16]

$$
\gamma=\frac{\text { Liquid density }}{\text { Water density }} \text { or } \frac{\text { Gas density }}{\text { Air density }}
$$

American Petroleum Institute introduces another term and method for reporting hydrocarbon density which is called API gravity scale.

$$
{ }^{0} A P I=\frac{141.5}{\gamma}-131.5
$$




\subsection{Viscosity}

Viscosity is the resistance of fluid to flow due to intermolecular friction when layers of fluid are trying to slide on each other. Pascal second (Pas) is viscosity unit in SI and centipoise (cp) in field units. One centipoise is equal to 0.001 Pas. For Newtonian fluids viscosity is constant and is equal to the slope of shear stress versus shear rate. [7]

$$
\mu=\frac{\text { Shear stress }}{\text { Shear rate }}
$$

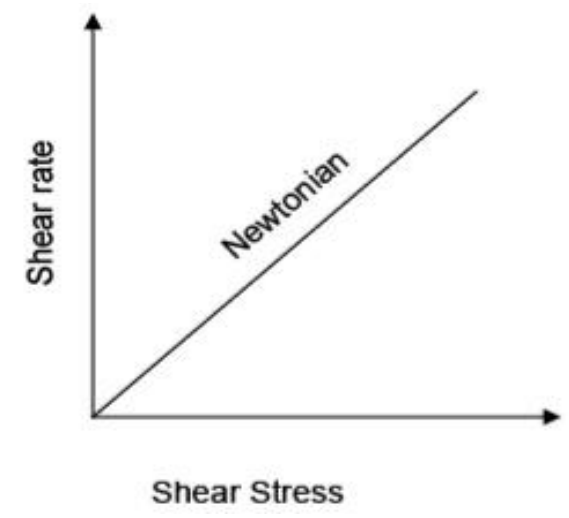

Figure 2 - 17 Newtonian Fluids Behavior [7]

For non-Newtonian fluids shear rate is not constant and the value at each point should be substitute in the equation for viscosity calculating.

$$
\mu=\frac{\text { Shear stress }}{\text { Shear rate }}=\frac{\tau}{\frac{d V}{d y}}
$$

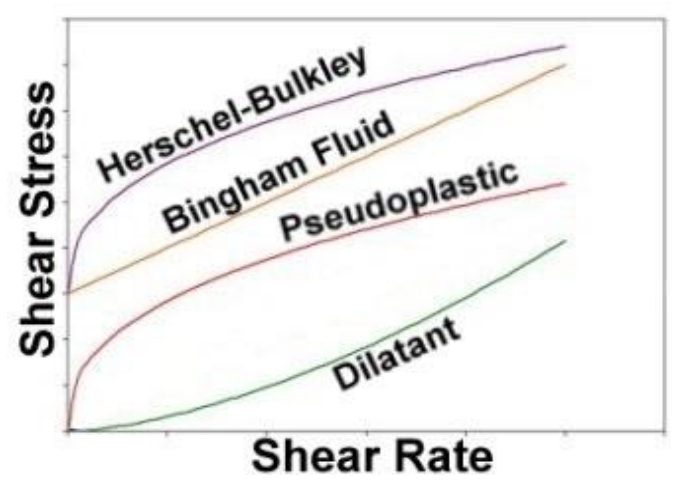

Figure 2 - 18 Non Newtonian Fluids Behavior [15] 
Kinetic viscosity is the ratio of dynamic viscosity over fluid density and the unit is centistokes (cSt).

$$
v=\frac{\mu}{\rho}
$$

Pressure and temperature are two key elements in controlling viscosity. In liquids viscosity decreases by temperature increasing and in high pressures the viscosity has a direct relationship with pressure and a little bit change in pressure leads to increase in viscosity. In gases due to molecular momentum exchange mechanism viscosity shows different behavior respect to temperature and they have a direct relationship. Molecular number is another factor that can influence on viscosity. As the number of molecules and hydrocarbon chains increases the viscosity will increase too. [16]

\subsection{Oil recovery}

Oil recovery is basically divided to three stages which are known as primary, secondary and tertiary oil recovery.

\subsubsection{Primary Recovery}

During the primary production the hydrocarbon is produced by the use of natural energy which exists in reservoir. [17] These forces could be rock and fluid expansion, solution gas drive, gas cap expansion and aquifer encroachment. [18]

\subsubsection{Secondary Recovery}

By passing the time the reservoir pressure declines due to production and after several years it couldn't sustain production rate anymore so secondary recovery methods are used. In secondary recovery by injecting gas or water, hydrocarbon is pushed toward the producing wells. This method is also known as pressure maintenance method. Secondary recovery can be done in different ways such as gas injection to reservoir gas cap, water injection to aquifer to push the hydrocarbon up and maintain the reservoir pressure, and water flooding in which water is injecting in producing zone to push the hydrocarbon toward producers. Most of the time secondary recovery is known as water flooding. [17] 


\subsubsection{Tertiary recovery}

After a period of time secondary recovery is not economical anymore because of high water-oil ratio or gas-oil ratio due to water/gas coning or water breakthrough, so another methods of recovery are used which are known as tertiary recovery or EOR. [19] In these methods by trying to change the rock and/or fluid properties, the amount of residual oil saturation will be reduced and another percentage of initial hydrocarbon in place (IHIP) can be extracted. [17] There are different EOR methods but the most famous ones are chemical processes, in situ combustion processes, miscible process, microbial EOR. [19] In follow some of EOR methods will be discussed.

\subsubsection{Chemical Processes}

In this process by injecting special kind of fluid such as surfactant/polymer the IFT force between the oil and displacing fluid will be reduced significantly, therefore the amount of residual oil saturation decreases and more percentage of IHIP is produced.[17] Figure 2-19 shows the steps of performing chemical EOR process.

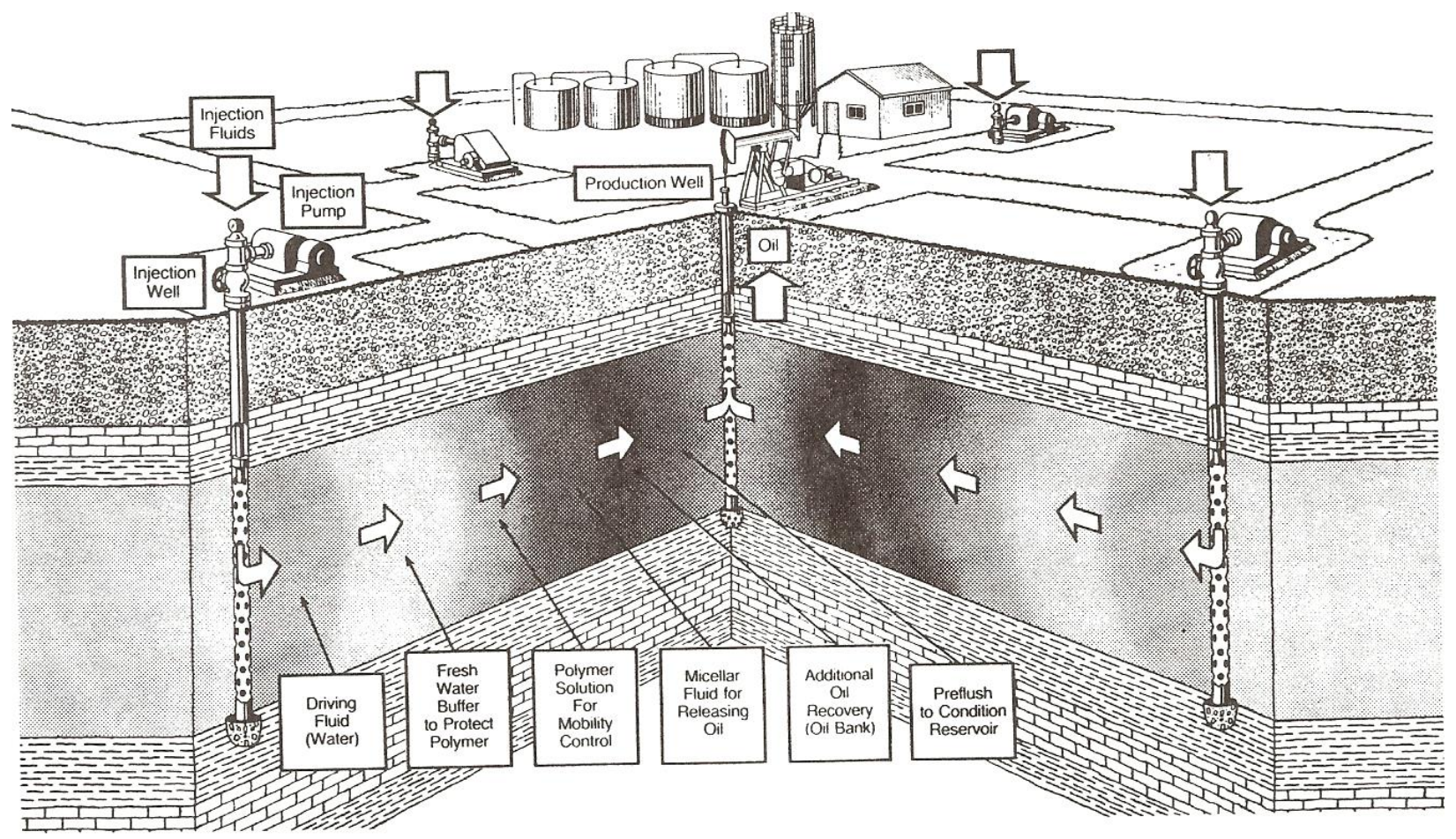

Figure 2 - 19 Surfactant/Polymer Process [17] 


\subsubsection{In Situ Combustion Processes}

Reducing oil viscosity is the main goal of this method. There are two methods for doing it: forward combustion and reverse combustion. Air and water are injected into the well and by providing superheated steam near the injection well and after ignition the burning front pushes the oil forward. [19]

\subsubsection{Miscible Process}

The primary goal of this method is to push out the trapped oil in pore throats by using another fluid which is miscible with oil. Some fluids are dissolved in oil with the first contact but other types by multiple contacts so especial reservoir condition such as pressure and temperature should be considered before injection. The famous fluid which is used for this method is carbon dioxide. [17] Fig 2-20 shows $\mathrm{CO}_{2}$ injection platform.

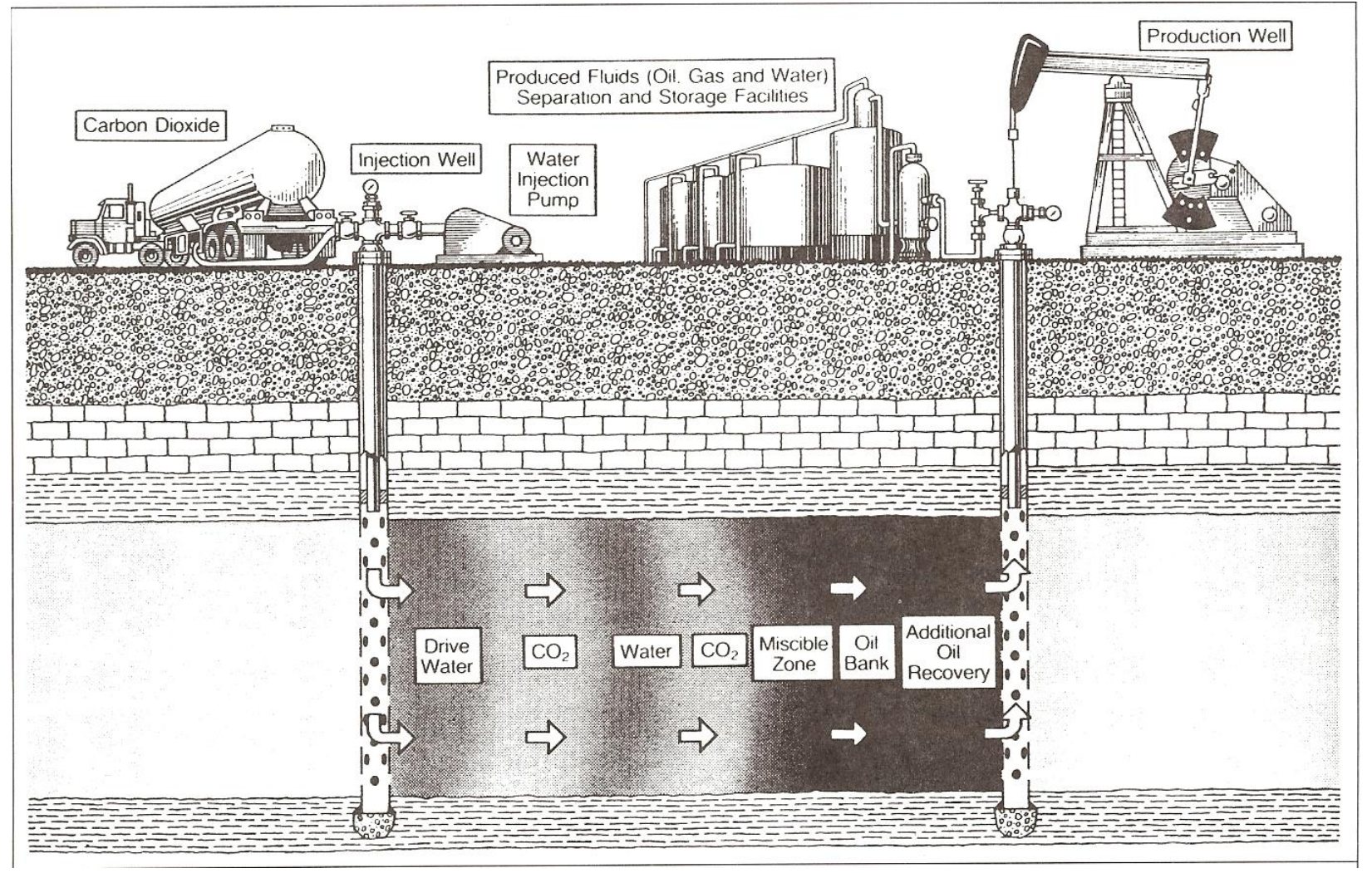

Figure 2 - $20 \mathrm{CO}_{2}$ Miscible Process [17] 


\subsection{Nano Technology and Oil Industry}

World energy demand is increasing day by day and scientists are trying to introduce new methods for providing enough energy for human consumption. One of these technologies that has been introduced to oil industry is nano technology. Nano technology is kind of applied science and technology which focuses on the material within the size of atom or molecule (100 nm or smaller) and also designing and producing the devices within this range. Nano technology has broad range of application in upstream, midstream and downstream in oil industry. [20] Table 2-3 shows common applications of nano technology in oil industry.

Table 2 - 3 Application of Nano Technology in Oil industry [20]

\begin{tabular}{|c|c|c|}
\hline Area & Industry Needs & Nanotech Solutions \\
\hline Exploration & $\begin{array}{l}\text { Less invasive methods of exploration, remote sensing } \\
\text { Methods to "sniff" for new pockets of oil } \\
\text { Enhanced resolution for subsurface imaging and computational } \\
\text { techniques } \\
\text { Improved temperature and pressure ratings in deep wells and hostile } \\
\text { environments } \\
\text { Improved instrumentation for gas adsorption } \\
\text { Improved 1,2,3 and 4-D seismic resolution }\end{array}$ & $\begin{array}{l}\text { Nanosensors and } \\
\text { imaging }\end{array}$ \\
\hline \multirow[t]{3}{*}{$\begin{array}{c}\text { Reservoir } \\
\text { management }\end{array}$} & $\begin{array}{l}\text { Enhanced remote imaging, real time continues monitoring of flow rate, } \\
\text { pressure and other parameters during production, wireless telemetry, in } \\
\text { situ chemical sensing } \\
\text { Accurate early warning detection and location of leaks (preventing } \\
\text { environmental hazards) } \\
\text { Improved reservoir illumination and characterization, including } \\
\text { improved signal-to-noise ratio of subsalt events, improved velocity- } \\
\text { modeling accounting for anisotropy }\end{array}$ & Nanosensors \\
\hline & $\begin{array}{l}\text { Improved sand exclusion and mobility of injectant } \\
\text { Controlled agglomeration of particles } \\
\text { Ability to capture and store } \mathrm{CO}_{2}\end{array}$ & Nanomembranes \\
\hline & $\begin{array}{l}\text { Improved the stability and pressure integrity and heat transfer } \\
\text { efficiency } \\
\text { Ability to minimize damage to formation of offshore platforms, reduce } \\
\text { their weight requirements, and increase their sturdiness }\end{array}$ & $\begin{array}{c}\text { Nanomaterials, } \\
\text { fluids, and coating }\end{array}$ \\
\hline Drilling & $\begin{array}{l}\text { Increased the effectiveness and longevity of drilling components, } \\
\text { making cheaper, lighter and stronger pipes and drill bits } \\
\text { Extended lifetime of equipment with corrosion resistance, adhesion } \\
\text { enhancement and wear resistance } \\
\text { Improved strength-to-weight ratio for an expanding range of geological } \\
\text { setting } \\
\text { Expandable tubular for deeper wells without needing to telescope the } \\
\text { well, or casingless wells } \\
\text { Improved cement integrity - light density and high strength, hole } \\
\text { quality and well placement, hermetic seals }\end{array}$ & $\begin{array}{c}\text { Nanomaterials and } \\
\text { coatings }\end{array}$ \\
\hline
\end{tabular}




\begin{tabular}{|c|c|c|}
\hline & $\begin{array}{l}\text { Innovation drill engines than can be sent deep into the shaft; improved } \\
\text { elastomers } \\
\text { Ability to prevent bio-fouling }\end{array}$ & \\
\hline Drilling & $\begin{array}{l}\text { Improved drilling fluids and thermal conductivity } \\
\text { Removal of toxic metals (mercury, cadmium, lead) } \\
\text { Ability to prevent drilling mud invasion, separating mud filtrate and } \\
\text { formation water }\end{array}$ & $\begin{array}{l}\text { Nanofluids and } \\
\text { nanomembranes }\end{array}$ \\
\hline \multirow{4}{*}{ Production } & $\begin{array}{l}\text { In situ sensing and control, monitoring of stress in real-time } \\
\text { Ability to direct fracturing and withstand high temperature to go deep } \\
\text { into challenging resources of wellbore deep reading of oil-water } \\
\text { interface } \\
\text { Chemical detection with no active components downhole } \\
\text { Enhanced measurements in the borehole (pressure, temperature, } \\
\text { composition, conductivity) } \\
\text { Accurate detection and location of leaks (pipeline, downhole) } \\
\text { Improved understanding of matrix, fracture, fluid properties and } \\
\text { production related changes }\end{array}$ & Nanosensors \\
\hline & $\begin{array}{l}\text { Increased water resistance } \\
\text { Self-healing materials } \\
\text { Pressure integrity, improved robustness } \\
\text { Enhanced hydro-phobic or hydrophilic behavior for waterflood } \\
\text { applications }\end{array}$ & $\begin{array}{l}\text { Nanomaterials and } \\
\text { coatings }\end{array}$ \\
\hline & $\begin{array}{l}\text { Improved water filtration (for industrial, agriculture and potable use) } \\
\text { Filtration of impurities from heavy oil and tight gas } \\
\text { Desulfurization, inhibiting } \mathrm{H}_{2} \mathrm{~S} \text { producing bacteria } \\
\text { Cost effective } \mathrm{CO}_{2} \text { sequestration } \\
\text { Sand exclusion } \\
\text { Effective water-shutoff } \\
\text { Scale/wax removal } \\
\text { Easy separation of oil/water emulsion on the surface }\end{array}$ & Nanomemberanes \\
\hline & $\begin{array}{l}\text { High strength/lightweight proppants } \\
\text { Environmentally friendly fluids } \\
\text { Enhanced oil recovery: enhanced fluid viscosity and molecular } \\
\text { modification } \\
\text { Improved production rates and water disposition } \\
\text { Reversible/reusable swellables } \\
\text { Ability to manipulate the interfacial characteristics of rock-fluid } \\
\text { relationship } \\
\text { Reversible and controllable making and breaking of emulsion or foam } \\
\text { Improved combustion and enhanced prevention of fouling and } \\
\text { corrosion }\end{array}$ & Nanofluids \\
\hline \multirow[t]{2}{*}{$\begin{array}{l}\text { Refining \& } \\
\text { Processing }\end{array}$} & $\begin{array}{l}\text { Increased refining capacity \& speed. Better insulation and separation } \\
\text { materials } \\
\text { Efficient conversion of hydrocarbons and refining efficiency (including } \\
\text { extra heavy and sour crude oils) into clean transportation fuels }\end{array}$ & $\begin{array}{c}\text { Nanomembranes and } \\
\text { nanocatalysts }\end{array}$ \\
\hline & Improved monitoring during oil refining & Nanosensors \\
\hline
\end{tabular}




\subsubsection{Nano Particles}

The Royal Society \& The Royal Academy of Engineering assigned the following definition for nano particles: "Nano particles are (in most cases) defined as particles of less than $100 \mathrm{~nm}$ in diameter that exhibit new or enhanced size-dependent properties compared with larger particles of the same material."

The nano particles that have been used in this study are polysilicon. The main component of polysilicon is $\mathrm{SiO}_{2}$ which is an ultra-fine powder with the particle diameter range of 10 to $500 \mathrm{~nm}$. [21] Silica or silicon dioxide is an organic and non-crystalline solid. Polysilicon can be divided to three types according to their surface wettability: Hydrophobic and Lipophilic Polysilicon (HLP), Natural Wet Polysilicon (NWP) and Lipophobic and Hydrophilic Polysilicon (LHP). [21]

\subsubsection{Nano particles as an EOR agent}

Since the primary and secondary oil recovery cannot lead to produce a big portion of initial hydrocarbon in place in reservoirs, tertiary methods or EOR methods are used to improve the recovery. Nano particles by modifying the injection fluids properties such as density, viscosity, thermal resistance and etc. help to fulfill the higher recovery factor goal. [22] Some of the famous nano particles which are used in EOR processes are:

\subsection{Metal Nano Particles}

Metal nano particles such as Aluminum oxide $\left(\mathrm{Al}_{2} \mathrm{O}_{3}\right)$ are used for reducing the viscosity of heavy oil [23] or they can be used for improving thermal conductivity of super critical- $\mathrm{CO}_{2}$ which helps to reduce the oil viscosity as well as increasing the mobility of the oil by dissolving in it. [24]

\subsection{Paramagnetic Nano Particles}

Paramagnetic nano particles are used not only for improving oil recovery but also for evaluating oil saturation. They can improve oil recovery by controlling the behavior of injected fluid by imposing an external field. In addition by imposing the magnetic field around the wellbore to the injected fluid and measuring the responses oil saturation can be estimated. [25] 


\subsection{Silica Nano hybrid Particles}

This kind of nano particles can be used as an EOR agent due to their interfacial tension activity. By delivering the catalytically active nano-hybrid particles to oil water interface, they can change oil properties and improve its mobility properties which in turn helps the oil production and recovery. [26]

\subsection{Nano Silicon Particles}

Nano silicon can improve the production by sparkling mechanism. Nano particles which dispersed in fluid during flowing in porous media can hit the grains' wall and remove the oil which sticks on them, therefore the residual oil saturation can be reduced significantly and the final recover factor will be improved. [27]

\subsubsection{Nano Fluids}

Nano fluids are new kind of two phase system fluids which are obtained by suspending nanometer size materials (nanoparticles, nano fibers, nanotubes, nano rods, nanowires, nano sheet or droplets) in a base fluid. Nano fluids have shown a great influence in all industries by their features such as controlling thermal conductivity, diffusivity, viscosity and etc. due to their high surface to volume ratio. [28] One of the main issues that has to be overcome in preparing nano fluid is stability. Stability is achieved when particles' attractive force is less than repulsive forces which prevents from particles aggregation.

Different methods are introduced but the most common and economical one is two-step method. In twostep method the nano material are produced in the form of dry powder by physical and chemical methods and in the next step the powder is dispersed in the base fluid by the help of ultrasonic agitation, ball milling, and intensive magnetic force agitation, high shear mixing and homogenizing. In some cases adding a little surfactant can improved stability features. [28] 


\section{Chapter 3: Experimental Procedures and Apparatuses}

\subsection{Introduction}

This chapter will cover the laboratory setup for conducting the experiment on investigation of nano particles' effect on wettability alteration as well as interfacial tension changes which leads to increase oil recovery factor. The chapter will discuss the procedures that have to be followed to conduct the experiment in the best way along with giving a short summary on each apparatus and machine that has been used at each stage of this experiment to provide information on the accuracy of the measurements and the result data.

\subsection{Core Preparation}

Preparation of core sample is consist of several steps, such as plugging, cleaning, and porosity and absolute permeability measurement. In follow the machines and methods which were used in each step will be discussed.

\subsubsection{Plugging Machine}

Plugging machine is used for taking the plug out of the rock samples in different lengths and diameters. As Figure 3-1 shows it consists of a driller at the top which has been fixed to a lever than can move upward and downward by using an anchor, and a hollow cylindrical bit at the bottom for taking the plug out of the core or outcrop. The inner diameter of the bit is usually 1.5 inch since most of the laboratory apparatus are made for this outer diameter size. Water is used for cooling the drilling bit during the plugging but in clay content rocks such as shale special kind of oil is used to prevent clay swelling and damaging the sample. In this experiment since the samples were sandstone water was used for cooling the bit. 


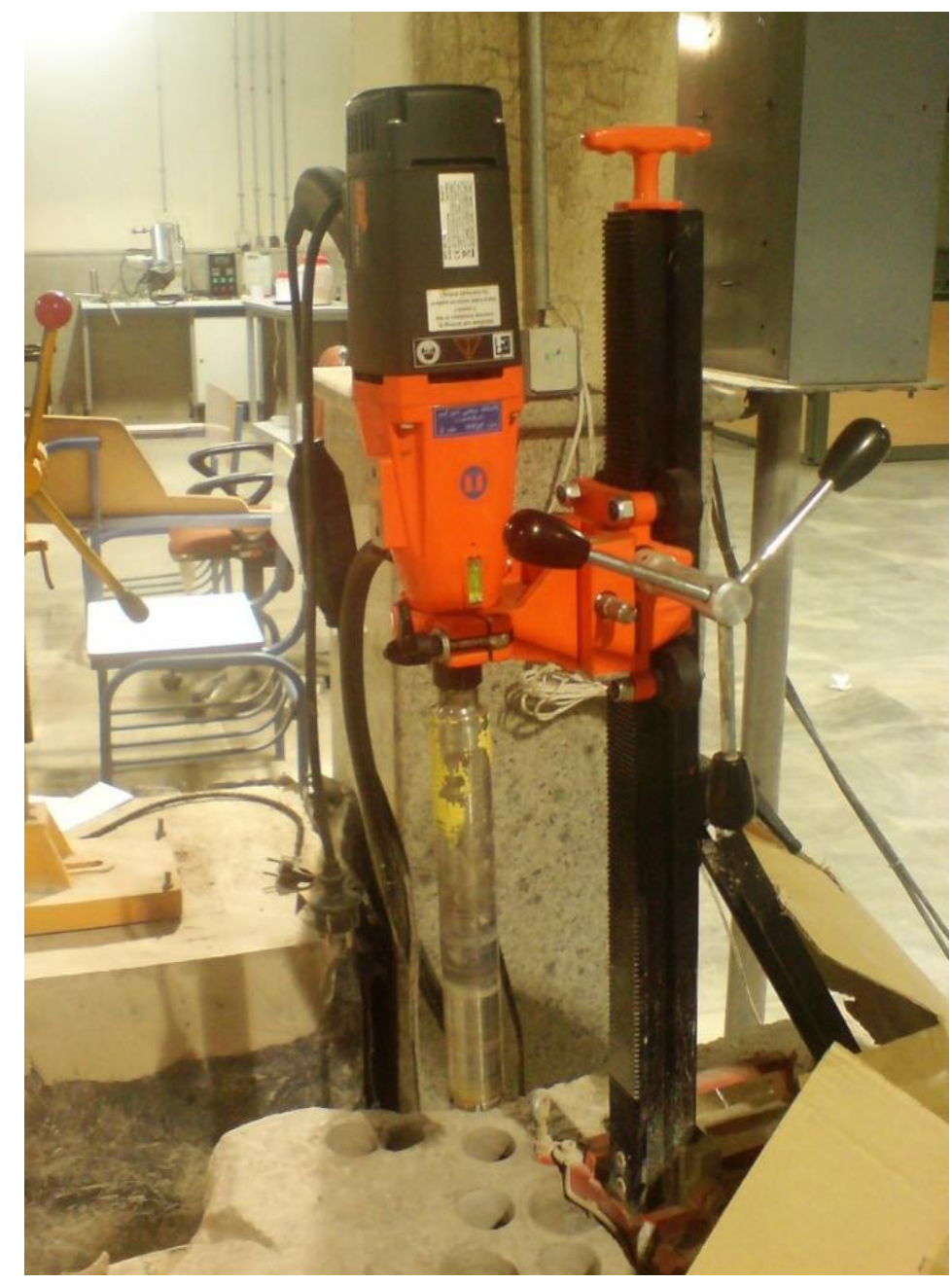

Figure 3 - 1 Plugging Machine

\subsubsection{Trimming Saw Machine}

Cutting machine has a disk shape blade which can cut the plug sample in the longitudinal and transversal direction, as Figure 3-2 shows. The cooling system of the machine is water for sandstone and carbonate rocks and oil with high boiling point for shale samples to prevent clay swelling and grain collapsing. The main application of this machine is to prepare the plugs in appropriate length for using in other laboratory apparatus such as core flood, three axial machine and porosimeter; as well as cutting and smoothing the top and bottom of the samples. The prepared samples for conducting this experiments had the length of 2 inch and diameter of 1.5 inch. Figure 3-3 shows the trimmed and smoothed plugs. 


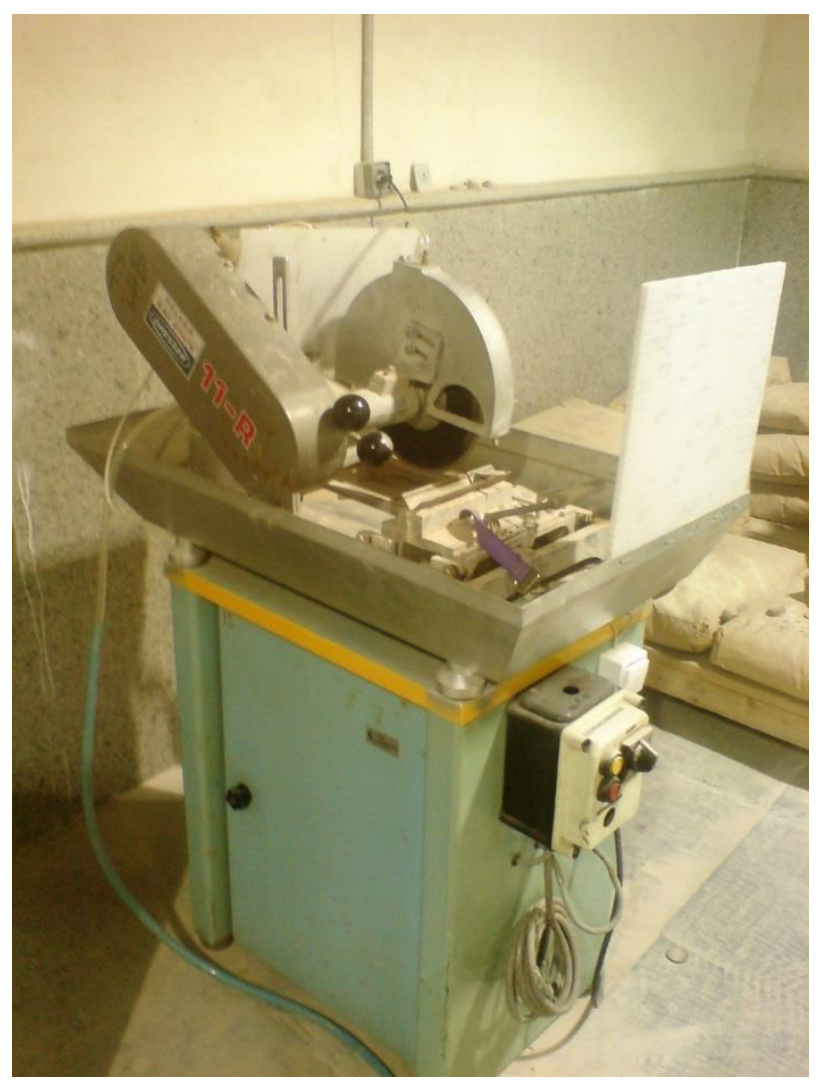

Figure 3 - 2 Trimming Saw Machine

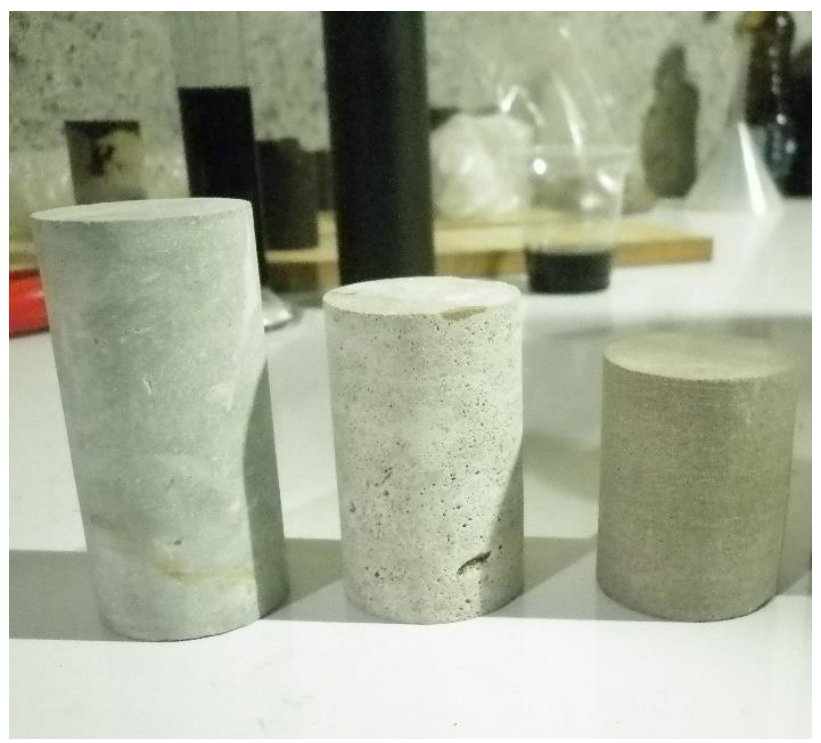

Figure 3 - 3 Prepared Plugs 


\subsubsection{Gas Permeameter and Porosimeter}

Keyphi is the gas permeameter and porosimeter instrument purchased from Vinci Technologies Inc., France. The machine has the ability to measure Klinkenberg permeability, air permeability within the range of 1 micro Darcy to 10 Darcy, slip factor (b), turbulence factor $(\beta)$ and porosity with the wide range of $0.1 \%$ to $60 \%$. Samples with the length of 0.5 to 3 inch and diameter of 1 to 1.5 inch can be used in Keyphi instrument. [29] Figure 3-4 shows Keyphi permeameter and porosimeter. The mechanism of porosity and permeability measurement in this machine will be discussed in follow.

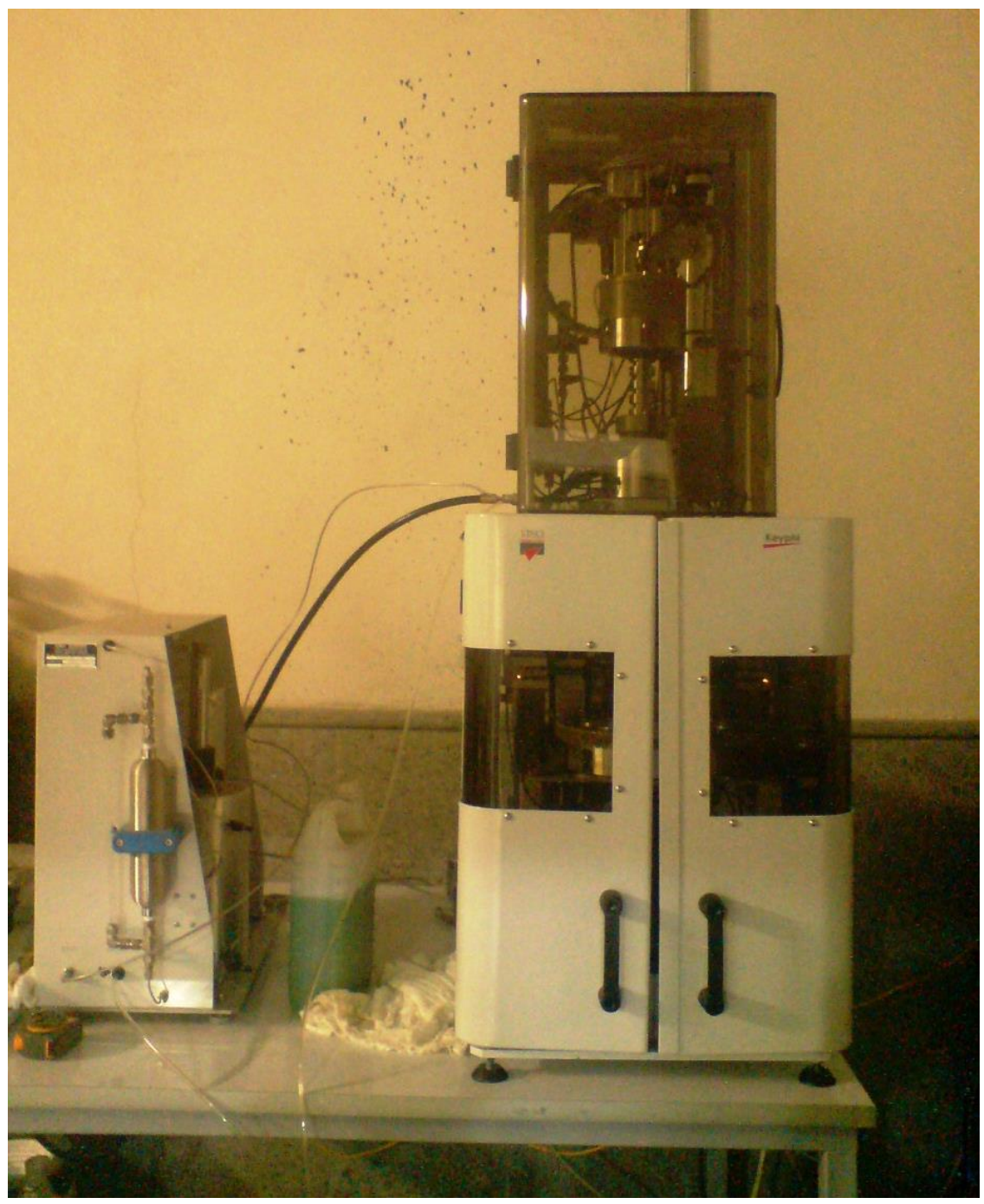

Figure 3 - 4 Keyphi Porosimeter and Permeameter 


\subsubsection{Porosity Measurement}

Keyphi measures the porosity and pore volume on the basis of Boyle's and Charles' law techniques. [29] As Figure 3-5 shows two chambers with equal volume are connected to each other by the valve. One of the chambers is called reference chamber that has the volume of $V_{1}$ and filled with helium or nitrogen at initial pressure of $P_{1}$ (usually $100 \mathrm{psig}$ ) and the other cell is called sample chamber with the unknown volume of $V_{2}$ and initial pressure of $P_{2}$ (usually atmospheric pressure). [10]

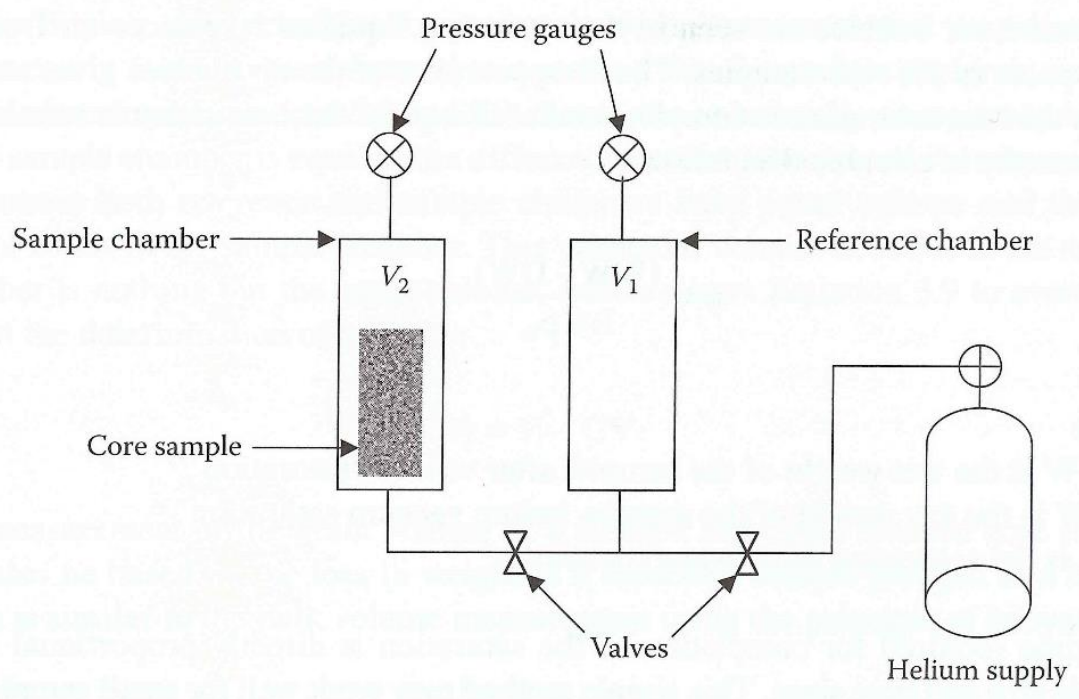

Figure 3 - 5 Schematic Illustration of a Helium Porosimeter [10]

After opening the connector valve and waiting on the system for equilibrium achievement, the following equations can be used to determine the porosity.

$$
P_{1} \times V_{1}+P_{2} \times V_{2}=P_{\text {equilibrium }}\left(V_{1}+V_{2}\right)
$$

By rearranging the formula's parameters:

$$
V_{2}=V_{1}-B V+P V
$$


Where:

$B V:$ Bulk volume of the sample, $c c$

$P V:$ Pore volume of the sample, $c c$

Therefore porosity can be determined by the following equation:

$$
\varphi=\frac{\mathrm{V}_{2}-\mathrm{V}_{1}+\mathrm{BV}}{\mathrm{BV}} \times 100
$$

\subsubsection{Permeability Measurement}

As discussed in section 2.2., permeability can be measured by using Darcy's law. By measuring sample dimensions, liquid viscosity and applying pressure at the core inlet by injecting certain flow rate, permeability can be calculated easily. But sometimes measuring the permeability by using liquid leads to formation damage and changing the pore networks; therefore gas is the best substitution for liquid. Since one of the main assumptions in Darcy law is the incompressibility property of the flowing fluid, gas cannot meet this criteria and the Darcy equation should be modified, therefore some steps should be followed. [10] Based on Boyle's law the product of inlet flow rate and pressure $\left(Q_{1}, P_{1}\right)$ is equal to the product of outlet flow rate and pressure $\left(Q_{2}, P_{2}\right)$.

$$
Q_{1} \times P_{1}=Q_{2} \times P_{2} \text { (Temperature is constant) }
$$

This product can be equal to product of average pressure and flow rate $\left(Q_{a v g}, P_{\text {avg }}\right)$ :

$$
Q_{1} \times P_{1}=Q_{2} \times P_{2}=Q_{a v g} \times P_{a v g}
$$

By substituting the average flow rate in Darcy equation, gas expansion will be considered in calculations:

$$
Q_{\text {avg }}=\frac{K A\left(P_{1}-P_{2}\right)}{\mu L}
$$


By replacing $Q_{a v g}$ from Equation 3-5 in 3-6, the modified Darcy law for gases will be:

$$
Q_{2}=\frac{K A\left(P_{1}^{2}-P_{2}^{2}\right)}{2 \mu L P_{2}}
$$

Where:

$Q_{2}:$ Gas flow rate measured at the outlet of the sample, $\frac{m^{3}}{\mathrm{~s}}$

K: Absolute permeability, $m^{2}$ (Can be converted to Darcy by using conversion factor in section 2.2)

$A:$ Sample cross section ares, $m^{2}$

$P_{1}:$ Inlet sample pressure, $\frac{N}{m^{2}}$

$P_{2}:$ Outlet sample pressure, $\frac{N}{m^{2}}$

$\mu:$ Gas viscosity, $N \frac{s}{m^{2}}$

$L:$ Sample's lenght, $m$

Gas permeability is greater than liquid permeability because of the slippage phenomenon which is also called Klinkenberg effect. This difference is due to gas molecular size which is smaller than liquid and they can travel in porous media easily. To correct this effect several permeability measurements are conducted at different mean pressures. By plotting observed gas permeability data versus inverse of mean pressure and find the linear trend line between the points, liquid permeability as well as slippage factor can be achieved. Equations 3-8 and 3-9 shows the relationship between these parameters.

$$
K_{\text {gas }}=K_{\text {liquid }}+m\left[\frac{1}{P_{\text {mean }}}\right]
$$

Where:

$K_{\text {gas }}:$ Gas Permeability

$K_{\text {liquid }}:$ Equivalent liquid permeability or the Klinkenberg corrected liquid permeability 
$m$ : Slope of the straight line

$P_{\text {mean }}=\frac{P_{1}+P_{2}}{2}$

And slippage factor can be calculated by the following equation:

$$
b=\frac{m}{K_{\text {liquid }}}
$$

\subsection{Fluid Preparation}

Fluid preparation is the set of processes which is done to prepare injection fluids, such as reservoir oil filtration and removing fine particles, synthetic formation water preparation and nano fluid preparation. In follow each step will be discussed in details.

\subsubsection{Crude Oil Filtration}

The oil which was used in this experiment was collected from one of the oil field's well heads and it contained some impurities such as sand particles. Contaminants were removed by using vacuum pump. Figure 3-6 shows oil filtration setup.

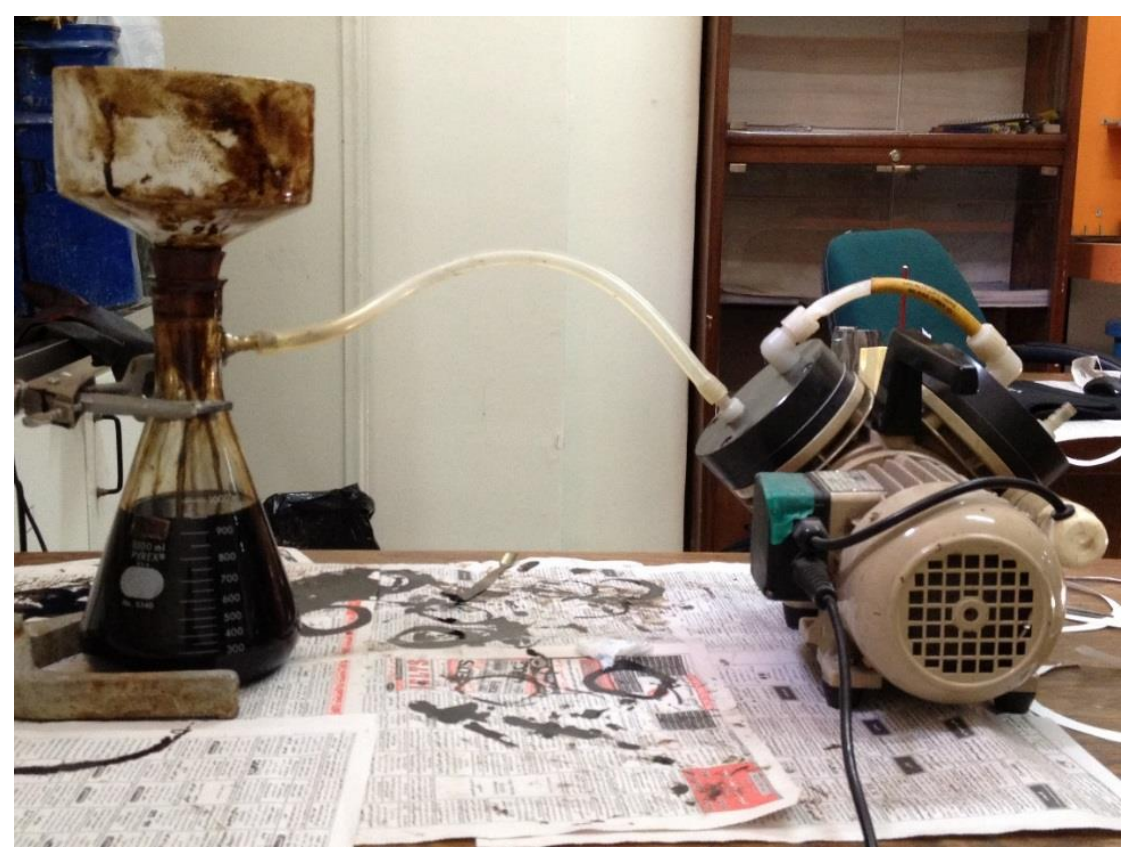

Figure 3 - 6 Oil Filtration Setup 
After heating the crude oil up to $80^{\circ} \mathrm{C}$, it was poured on the filter paper that had been placed inside the funnel and the funnel was connected to erlenmeyer flask and sealed by assorted rubber stopper to prevent gas leakage when vacuum pump was sucking the air with the moderate flow rate. To increase the purity of filtrated crude oil, filter paper was changed in $100 \mathrm{cc}$ intervals.

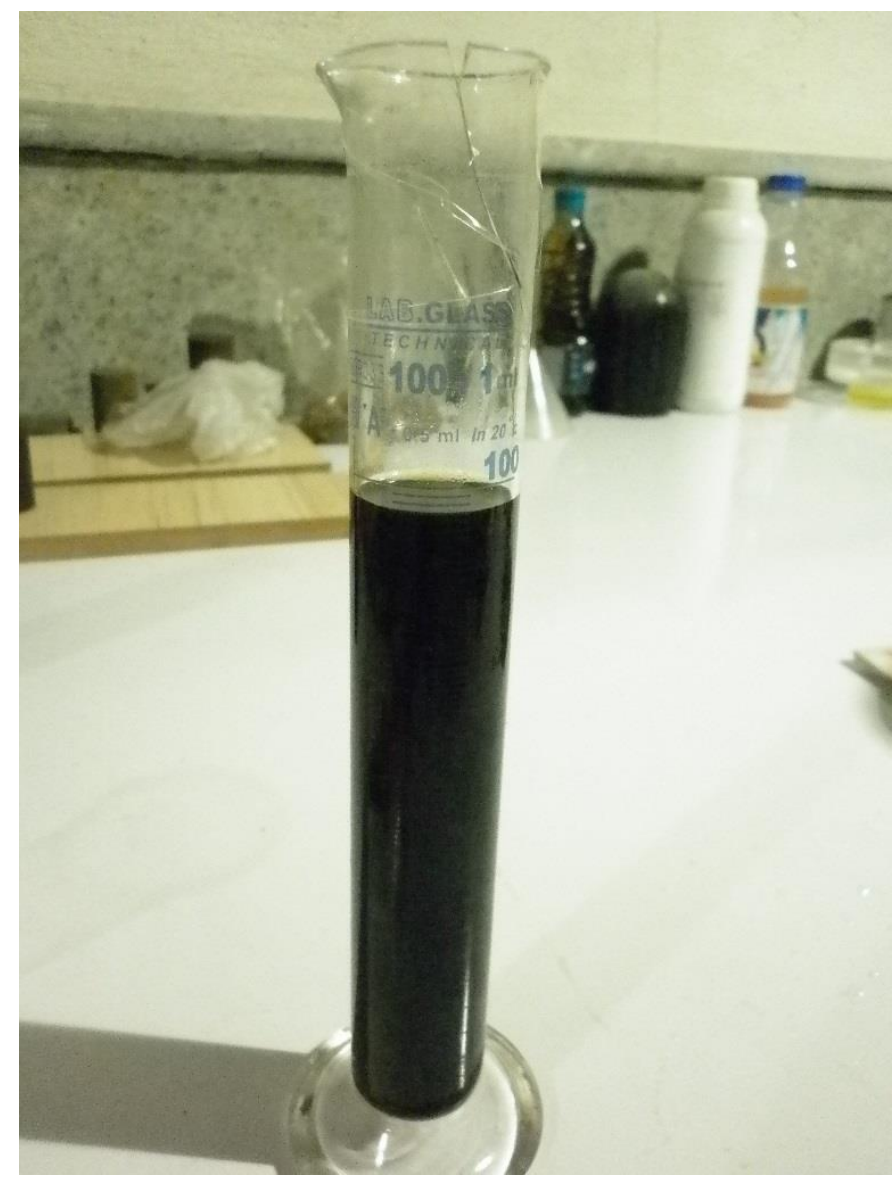

Figure 3 - 7 Filtrated Oil

\subsubsection{Synthetic Formation Water Preparation}

In this experiment brine with the salinity of $45,000 \mathrm{ppm}$ was used as the formation water for water injection as well as simulating the initial water saturation in the sample. To prepare the brine, 45 gram of $\mathrm{NaCl}$ was dissolved in pure water by stirring. Figure 3-8 shows the prepared brine sample which was used in experiment. 


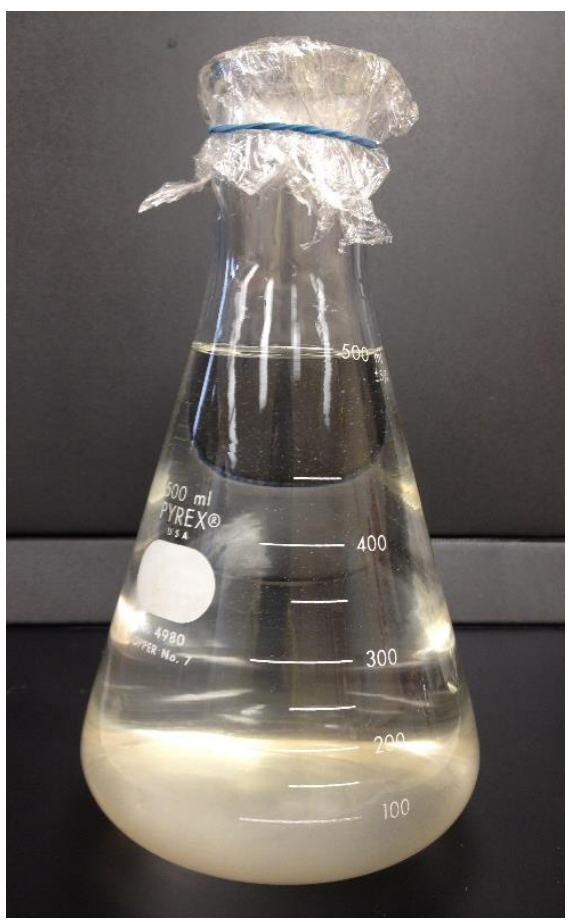

Figure 3 - 8 Prepared Synthetic Formation Water Sample

\subsubsection{Nano Fluids Preparation}

Two types of polysilicon nano particles were used in this experiment, NWP and HLP. HLP has hydrophobic feature, while NWP nano particles show neutral wetting tendency. Figure 3-9 shows polysilicon nano particle powder.

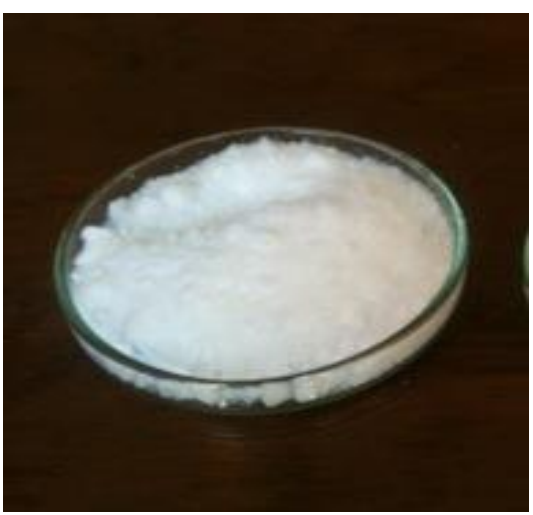

Figure 3 - 9 Polysilicon Nano Particles 
For NWP and HLP nano particles, non-polar fluid such as an organic solvent should be used as the carrier fluid. In this experiment ethanol was chosen due to its low instability and poisonous, immiscibility with oil, ability to dissolve in formation water and it is cheaper and more abundant. After dispersing the nano particle powder in ethanol by stirring, ultrasonic device was used again to suspend the particles in the fluid and prevent from settlement or agglomeration.

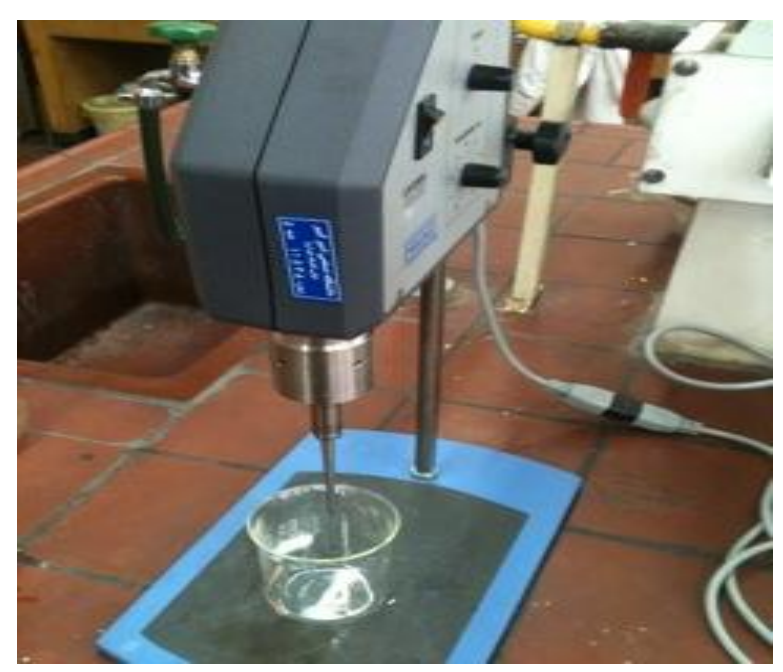

Figure 3 - 10 Ultra Sonic Device

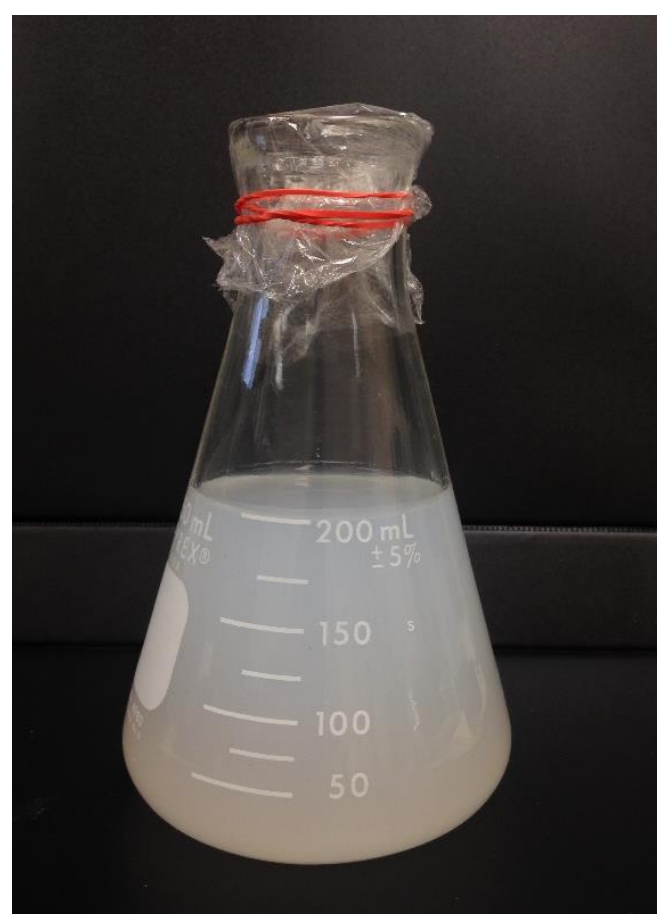

Figure 3 - 11 Prepared Nano Fluid 


\subsection{Contact Angle Measurement}

To compare the effect of nano fluids on wettability alteration, contact angle should be measured before and after of using nano fluids. By using trimming saw machine several core slices with the thickness of 0.5 $\mathrm{cm}$ were prepared from sandstone and the contact angle was measured. Figure 3-12 shows the prepared slices for contact angle measurement test.

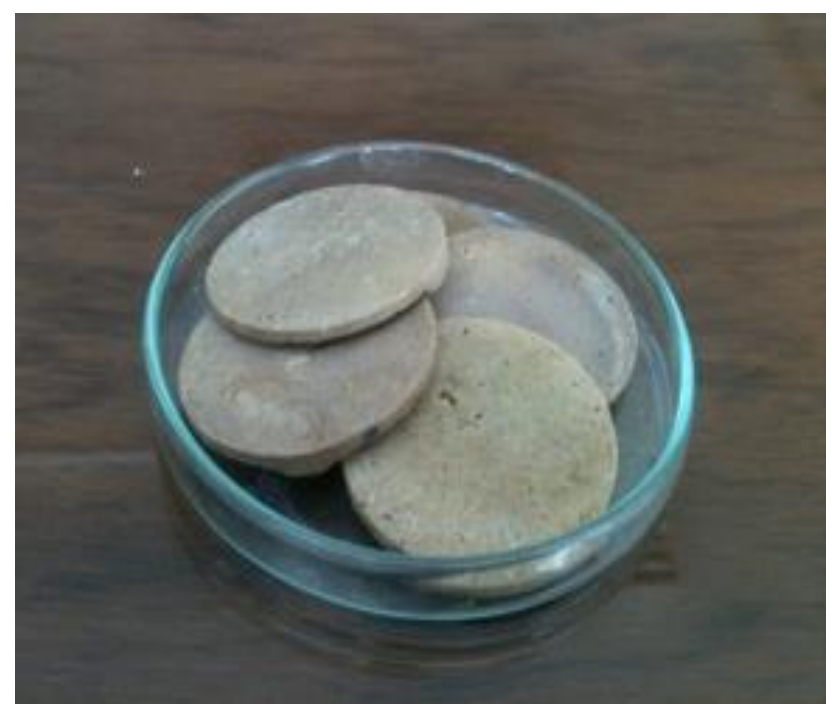

Figure 3 - 12 Prepared Rock Slices

The same process was done for nano fluid; after aging the slices in different concentration of nano fluids, contact angle was measured by using the contact angle measurement apparatus. The contact angle measurement apparatus measures the contact angle by the contact angle measurement method which discussed in section 2.6.4.1.

\subsection{Interfacial Tension Measurement}

To study interfacial tension changes' effect on recovery factor, the IFT measurement apparatus was once filled with brine and another time by the studying fluid (nano fluid) and a droplet of oil was hanged from the needle at each stage. By taking the photo of oil droplet, IFT was calculated by the equation 2-14. 


\subsection{Core Flooding \\ 3.6.1. Core Flooding Apparatus}

To conduct the flooding test Formation Damage and Well Treatment Evaluation System (FDS 350) machine was used (Figure 3-13). The machine is the product of Vinci-Technologies Inc., France. It has the ability to measure liquid permeability, unsteady state two phase relative permeability, static and dynamic filtration tests, mud invasion evaluation, sample flooding by three types of fluid individually and simultaneously, and conducting stimulation test on a core sample at reservoir pressure and temperature condition. [30]

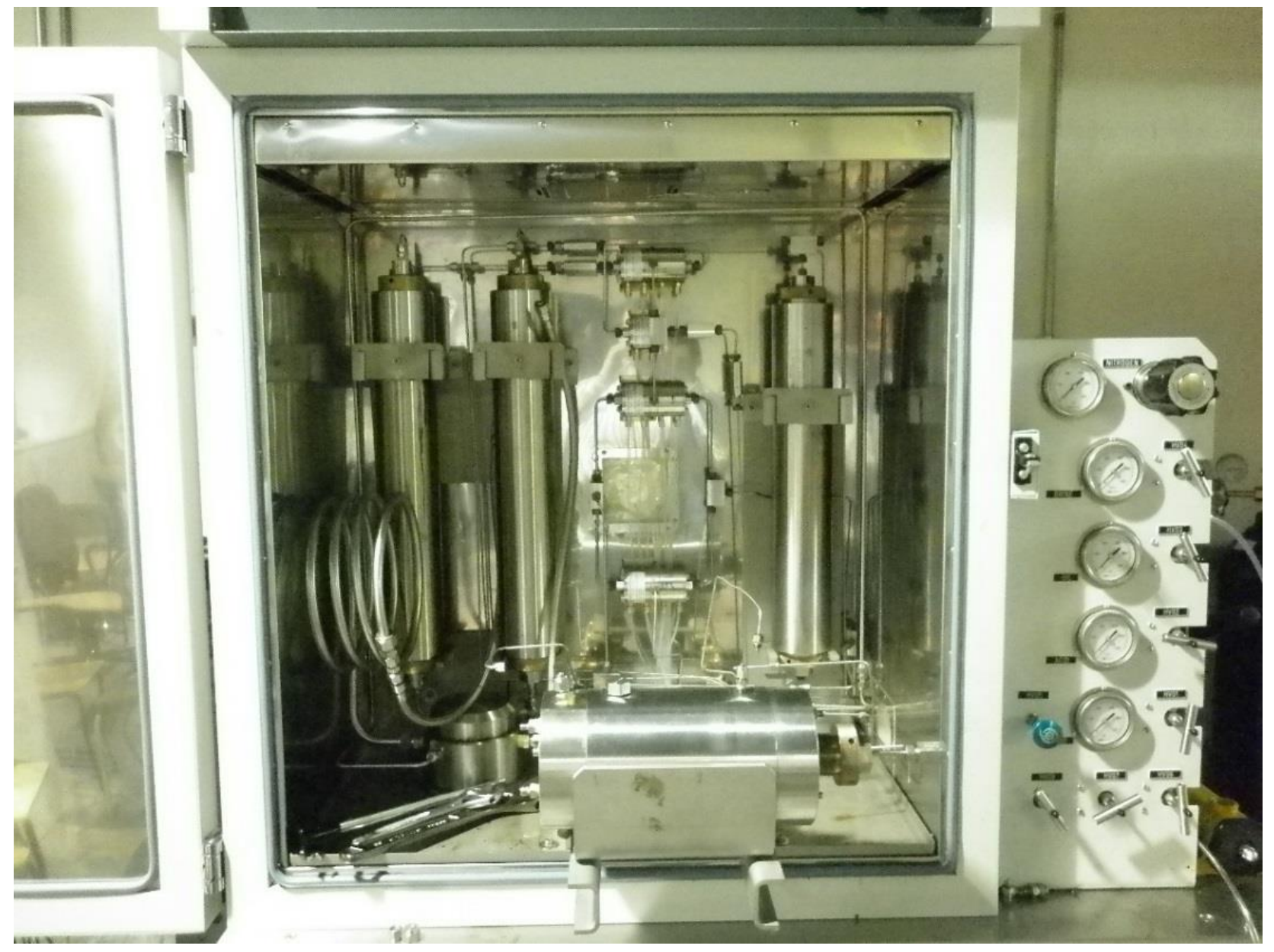

Figure 3 - 13 FDS 350 Machine 
FDS 350 can work under the confining pressure of 10,000 psi as well as pore pressure of 5,000 psi with the maximum temperature of $150{ }^{\circ} \mathrm{C}\left(300{ }^{\circ} \mathrm{F}\right)$. [30] Figure 3-14 shows the machine software environment and the piping schematic between components. Main components will be discussed in follow.

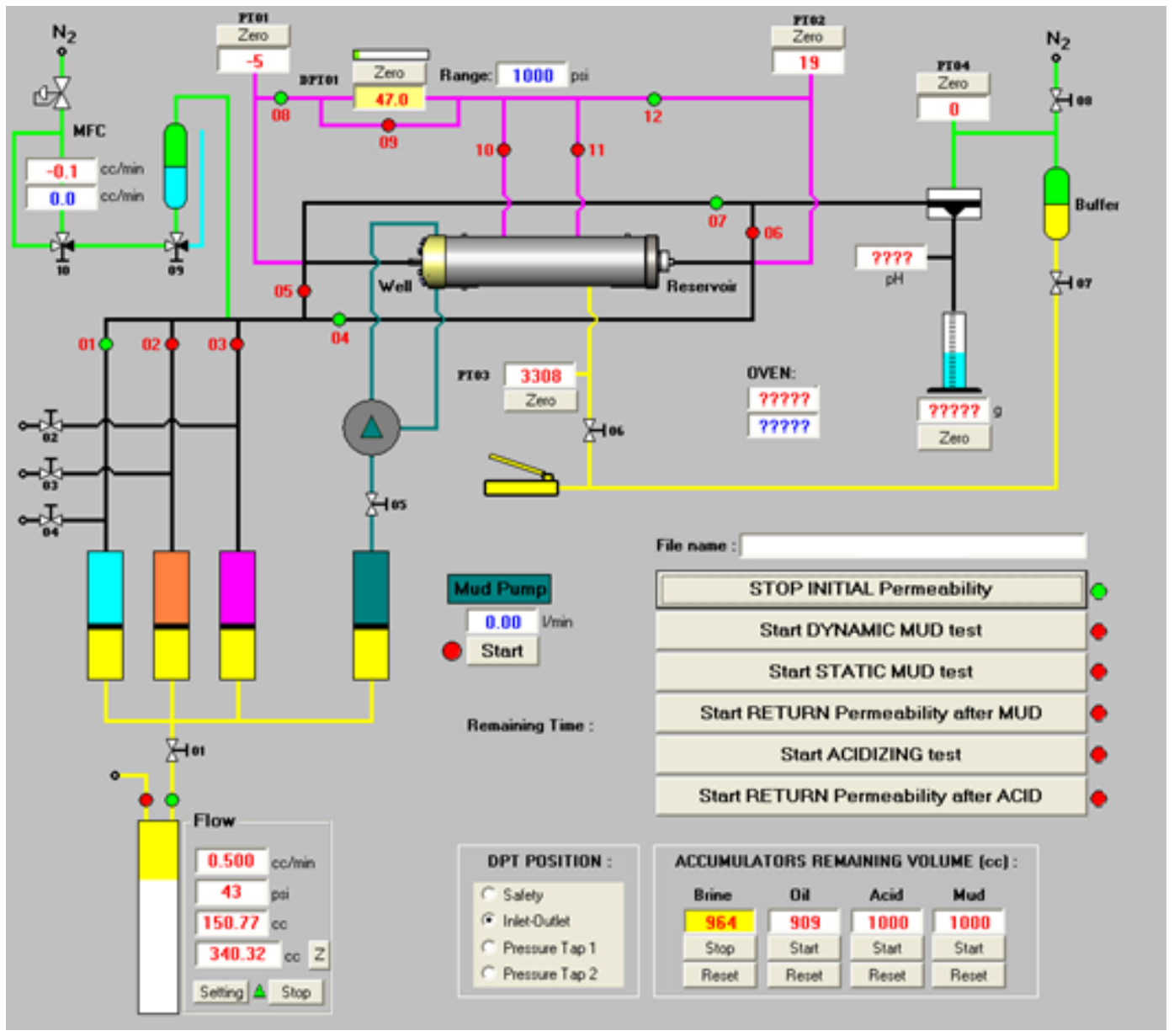

Figure 3 - 14 FDS 350 Program Environment and Piping Schematic

\subsubsection{Injection Pump}

FDS 350 has a syringe injection pump model BSP 500 made by ENERPAC with the capacity of $900 \mathrm{ml}$. The pump injects the driving fluid into the accumulator with the adjustable wide range of 0.001 to $50 \mathrm{ml} / \mathrm{min}$ by the increment of $0.001 \mathrm{ml}$. [30] Figure 3-15 shows the BSP pump. 


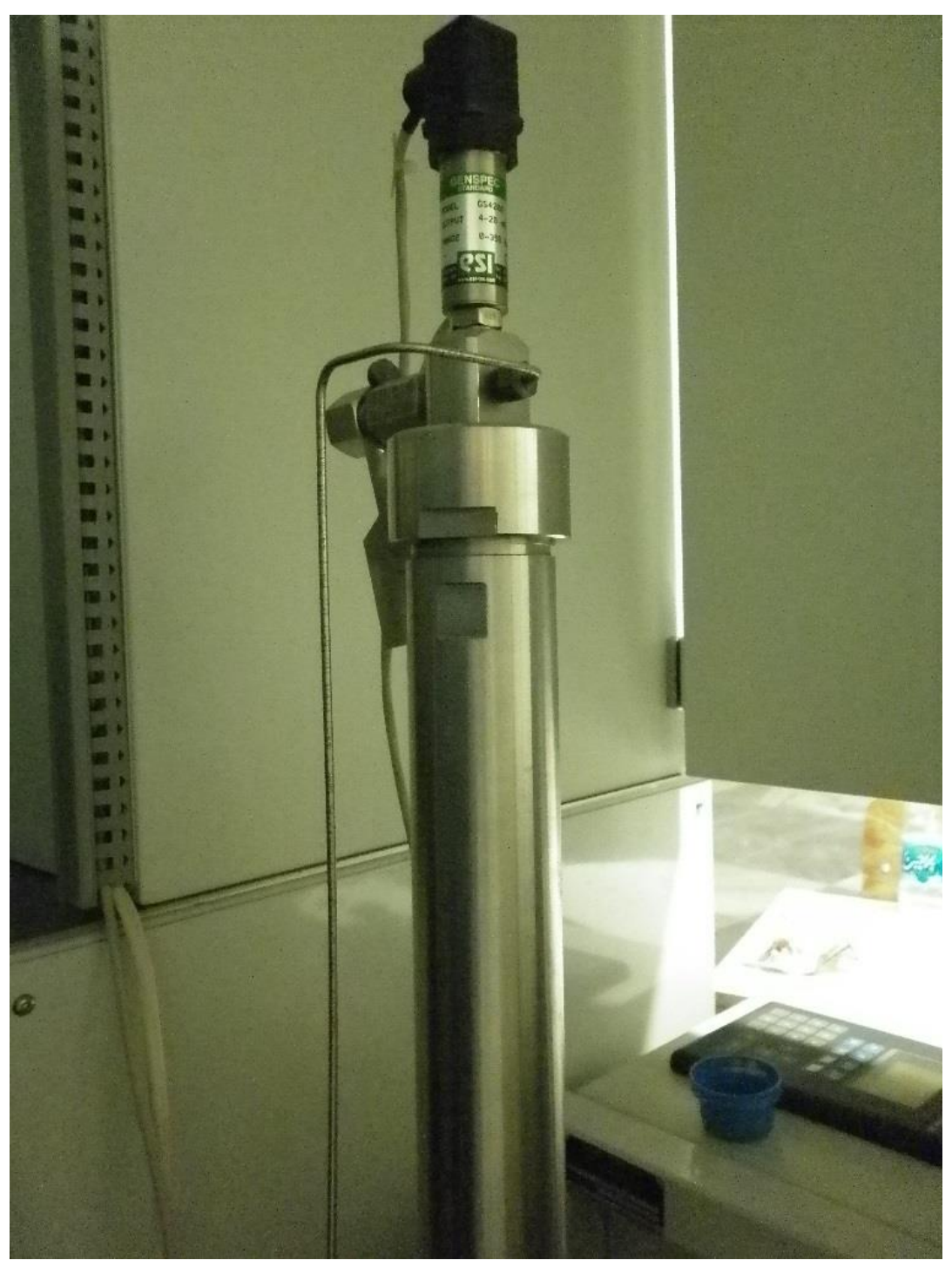

Figure 3 - 15 Injection Pump (BSP 500)

\subsubsection{Accumulators}

Accumulator is a cylindrical tank which is used for storing the testing fluid at the reservoir condition. Accumulator consists of two plugs at the top and bottom and a floating piston inside which separates testing fluid and driving fluid (water or hydraulic oil). FDS 350's accumulators made of stainless steel-316 which prevents body corrosion (Figure 3-16). [30] There are three accumulators inside the FDS 350 machine for holding oil, brine and third studying fluid (acid, polymer, nano fluid and etc.), and one outside of the machine for holding drilling mud for invasion studies. 


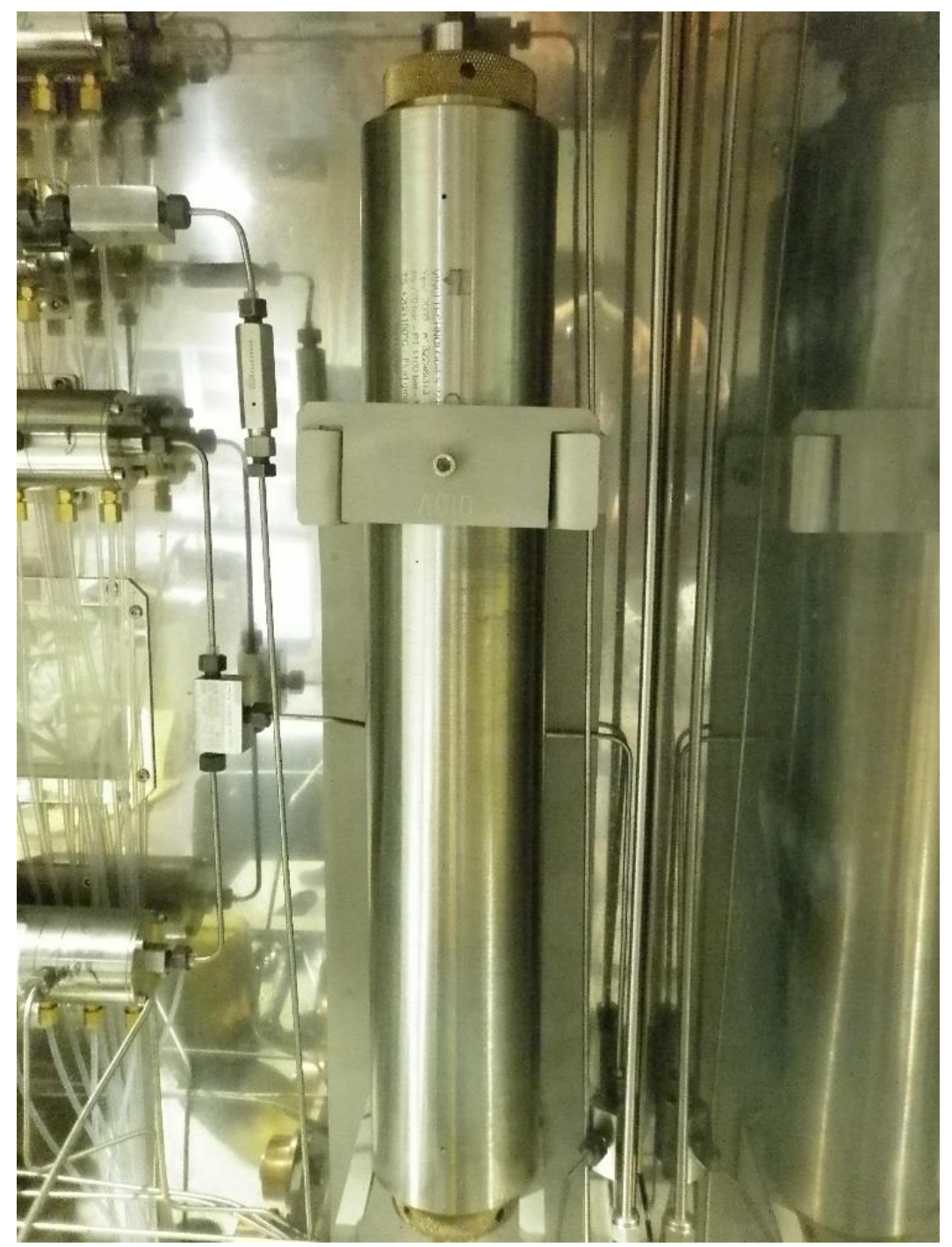

Figure 3 - 16 Accumulator

Accumulators can be refilled in two ways, direct and indirect. In direct method accumulator's piston is lowered by removing the driving fluid with the BSP pump by adjusting the injection value on a negative number; unscrewing the top plug, refilling the chamber by the testing fluid and fastening the plug. In indirect method, a plastic cylinder is filled with the liquid and the liquid is pushed into the accumulator by using the air compressor (Figure 3-17 and Figure 3-18). 


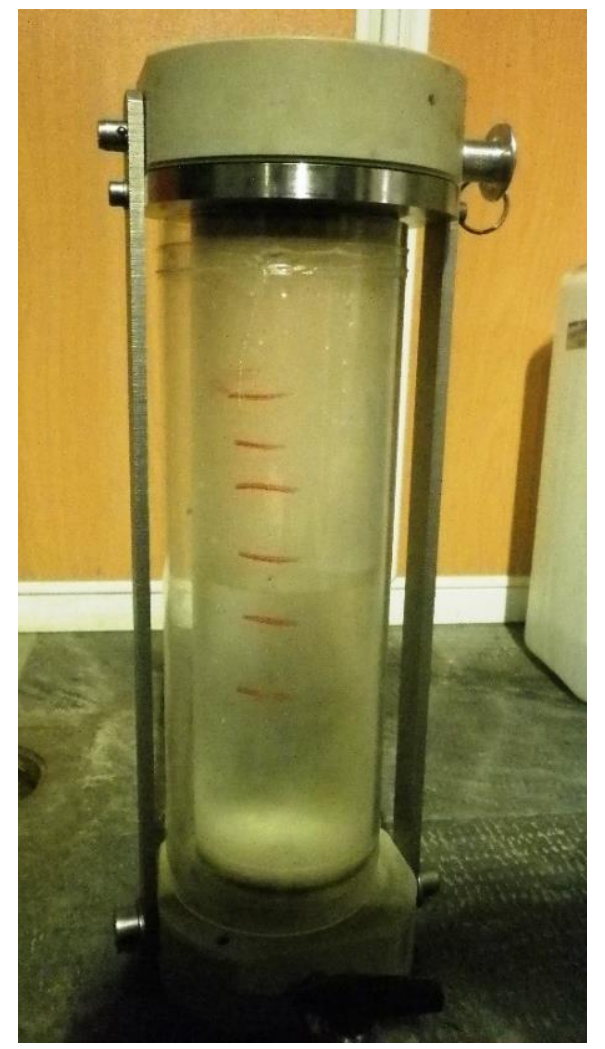

Figure 3 - 17 Plastic Cylinder for Refilling the Accumulator in Indirect Method

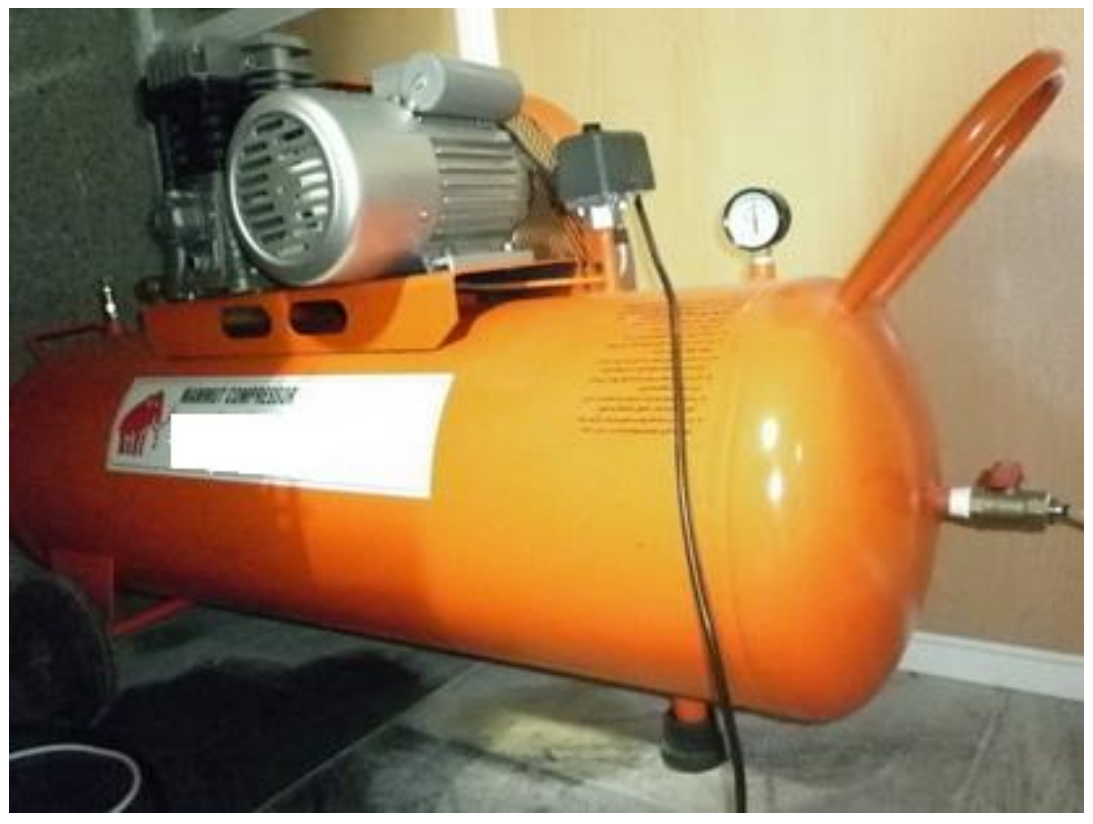

Figure 3 - 18 Air Compressor for Pushing the Fluid into the Accumulator 


\subsubsection{Core Holder}

The core holder in FDS 350 is designed by Vinci-Technologies Inc., France. The body metallurgy is 316stainless steel which can resist up to of 10,000 psi pressure. The rubber sleeve inside the core holder sticks to the sample and spread the confining pressure all around it. Different core lengths can be installed in it from $25 \mathrm{~mm}$ to $100 \mathrm{~mm}$ with the diameter of $38.1 \mathrm{~mm}$ ( $1.5 \mathrm{in})$. The rubber sleeve can sustain the temperature of $150{ }^{\circ} \mathrm{C}\left(300^{\circ} \mathrm{F}\right)$. [30] Figure 3-19 shows the picture of core holder.

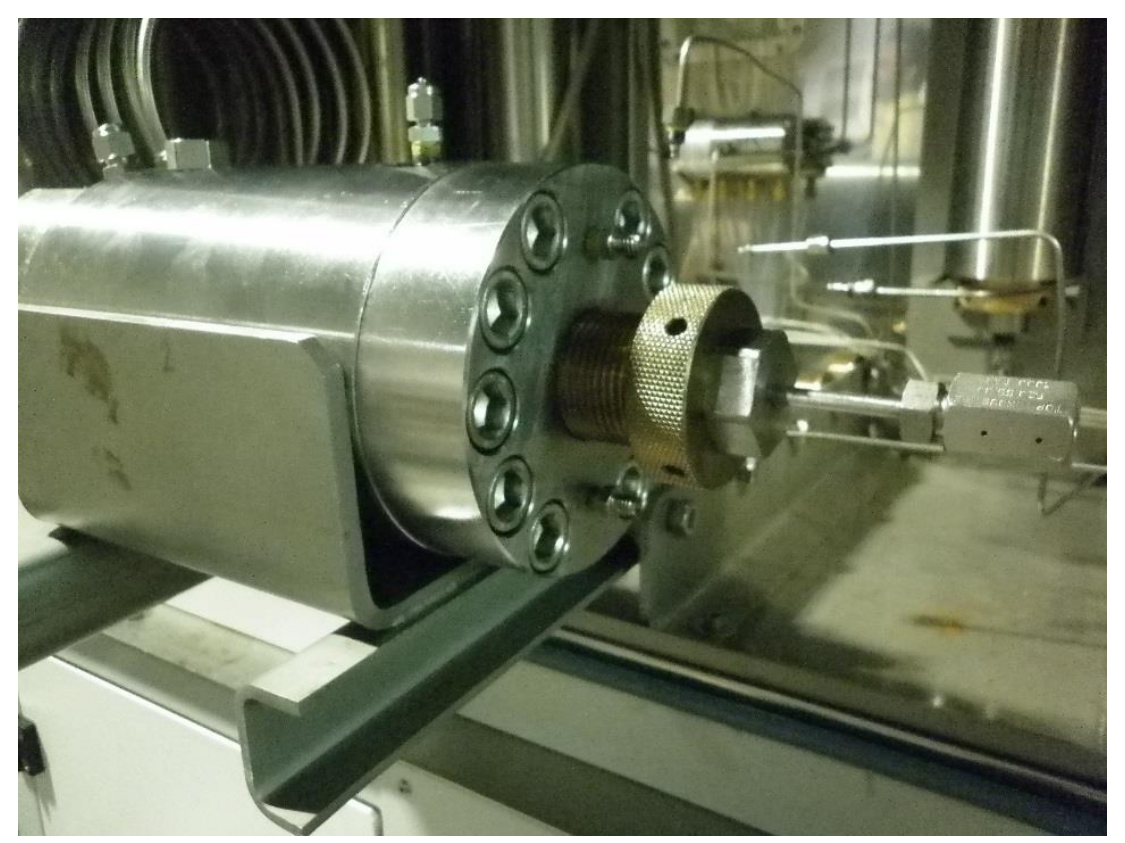

Figure 3 - 19 Core Holder

\subsubsection{Confining System}

To simulate the overburden pressure as well as sealing around the core sample and fluid flow prevention in an annular space between the core sample and rubber sleeve, overburden pressure should be applied. A hand pump with the hydraulic oil (low viscosity Silicon oil) filled tank is allowed to make a required confining pressure up to 10,000 psi. The pump's oil tank has the capacity of $900 \mathrm{ml}$ and it can pump 2.47 $\mathrm{ml}$ of oil per stroke. [30] Figure 3-20 shows the hand pump which is used in FDS 350 machine. 


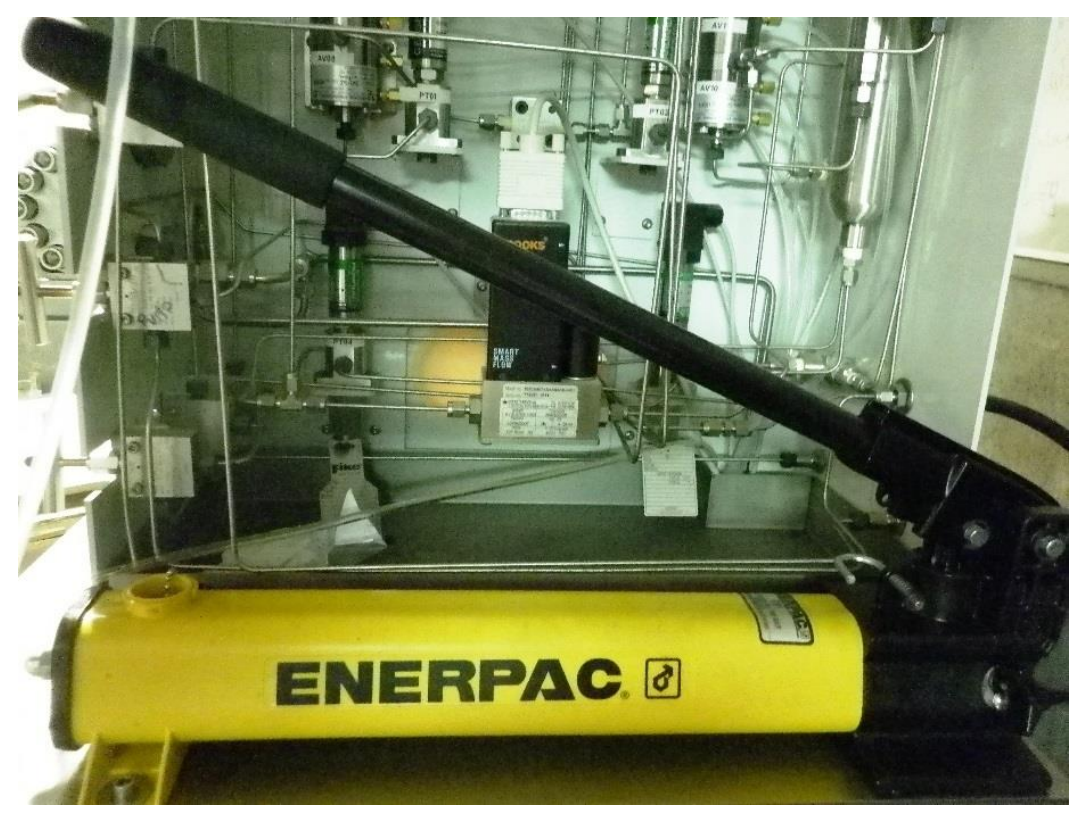

Figure 3 - 20 Hand Pump

\subsubsection{Heating System}

Eurotherm model 2416 is used for controlling hot air bath temperature which provides heat for warming the core holder and accumulators' fluid to simulate reservoir temperature condition. The maximum operating temperature is $150^{\circ} \mathrm{C}\left(300^{\circ} \mathrm{F}\right)$. $\mathrm{J}$ and $\mathrm{K}$ thermocouple types are measuring oven and core holder temperature with the accuracy of $\pm 0.1{ }^{\circ} \mathrm{C}$ respectively. [31] Figure 3-21 shows the thermometer display screen.

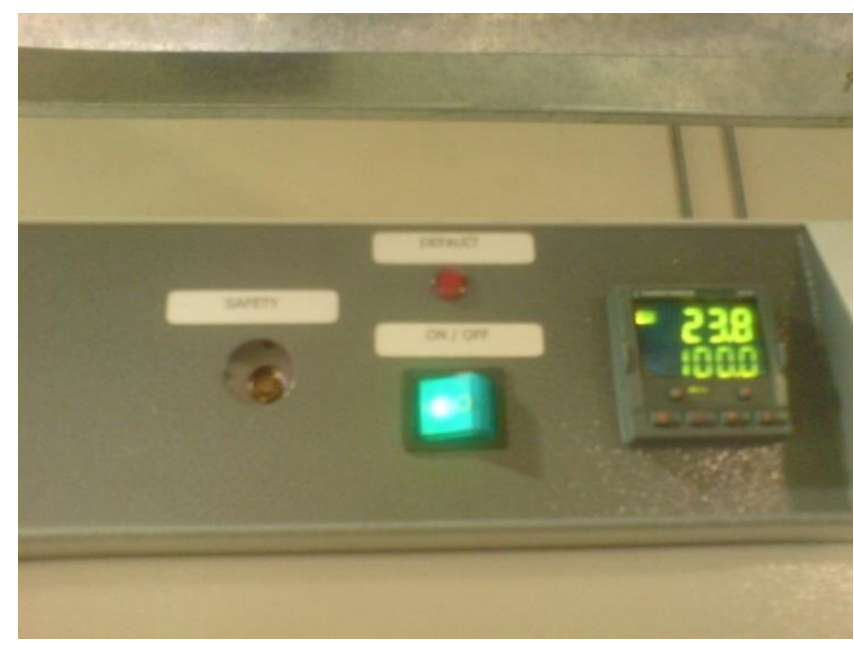

Figure 3 - 21 Thermometer 


\subsubsection{Fraction Collector}

The Spectra/Chrome CF-2 Fraction collector purchased from Spectrum Chromatography Company, USA. The device is used for collecting liquids from the core's outlet. As Figure 3-22 indicates the device has 29 tube racks and each rack has 4 tube holders which rotate on the basis of the defined program. The collection can be done on the basis of different events, such as time (6 seconds to 999 minutes and 59 seconds in 1 second increment), or counted droplets (1 to 9999 drops) or any other counted events than can be programmed to the device. [32]

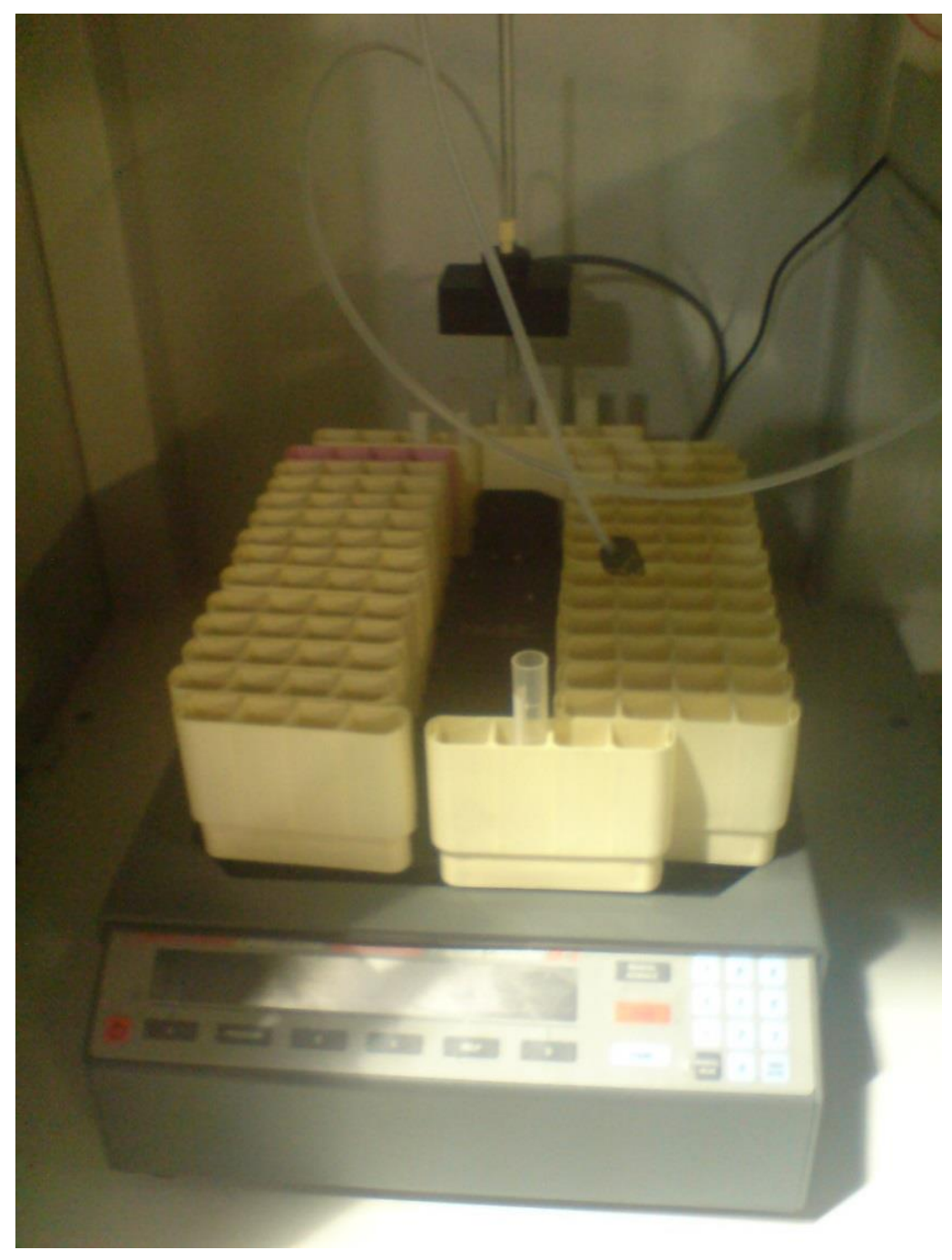

Figure 3 - 22 Fraction Collector 


\subsubsection{Pressure Transducer}

Pressure transducers in FDS 350 purchased from ESI Technology Ltd., UK. The operating pressure range is 0 to 10,152 psi with the accuracy of $\pm 0.05 \%$ of full scale. FDS 350 is equipped with 4 pressure transducers, one monitors the confining pressure, two gauges monitor the inlet and outlet pore pressure of the core sample and one monitors back pressure regulator (BPR) pressure. [30] Advanced FDS 350 machine equipped with two more pressure transducers on the injection pump and gas supply inlet. Figure 3-23 shows the ESI, model GS 4200 pressure transducer in FDS 350 machine.

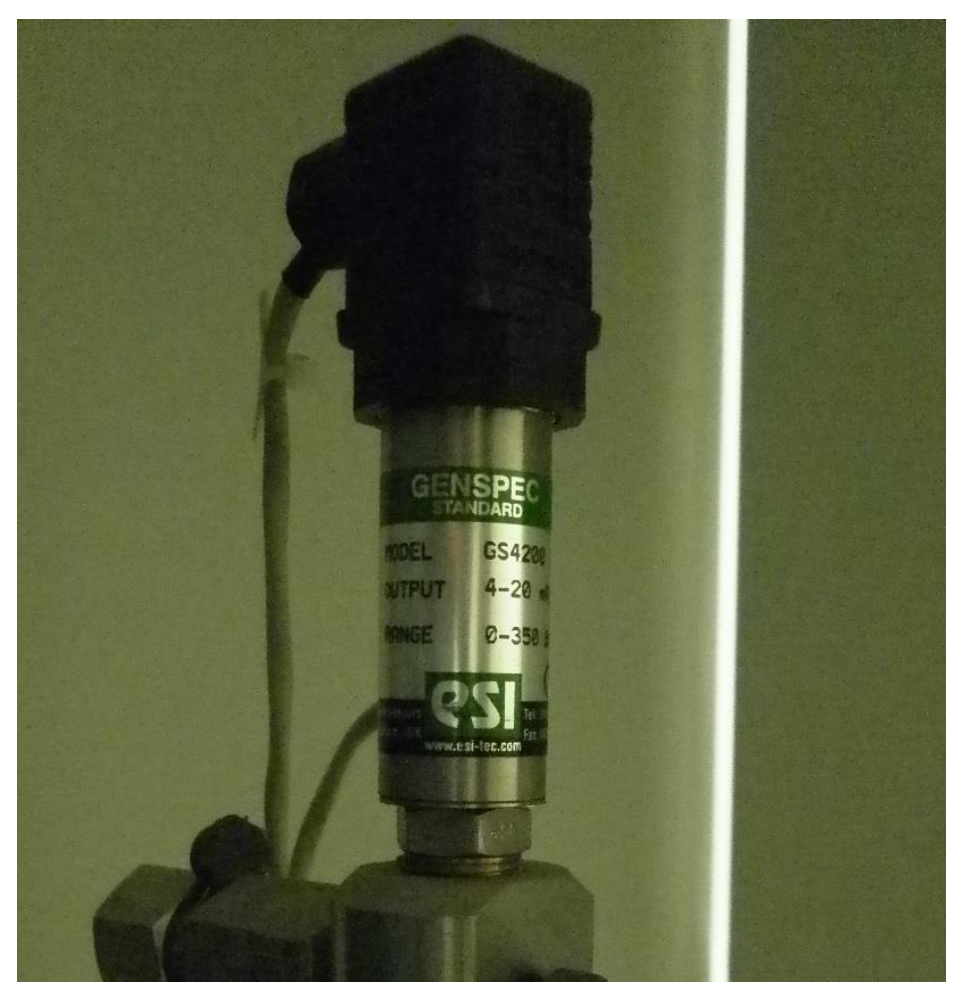

Figure 3 - 23 Pressure Transducer

\subsubsection{Flow Line}

Transferring vessels are Stainless Steel 316, Hastelloy C-276 with the inner diameter of $\frac{1}{8}$ inch and $\frac{1}{4}$ inch and outer diameter of $\frac{3}{8} \mathrm{inch}$. The flow lines can sustain high pressure up to $10,000 \mathrm{psi}$ and temperature of $150{ }^{\circ} \mathrm{C}\left(300{ }^{\circ} \mathrm{F}\right)$. For low pressure vessels, white and clear plastic tubes Teflon made are used which can 
sustain the oven temperature and maximum pressure of 145 psi. [30] Figure 3-24 shows the transferring vessels in FDS 350 machine.

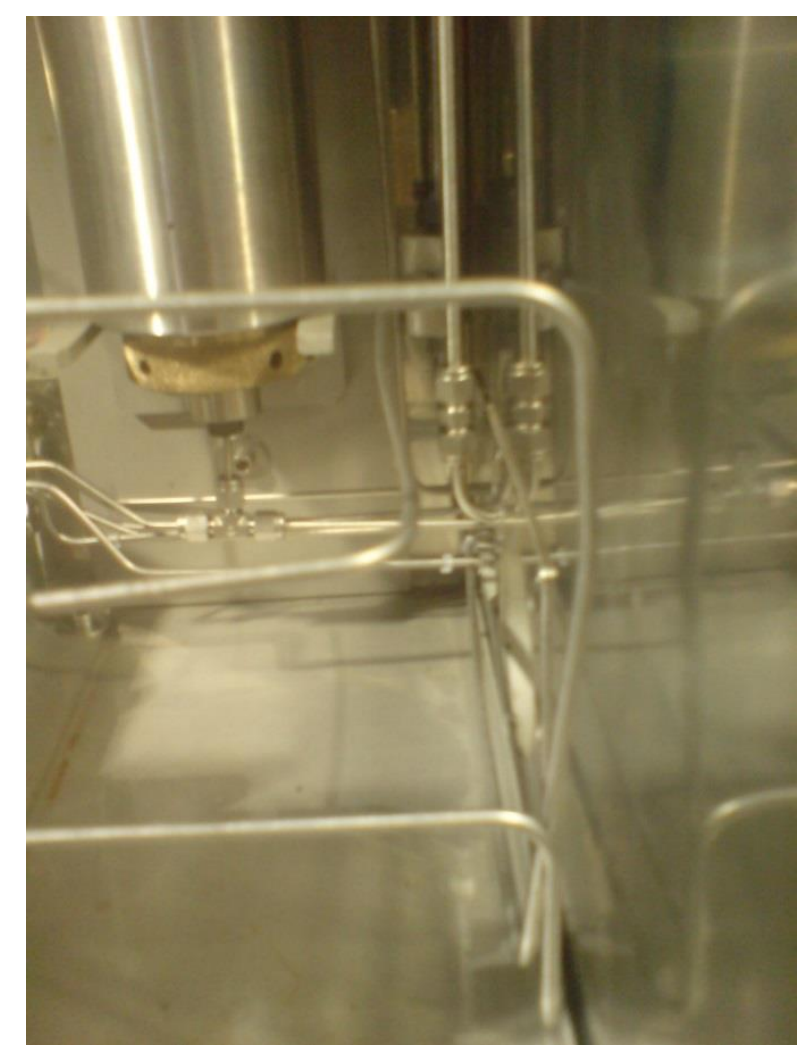

Figure 3 - 24 High Pressure Flow line

\subsubsection{Balance}

FDS 350's balance was purchased from Sartorius AG Company, Germany. It has the accuracy of 0.01 gram and the full scale range of 2,200 gram. The balance was used for weighting nano powder and core samples in this experiment. [33]

\subsubsection{Establishing Initial Saturations}

To establish and determine the initial water saturation, dried samples were weighted and submersed in a half full vacuum flask which hold brine; the flask's lid was sealed with high viscous oil ,Vaseline, while the pump was sucking the inside air. After a couple of days when no gas bubble could be seen around the samples, it was an evidence of completely saturated with brine. The saturated samples were weighted again 
to calculate the weight of trapped water. In the next step, each sample was placed in FDS 350 for flooding test. At the beginning of each test two pore volume of water was injected into the sample. The machine recorded the amount of injected fluid and at the same time the collector recorded the amount of produced water; dead volumes were already known from the company catalog, therefore the volume of trapped water at $S_{w}=100 \%$ was calculated. In the next step the core was flooded with the crude oil for three pore volume at small flow rate. By recording the volume of produced water and oil and having the volume of injected oil and system's dead volumes, trapped water volume was calculated. The initial water saturation is calculated by dividing trapped water volume by the stored water volume at the water saturation of $100 \%$.

\subsubsection{Water Flooding Process}

Flooding was the main part of this experiment; prepared core with initial water and oil saturation had already been installed in the core holder. Brine was injected into the core sample to mimic primary and secondary recovery. The injection should be done with small flow rate to prevent fingering effect as well as increasing volumetric sweep efficiency. After injecting several pore volumes of brine and collecting the produced fluids, recovery factor can be calculated by the following equation:

$$
R F_{w}=\frac{V_{o p}}{V_{o i}} \times 100 \%
$$

Where:

$R F_{w}:$ Recovery factor due to water flooding

$V_{o i}:$ Core sample initial oil volume, $c c$

$V_{o p}:$ Core sample produced oil volume,cc

Residual oil saturation can be calculated by the following equation:

$$
S_{o r}=\frac{V_{o i}-V_{o p}}{P V} \times 100 \%
$$


Where:

$P V:$ Sample pore volume, $c c$

\subsubsection{Nano Fluid Injection Process}

After secondary recovery, prepared nano fluid was injected into the core sample to simulate the tertiary recovery. Recovery factor can be investigated by recording the produced oil during the flooding and by substituting the values in Equation 3-12.

$$
R F_{n f}=\frac{V_{o p n f}}{V_{o r}} \times 100 \%
$$

Where:

$R F_{n f}:$ Recovery factor due to nano fluid injection

$V_{\text {or }}:$ Residual oil volume after water flooding, cc

$V_{\text {opnf }}:$ Produced oil after nano fluid injection, cc

The final residual oil saturation after nano injection can be calculated by the following formula:

$$
S_{\text {ornf }}=\frac{V_{\text {or }}-V_{\text {opnf }}}{P V} \times 100 \%
$$

Where:

$S_{\text {ornf }}:$ Residual oil saturation after nano fluid injection

$V_{\text {opnf }}:$ Produced oil due to nano fluid injection, cc 


\section{Chapter 4: Results and Discussions}

\subsection{Introduction}

The goal of this chapter is to present the effectiveness of nano particles that were tested on different core samples and their ability to improve oil recovery by the means of EOR agent after conducting primary and secondary recovery methods on the core samples. To understand their improving mechanism, the changes in two main rock and fluid properties which are wettability angle and interfacial tension were studied.

Before conducting the flooding experiment the optimum concentrations of two types of polysilicon nano fluid that had a better effect on changing rock wettability and improving fluid properties were determined. In the next step the changes in recovery factor were recorded by flooding the samples first with brine and then with the appropriate concentration of nano fluid. In addition, beside of recovery factory, injection pore volume for brine and nano fluids was studied so that the optimum injection volume could be determined.

In this experiment two water wet sandstone plugs were used for flooding test. Table 4-1 shows the petrophysical properties of core samples. The oil which was used in this experiment was a light crude oil. Table 4-2 presents reservoir oil properties which has been measured by research institute of petroleum industry.

Table 4 - 1 Petrophysical Properties of Studied Samples

\begin{tabular}{|c|c|c|c|c|c|c|}
\hline 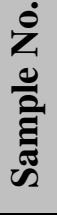 & $\begin{array}{c}\text { Length } \\
(\mathrm{cm})\end{array}$ & $\begin{array}{c}\text { Diameter } \\
(\mathrm{cm})\end{array}$ & $\begin{array}{l}\text { Porosity } \\
\text { Helium } \\
\text { (percent) }\end{array}$ & $\begin{array}{c}\text { Grain } \\
\text { Density } \\
\left(\mathrm{gr} / \mathrm{cm}^{3}\right)\end{array}$ & $\begin{array}{r}\mathbf{K}_{\text {klink }} \\
(\mathrm{mD})\end{array}$ & Lithology \\
\hline 7 & 5.19 & 3.88 & 24.0 & 2.68 & 580.91 & Sandstone \\
\hline 9 & 5.07 & 3.88 & 23.2 & 2.68 & 443.01 & Sandstone \\
\hline
\end{tabular}


Table 4 - 2 Reservoir Oil Properties

\begin{tabular}{|c|c|c|c|}
\hline Specification & Unit & Quantity & Test Method \\
\hline Specific Gravity @ $15.56{ }^{\circ} \mathrm{C}$ & - & 0.8065 & ASTM D - 4052 \\
\hline${ }^{0}$ API & - & 43.9 & ASTM D - 1298 \\
\hline Sulfur Content & $\%$ Wt. & 0.32 & ASTM D - 2622 \\
\hline Total Nitrogen & $\%$ Wt. & $<0.02$ & ASTM D - 3228 \\
\hline Base Sediment and Water & $\%$ Vol. & $<0.05$ & ASTM D - 1796 \\
\hline Water Content & $\%$ Vol. & $<0.05$ & ASTM D - 4006 \\
\hline Salt Content & P.T.B. & 3 & ASTM D - 3230 \\
\hline Kinetic Viscosity @ $10{ }^{\circ} \mathrm{C}$ & c.St. & 4.14 & ASTM D - 445 \\
\hline Kinetic Viscosity @ $20{ }^{\circ} \mathrm{C}$ & c.St. & 3.42 & ASTM D - 445 \\
\hline Kinetic Viscosity @ $40{ }^{\circ} \mathrm{C}$ & c.St. & 2.35 & ASTM D - 445 \\
\hline Pour Point & ${ }^{0} \mathrm{C}$ & $<-40$ & ASTM D - 5853 \\
\hline
\end{tabular}

\subsection{Optimum Concentration of Nano Fluids}

Two types of polysilicon nano particles were studied in this experiment, but the key factor before studying of their effects was to determine the optimum concentration of injection nano fluids. To fulfill this goal six different concentration ( $0.5 \mathrm{gr} / \mathrm{lit}, 1 \mathrm{gr} / \mathrm{lit}, 1.5 \mathrm{gr} / \mathrm{lit}, 2 \mathrm{gr} / \mathrm{lit}, 2.5 \mathrm{gr} / \mathrm{lit}$ and $3 \mathrm{gr} / \mathrm{lit})$ of nano fluids for NWP and HLP nano powders were prepared and their effect on wettability angle and interfacial tension were investigated. HLP and NWP nano particles due to their ability to change the wettability from water wet to oil wet and water wet to neutral wet tendency, were tested on sandstone samples. [34] The optimum concentration of nano fluid for each of these two different polysilicon was the one that could change the wettability angle as much as possible beside of reducing interfacial tension. In follow the result of this study for nano polysilicon will be discussed.

\subsubsection{NWP Nano Fluid}

To determine the optimum concentration of NWP nano fluid two parameters were studied, interfacial tension changes and wettability angle alterations. To investigate IFT changes, after preparing different concentration of nano fluids, they were poured in IFT apparatus cell and their interfacial tension values were determined. As Figure 4-1 shows oil/nano fluid interfacial tension is reducing by increasing of nano 
fluid concentration, therefore concentration of $3 \mathrm{gr} / \mathrm{lit}$ was chosen as the optimum concentration in the aspect of IFT reduction.

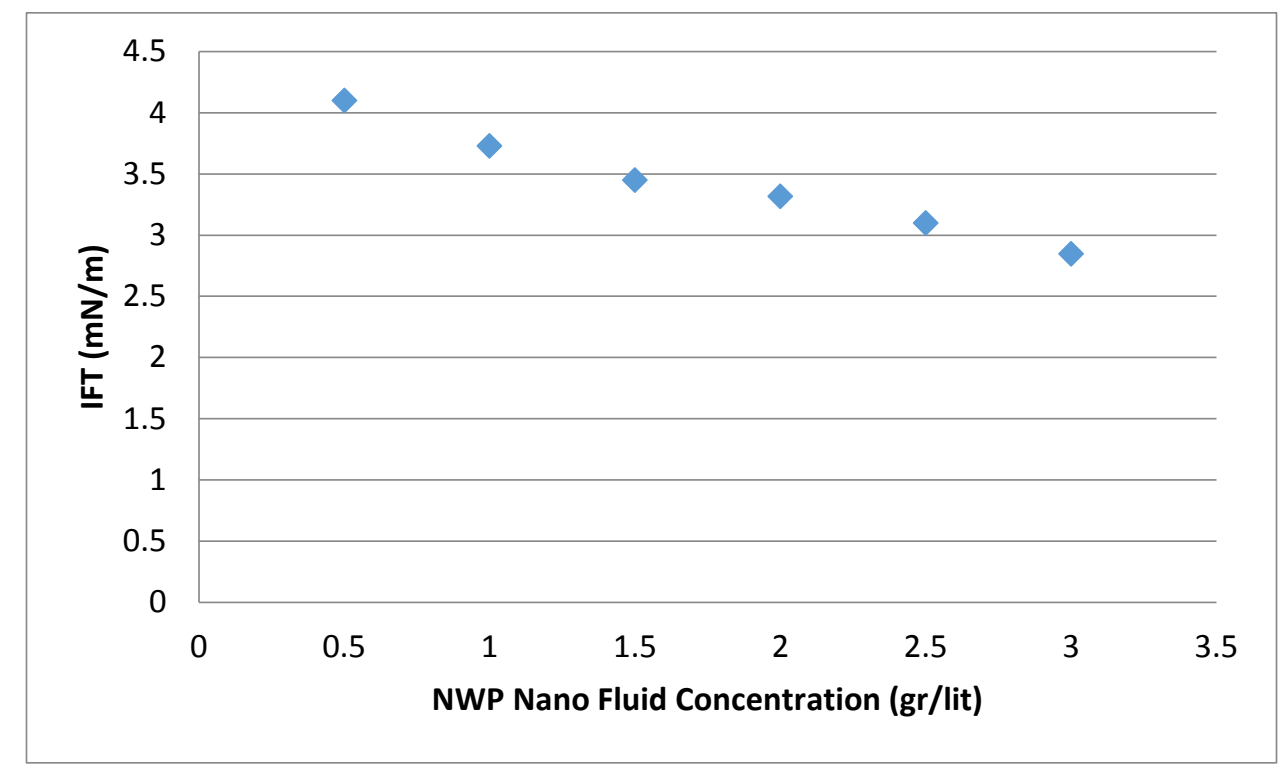

Figure 4 - 1 IFT Changes versus Different Concentration of NWP Nano Fluid

In the next step for studying the wettability alteration, seven slices of sandstone were prepared by using Trimming Saw machine. The slices were submersed in the nano fluids' beaker vertically to prevent any kind of nano deposition due to fluid instability assumption. In addition one slice was laid in brine as the reference sample. After a day contact angle for each of these seven slices was measured. As the Figure 4-2 shows increasing in nano fluid concentration will bring in smaller value of contact angle, therefore NWP nano fluid with the concentration of $3 \mathrm{gr} / \mathrm{lit}$ is the optimum one for wettability alteration. 


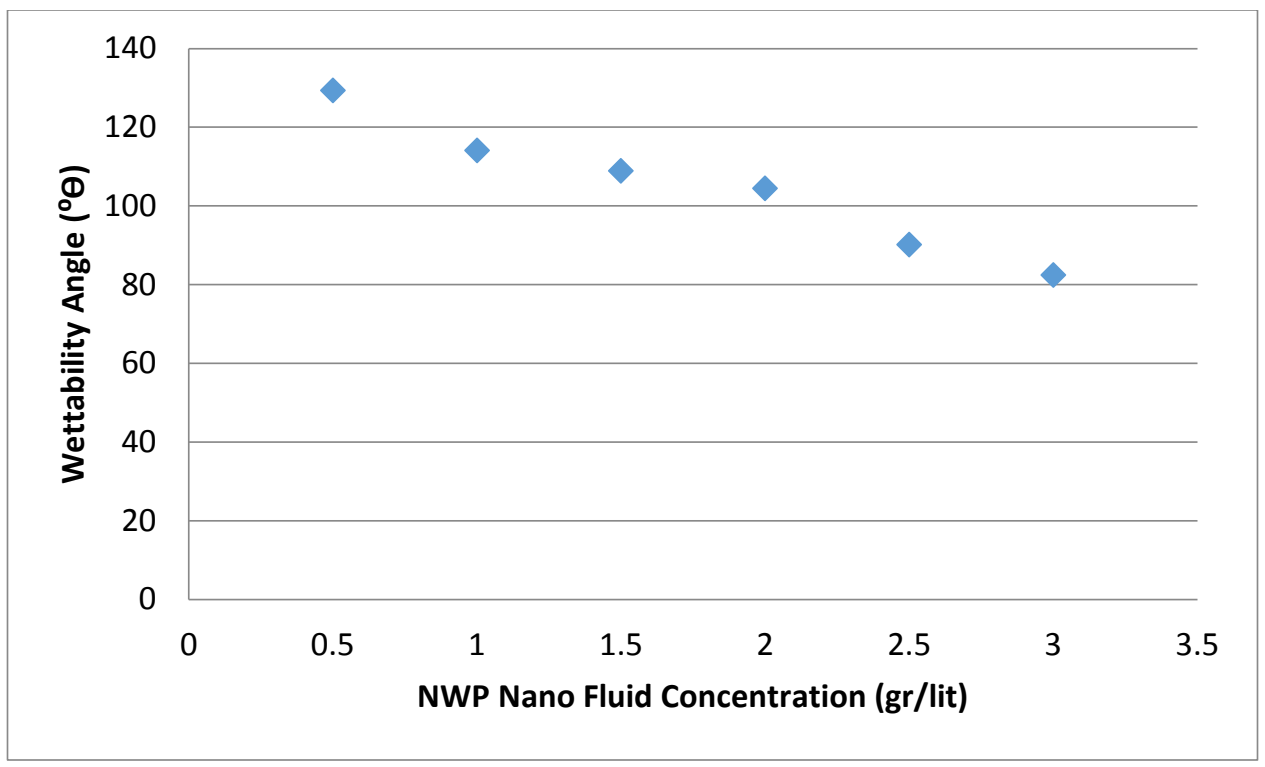

Figure 4 - 2 Wettability Angle Changes versus Different Concentration of NWP Nano Fluid

By comparing the result of IFT and wettability alteration studies, it was concluded that the concentration of $3 \mathrm{gr} / \mathrm{lit}$ is the optimum fluid concentration for using in core flooding apparatus. Figure 4-3 shows percentage of changes in wettability angle and IFT at each concentration respect to the values for minimum concentration of nano fluid. This conclusion can be taken that NWP nano particles have a greater effect on wettability alteration rather than IFT at higher nano fluid concentrations.

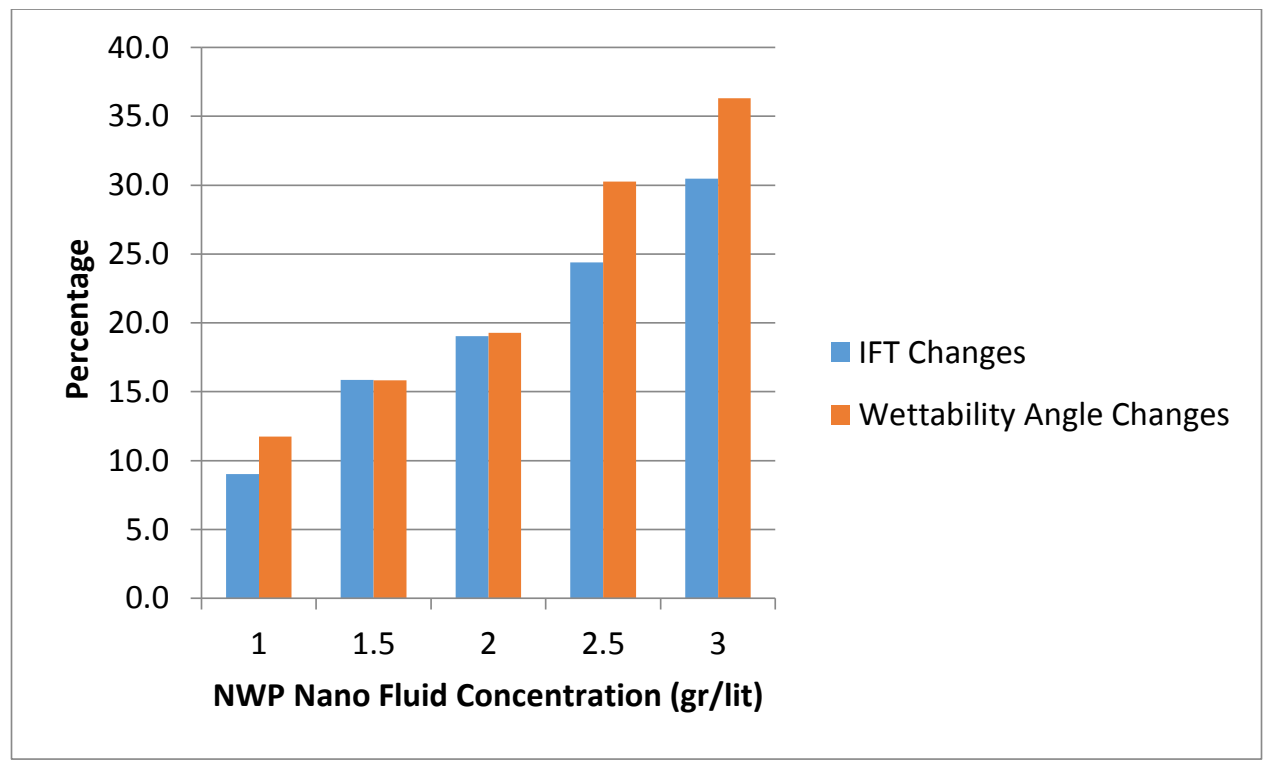

Figure 4 - 3 Comparing the Effect of Different Concentration of NWP Nano Fluid on IFT and Wettability Angle Alteration 


\subsubsection{HLP Nano Fluid}

Six different concentration of HLP nano fluid was prepared by stirring the nano powder in ethanol and stabilizing it by using ultra sonic device. Portion of prepared fluids was used in interfacial measurement apparatus separately and the tension between nano fluid and oil was measured. Figure 4-4 shows the result of the measurements. It was recognized that as the amount of nano particles in nano fluid increase, the larger reduction in interfacial tension can be expected. Therefore concentration of $3 \mathrm{gr} / \mathrm{lit}$ was chosen as the ideal concentration for HLP nano fluid in reducing IFT.

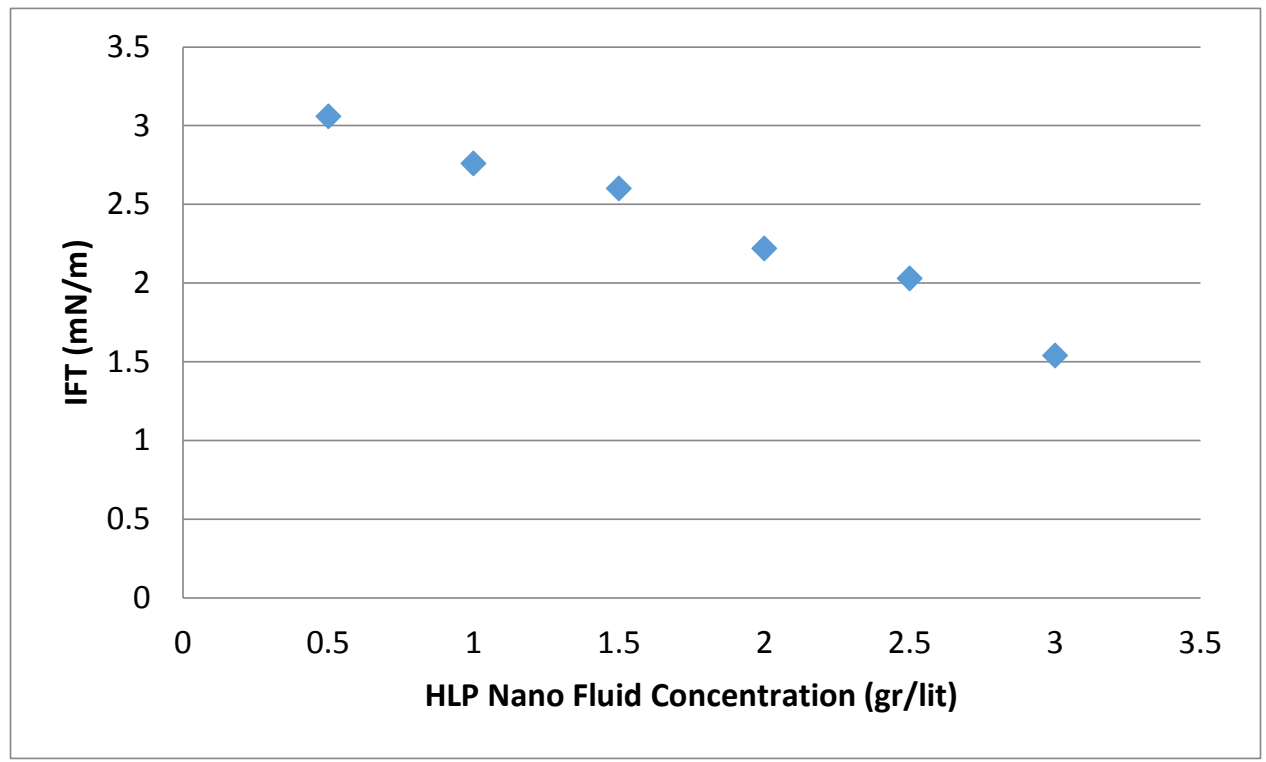

Figure 4 - 4 IFT Changes versus Different Concentration of HLP Nano Fluid

As discussed before HLP nano powder due to its hydrophobic feature can change water wet rock to oil wet rock or oil wet rock to strongly oil wet rock. Therefore wettability alteration is another crucial factor in choosing the appropriate concentration of nano fluid for injection. To find the best concentration, six slices of sandstone were placed in prepared nano fluids and after a day, the contact angle was measured for each one of them. As Figure 4-5 shows at low concentrations ( $0.5 \mathrm{gr} / \mathrm{lit}$ to $1.5 \mathrm{gr} / \mathrm{lit})$ wettability alteration is significant but for concentrations greater than $1.5 \mathrm{gr} / \mathrm{lit}$, the difference between two consecutive measured contact angles is small. On the basis of this, concentration of $1.5 \mathrm{gr} / \mathrm{lit}$ was selected as the optimum value for changing rock wettability. 


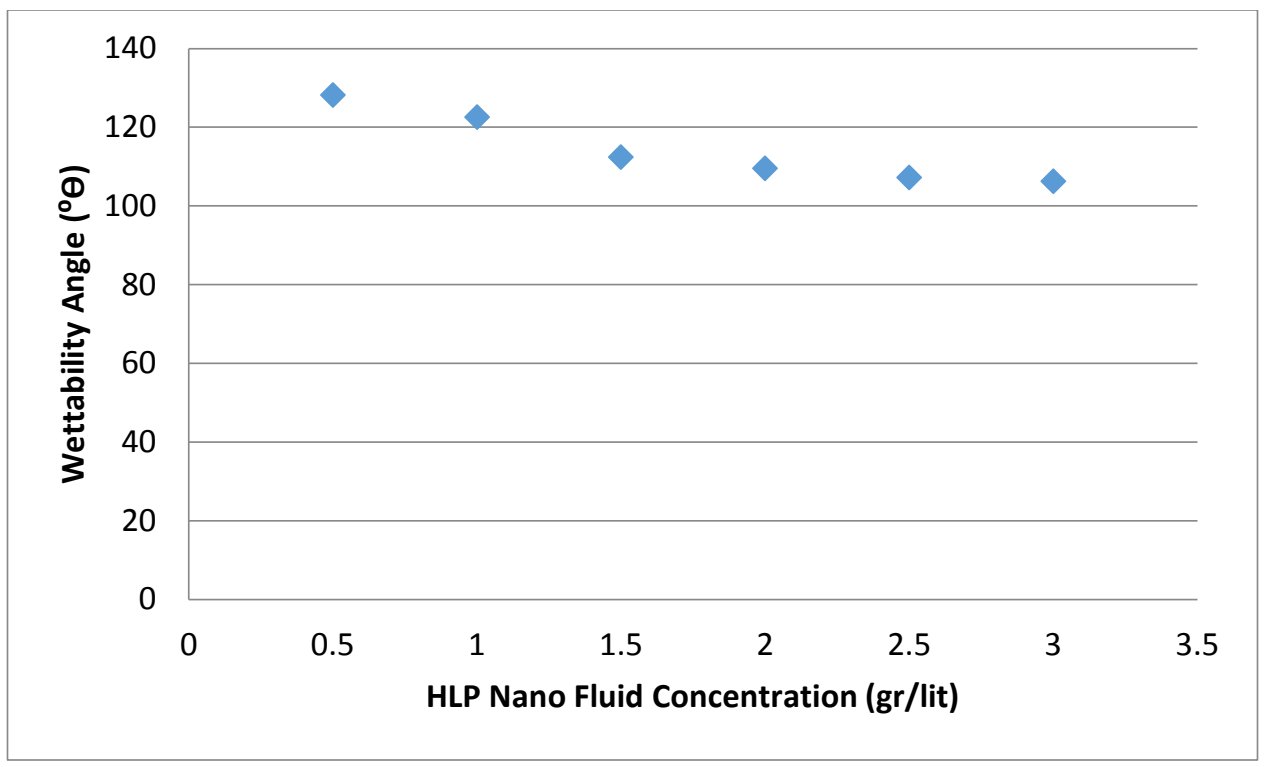

Figure 4 - 5 Wettability Angle Changes versus Different Concentration of HLP Nano Fluid

By considering both IFT and wettability angle it was understood that the optimum concentration for these two factors were different. By calculating IFT reduction and wettability alteration percentage for concentrations of greater than $1.5 \mathrm{gr} / \mathrm{lit}$ respects to $1.5 \mathrm{gr} / \mathrm{lit}$, it was recognized that for IFT the reduction for the nano fluid of $3 \mathrm{gr} / \mathrm{lit}$ was $40.7 \%$ while for contact angle was just about $5.4 \%$ as the Figure $4-6$ shows. On the basis of this comparison, concentration of $3 \mathrm{gr} / \mathrm{lit}$ was selected as the optimum value for core flooding process due to its ability to lower the IFT value significantly.

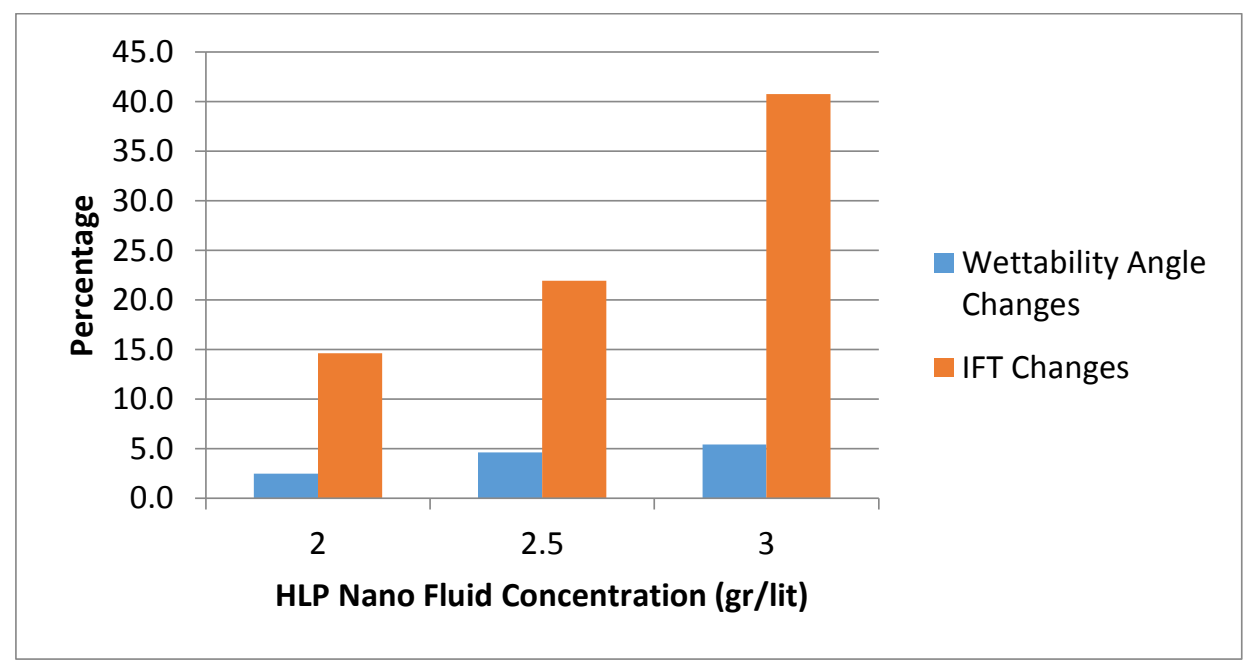

Figure 4 - 6 Comparison the Effect of Different Concentration of Nano Fluid on IFT and Wettability Angle Respect to the Concentration of $1.5 \mathrm{gr} / \mathrm{lit}$ Value 


\subsection{Core Flooding}

After determining the optimum concentration for each types of polysilicon, prepared core samples were first flooded with brine and then by nano fluid, and the volume of produced oil was recorded for calculating recovery factor and saturation changes analysis. In follow the result of injection for three type of nano polysilicon will be discussed.

\subsubsection{Flooding in Core \# 9}

To investigate the effect of nano particles on production improvement, a sandstone plug with the dimensions and properties which are presented in Table 4-3, was first flooded with water for four pore volume and then with NWP nano fluid with the concentration of $3 \mathrm{gr} /$ lit for three pore volume. The flushed out oil was recorded during the specific intervals for calculating recovery factor. The result of brine and nano fluid flooding are discussed in next parts separately.

Table 4 - 3 NWP Nano Fluid Studies Core Plug Properties

\begin{tabular}{|c|c|c|c|c|c|c|}
\hline 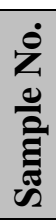 & $\begin{array}{l}\text { Length } \\
(\mathrm{cm})\end{array}$ & $\begin{array}{l}\text { Diameter } \\
(\mathrm{cm})\end{array}$ & $\begin{array}{c}\text { Porosity } \\
\text { Helium } \\
\text { (percent) }\end{array}$ & $\begin{array}{c}\text { Grain } \\
\text { Density } \\
\left(\mathrm{gr} / \mathrm{cm}^{3}\right)\end{array}$ & $\begin{array}{l}\mathbf{K}_{\text {klink }} \\
(\mathrm{mD})\end{array}$ & $\begin{array}{c}\mathbf{S}_{\mathbf{w}} \\
\text { (percent) }\end{array}$ \\
\hline 9 & 5.07 & 3.88 & 23.2 & 2.68 & 443.01 & 35.1 \\
\hline
\end{tabular}

\subsubsection{Water Flooding}

As Figure 4-7 presents, the final recovery factor after flooding the core with four pore volume of brine is $58.7 \%$, in which most of the oil production happened before the break through that is an evidence of water wet affinity of sandstone core. In addition, after two pore volume of injection no significant oil production can be seen and just $3.4 \%$ of the initial oil has been produced; therefore due to high water oil ratio, the optimum volume of water flooding is two pore volume in this case of study. 


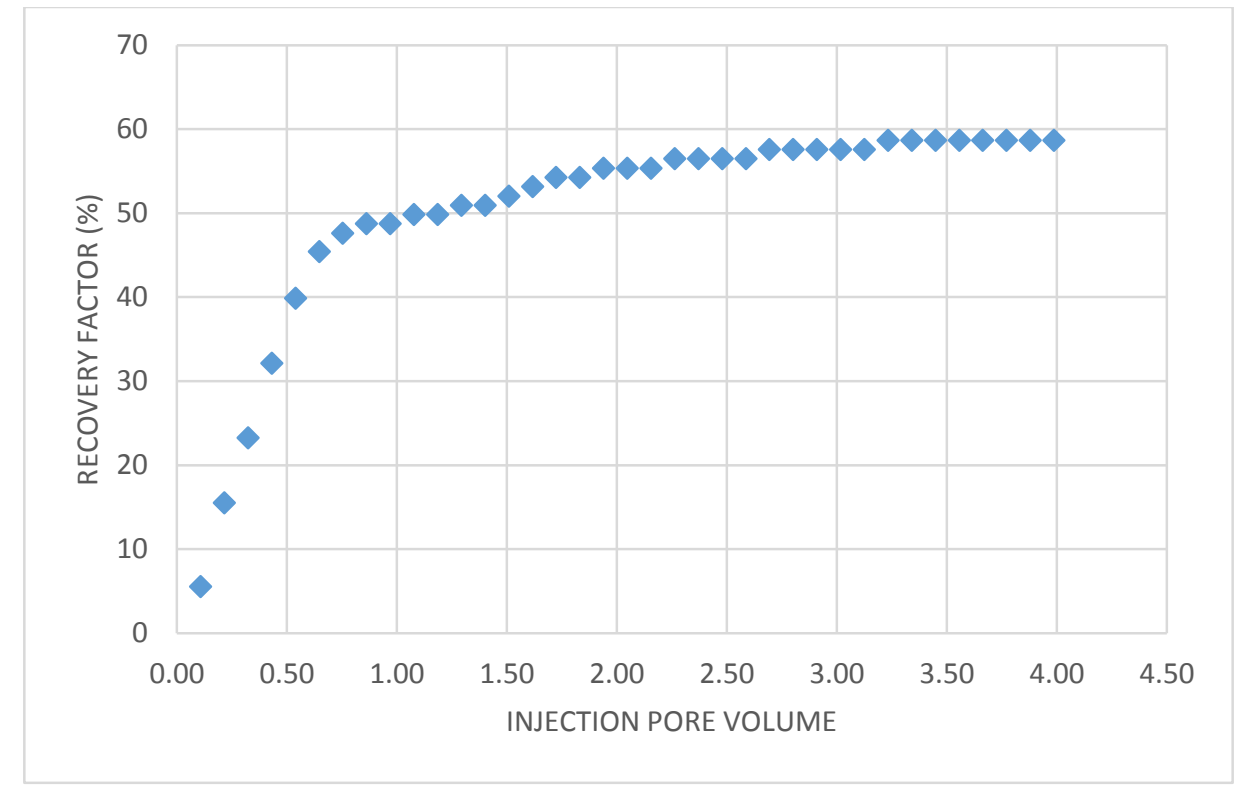

Figure 4 - 7 Recovery Factor in Sample \#9 Water Flooding

Saturation studies also indicate that oil saturation decreases with a sharp slope before break through due to flushing out the trapped oil at the center of large pores, Figure 4-8. After that because of high capillary pressure, oil droplets could not pass through the pore throats and they have been trapped in the porous media.

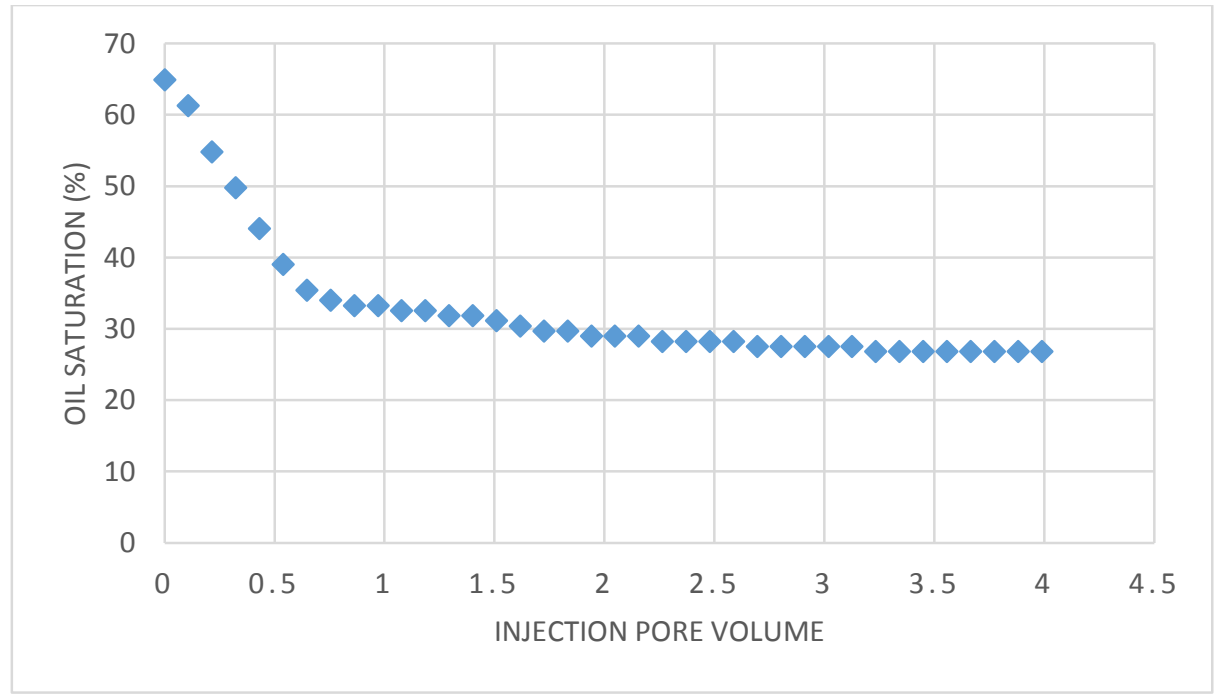

Figure 4 - 8 Oil Saturation Changes in Sample \#9 During Water Flooding 


\subsubsection{NWP Nano Fluid Injection}

After performing the primary and secondary recovery by flooding the sample, NWP nano fluid was injected into the sample. As Figure 4-9 illustrates at the beginning of the injection the recovery factor is zero because brine is still producing from the core outlet but as the nano fluid's front finds its path and break through happens, it flushes out trapped oil droplets out of the sample. The results shows NWP nano fluid could improve the total recovery factor up to $88.6 \%$.

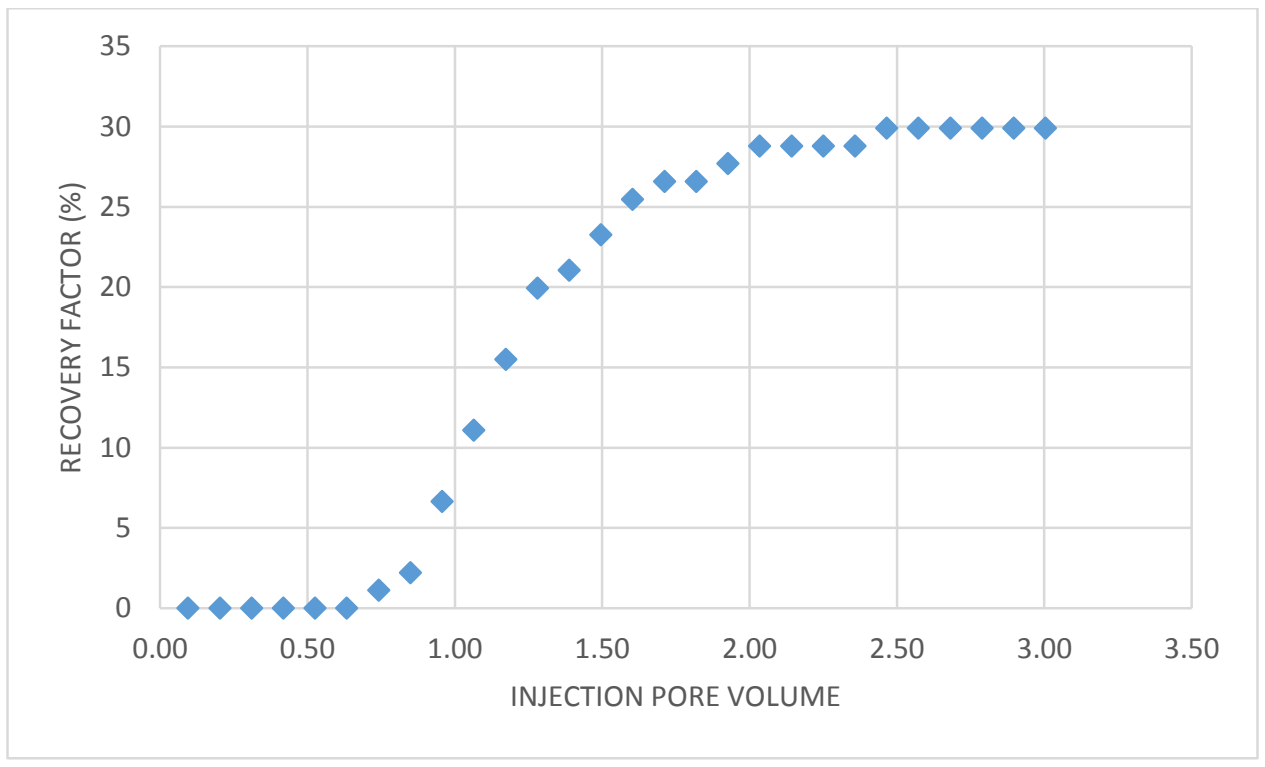

Figure 4 - 9 Recovery Factor Changes in Sample \#9 During NWP Flooding

Figure 4-10 is the result of saturation calculation by analyzing the produced oil. As the graph indicates nano particles can reduce oil saturation significantly. This phenomenon can be explained in two ways, IFT reduction and wettability alteration. Since previous studies showed, NWP nano fluid can act as a surfactant in reducing the IFT which helps the production by lowering the capillary pressure value. As the capillary pressure reduces, trapped oil droplets can pass through the small pore throats by the means of deformation which leads to oil production and reducing the residual oil saturation. Another aspect that can be considered is wettability alteration; NWP nano particles can change the rock wettability affinity from water wet or oil wet toward neutral wet which means a contact angle of around $90^{\circ}$. As discussed before capillary pressure has a direct relationship with cosine of $\theta$, therefore for intermediate wet rocks the capillary pressure value is minimum, which means the ease of production and lower residual oil saturation values. 


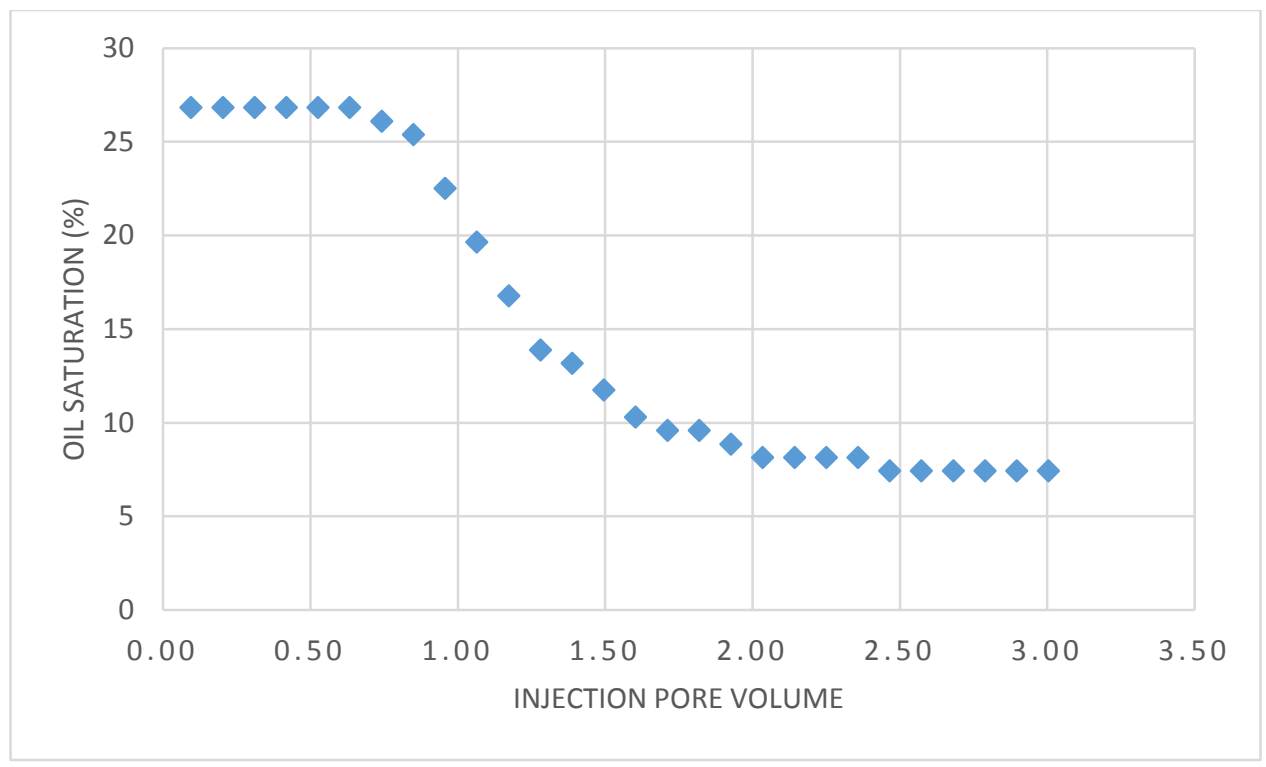

Figure 4 - 10 Oil Saturation Changes in Sample \#9 During NWP Flooding

\subsubsection{Flooding in Core \# 7}

In the second experiment a sandstone plug with the dimensions and petrophysical data which are presented in Table 4-4 was flooded with brine and HLP nano fluid respectively. The result of each floods are discussed in next parts. To have a better sweep efficiency and prevention from fingering or channeling effect, the injection rate of $1 \mathrm{cc} / \mathrm{min}$ was chosen for experiment.

Table 4 - 4 HLP Nano Fluid Studies Core Plug Properties

\begin{tabular}{|c|c|c|c|c|c|c|}
\hline 高 & $\begin{array}{c}\text { Length } \\
(\mathrm{cm})\end{array}$ & $\begin{array}{l}\text { Diameter } \\
(\mathrm{cm})\end{array}$ & $\begin{array}{l}\text { Porosity } \\
\text { Helium } \\
\text { (percent) }\end{array}$ & $\begin{array}{c}\text { Grain } \\
\text { Density } \\
\left(\mathrm{gr} / \mathrm{cm}^{3}\right)\end{array}$ & $\begin{array}{l}\mathbf{K}_{\text {klink }} \\
(\mathrm{mD})\end{array}$ & $\begin{array}{c}\mathbf{S}_{\mathbf{w}} \\
\text { (percent) }\end{array}$ \\
\hline 7 & 5.19 & 3.88 & 24.0 & 2.68 & 580.91 & 37.2 \\
\hline
\end{tabular}

\subsubsection{Water Flooding}

Four pore volume of brine was injected and the volume of produced oil was recorded within specific time intervals. By having the initial oil volume in the sample and the produced oil volume, recovery factor was calculated and Figure 4-11 was plotted. As figure illustrates, more than half of the initial oil was produced by simulating primary and secondary recovery and up to $86.2 \%$ of this production happened before water 
break through, which shows higher values of oil relative permeability respect to the water relative permeability for small water saturation that leads to displace the trapped oil. In addition, by considering the amount of production, the graph shows no significant amount of oil production after two pore volume of injection; therefore two pore volume is the optimum amount of injection.

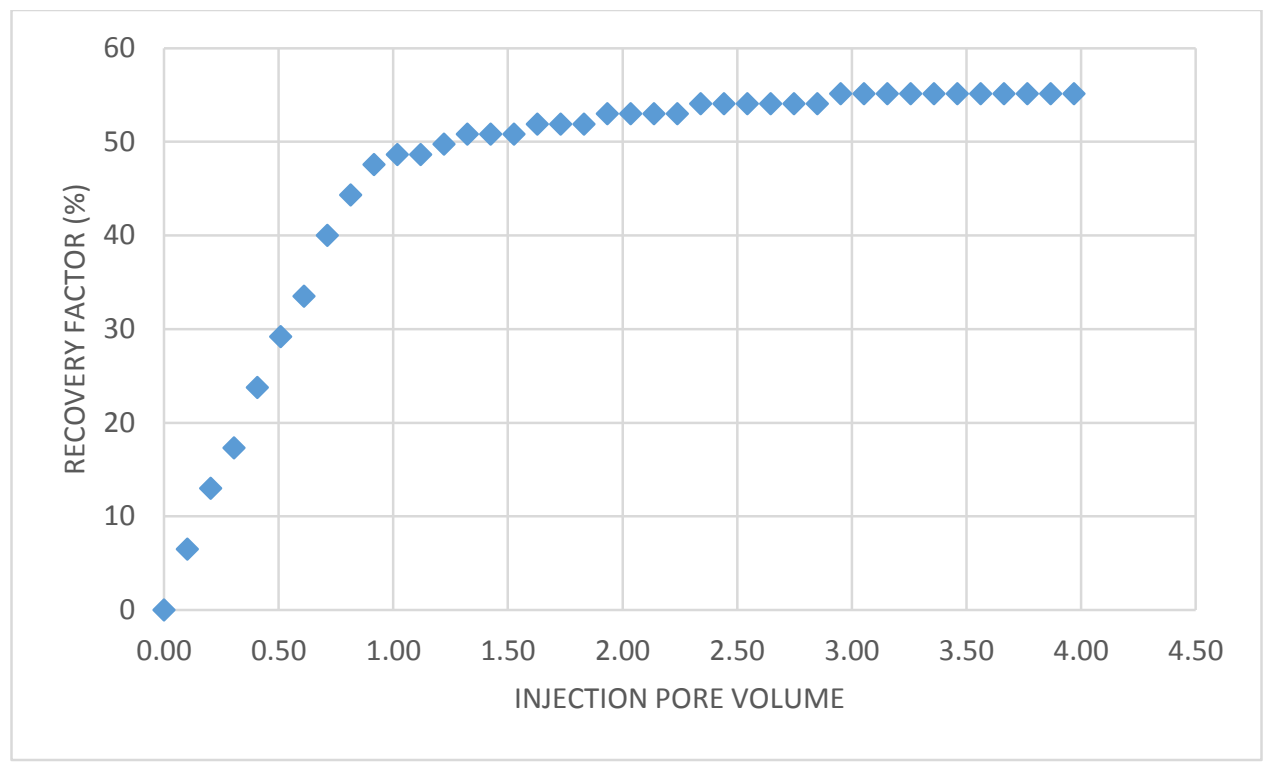

Figure 4 - 11 Recovery Factor in Sample \#7 Water Flooding

Figure 4-12 shows the result of oil saturation changes versus pore volume of injected water. The drastic reduction of oil saturation at the beginning of the injection can be interpreted due to the water wet tendency of grains' surface. Since the grains in water wet rock are covered with a thin film of water, during the water injection, water droplets are trying to attach to each other and occupy the pore's space; therefore they push out the oil droplets which are at the center of the large pore. But after the break through since water has already found its path in porous media, injected water is produced through the channels and most of the oil in channels has been already flushed out; thus injecting more pore volume of water does not lead to large produced oil volume. 


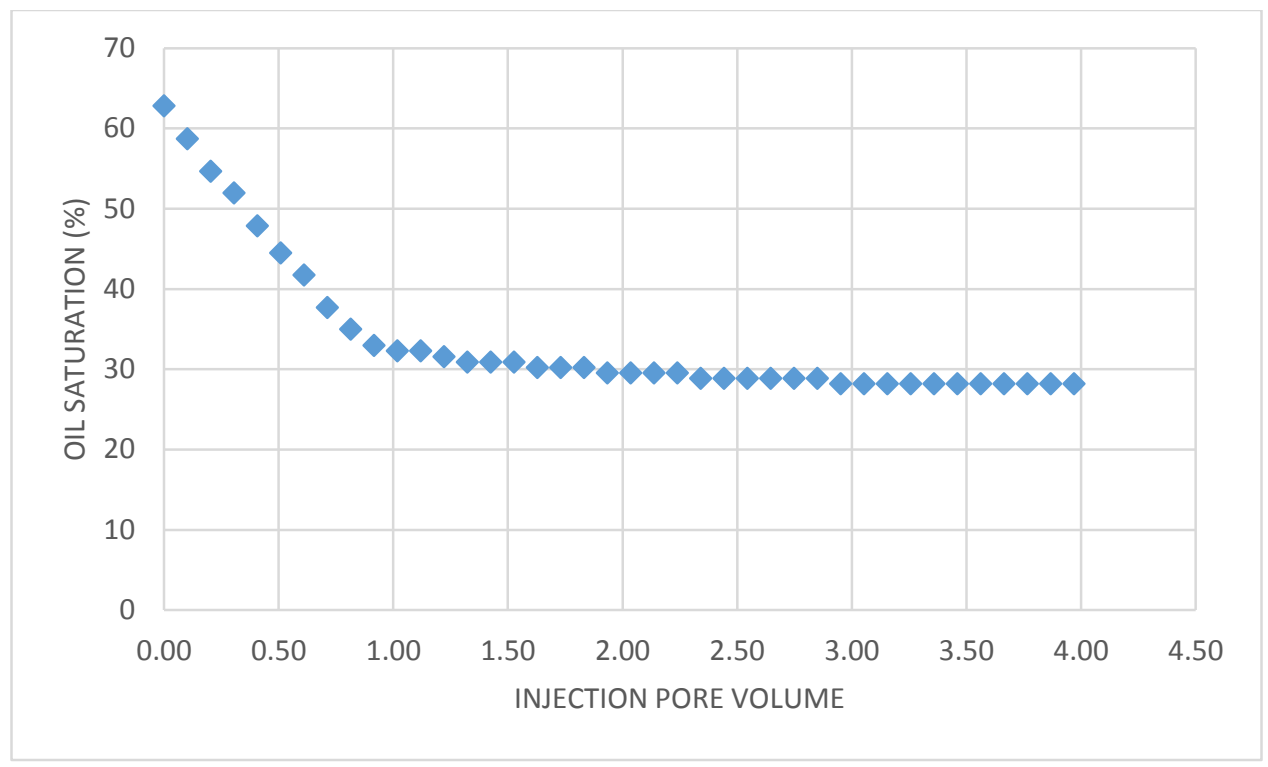

Figure 4 - 12 Oil Saturation Changes in Sample \#7 During Water Flooding

\subsubsection{HLP Nano Fluid Injection}

The water flooded sample, was subjected to HLP nano fluid injection with the concentration of $3 \mathrm{gr} / \mathrm{lit}$ for three pore volume and the produced oil was recorded in different time intervals. Figure 4-13 shows the calculated and plotted recovery factor for nano fluid injection. The graph illustrates that during the first tenths of injected pore volume, no changes can be seen in recovery factor and it can be explained due to the production of brine from the core outlet, since nano fluid's front has not traveled the length of the core sample yet. After a short while oil starts to produce and the nano fluid could recover up to $46.9 \%$ of the trapped oil after water flooding process. In this test the total recovery factor of $78.9 \%$ was achieved after water and nano fluid flooding. 


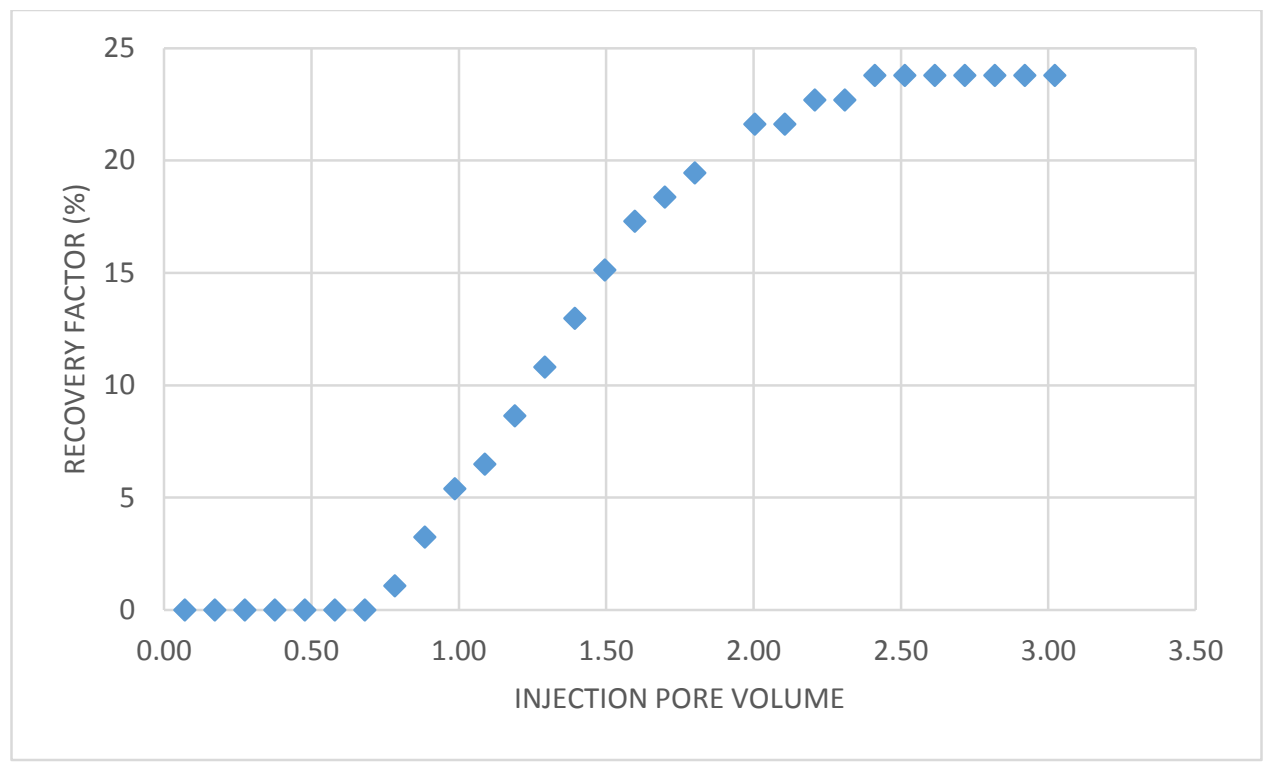

Figure 4 - 13 Recovery Factor Changes in Sample \#7 During HLP Flooding

Figure 4-14 shows the oil saturation variation versus injected pore volume of nano fluid. The graph presents no variation due to the reason discussed before, but as soon as nano fluid's front reaches to the core outlet, it brings the released oil droplet with itself. The records show the reduction of $14.9 \%$ in oil saturation just in 1.7 of pore volume. The decline saturation curve can be divided to two parts to discuss this phenomenon. In the interval of 0.7 to 1.7 of nano fluid injection, the saturation curve has a sharp slope in comparison with 1.7 to 2.3. The sharp reduction in the first part can be expressed because of IFT reduction in the first contact of nano fluid and trapped oil droplet in porous media, which leads to reduce capillary pressure value and ease of oil migration in porous media. Afterwards the production could be explained due to wettability alteration, since nano particles had enough time to settle on grains' surface and change their wettability from water wet to neutral wet which means the contact angle of close to $90^{\circ}$, in other words values of close to zero for capillary pressure which is a supportive agent for the oil droplets that could not be produced even by the help of surfactant property of injection fluid. 


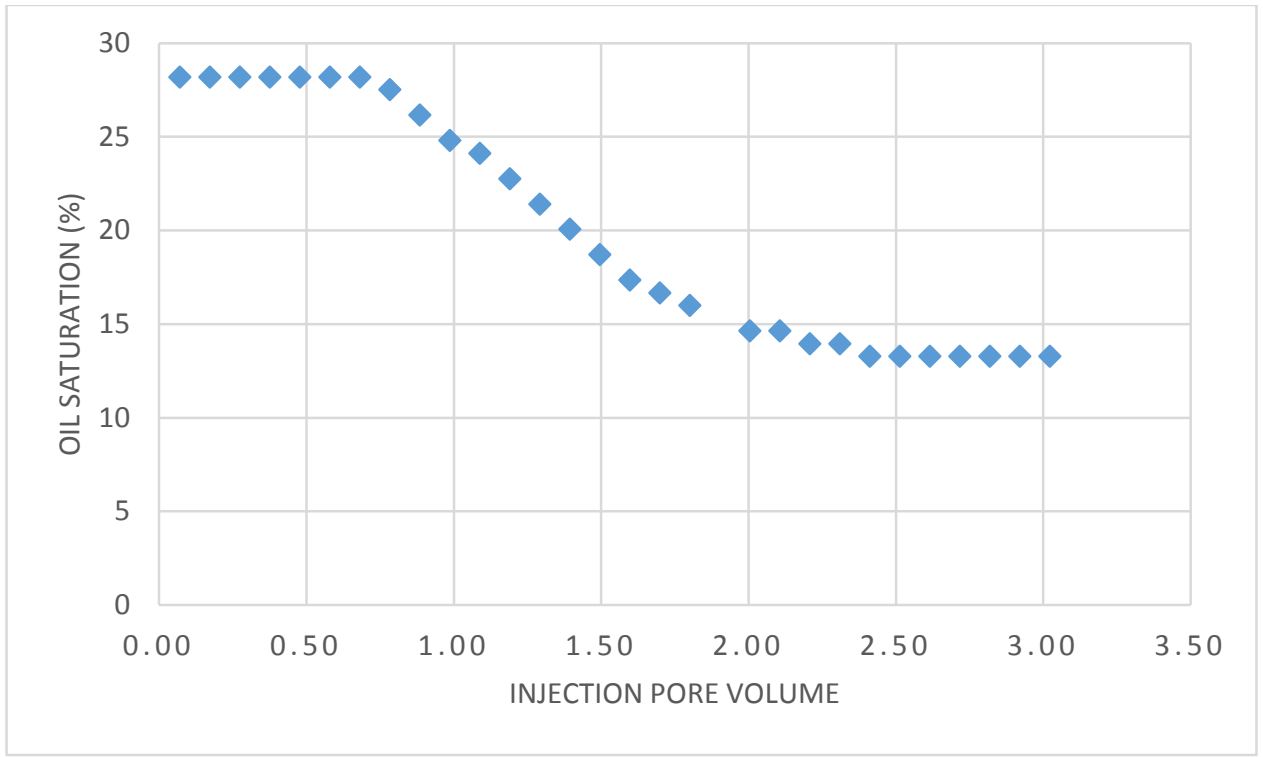

Figure 4 - 14 Oil Saturation Changes in Sample \#7 During HLP Flooding 


\section{Chapter 5: Conclusions and Recommendations}

\subsection{Summary of Conclusions}

In this research the effect of nano particles on additional oil recovery after conducting the primary and secondary recovery by the means of water flooding on three core plugs were studied. The main figured out points are listed as follow.

- Higher concentrations of NWP and HLP nano fluid reduce the interfacial tension value significantly. This can bring up the surfactant characteristic of these two types of nano particles when they are dispersing in ethanol.

- Higher concentrations of NWP nano fluid can lead to larger wettability alteration while in HLP nano fluid for the concentrations of greater than $1.5 \mathrm{gr} /$ lit, no significant changes can be noticed.

- The main mechanism of additional produced oil after using NWP and HLP nano fluid in core samples is reduction of IFT as well as changing the wettability angle of the rock.

- Additional produced oil after injecting the nano fluid into the porous media can be divided in two subsets. The first volumes of produced oil can be recognized due to interfacial tension value reduction after nano fluid contacted with oil and the capillary pressure reduced in porous media; and the last volumes after the settlement of nano particles on grains' surface and changing wettability angle to the values close to 90 degree which led to reduction of the capillary pressure and ease of oil migration through small pore throats, these two phenomenon caused additional oil recovery of $29.9 \%$ and $30.7 \%$ respectively.

- For sandstone plugs the optimum volume of water flooding was determined as two pore volume since most of the oil production happened before break through which means injecting more water is not economical due to high water/oil ratio.

- For NWP and HLP nano fluid the optimum concentration of injection was determined as 2.5 pore volume since no significant oil production could be seen after that. 


\subsection{Recommendations for Future Work}

Based on the findings of this experiment and the challenges encountered in this experiment in order to fully understand the related parameters to oil production and optimizing them, some recommendations are made for future work:

- In this experiment ethanol was chosen as the carrier fluid for dispersing nano particles, it is suggested to use other non-polar fluids with higher evaporating point to simulate high temperature reservoir condition and study the effect of nano particles on oil recovery at HPHT condition.

- Sodium chloride was used for preparing brine to conduct water flooding and simulating initial water saturation in core samples. It is recommended to use different salts which present in reservoir brine to prepare the synthetic formation water, since cations and anions may affect nano particles behavior in porous media.

- Relative permeability curves play an important role in reservoir simulation and predicting reservoir behavior; therefore plotting relative permeability curves are highly recommended for this study. For three phases flowing, XRD facilities should be used to track nano particles mitigation in porous media and determining the saturation at each point.

- Nano particles need time to settle on grains' surface and change the rock wettability, it is suggested to conduct different experiments with different aging time and measure the effect of time on amount of recovery factor.

- Nano particles were suspended in the fluid by help of stirring and ultra-sonic device; studying the nano fluid stability under HPHT condition by using XRD facilities is recommended.

- The study of formation damage is recommended since after injecting several pore volume of nano fluid, nano particles may block tight pore throats and reducing the permeability. 


\section{References}

[1] Hamid, M. F. and Sulaiman, W. S. W., "Fundamentals of Petroleum Engineering, Rock and Fluid Properties”, University Technology Malaysia, Department of Petroleum Engineering

[2] Atiia, A. M., "Review of Reservoir Rock and Fluid Properties", The British University in Egypt, Department of Petroleum Engineering

[3] http://pages.geo.wvu.edu/ jtoro/petroleum/Review\%202.html

[4] http://www.wvsoro.org/resources/pooling_unitization/slide_06.html

[5] http://www.geomore.com/oil-and-gas-traps/

[6] http://www.co2crc.com.au/imagelibrary3/storage.php?screen=4

[7] Abu-Khamsin S. A., "Basic Properties of Reservoir Rocks", King Fahad University of Petroleum \& Mineral, Dhahran, Saudi Arabia, 2004.

[8] Bateman, R. M., "Openhole Log Analysis and Formation Evaluation", Second Edition, Society of Petroleum Engineers, Richardson, Texas, 2012.

[9] Tarek Ahmad-Online

[10] Dandekar, A. Y., "Petroleum Reservoir Rock and Fluid Properties", Second Edition, Boca Raton, FL: CRC/Taylor \& Francis, 2006.

[11] Heinemann, Z. E., "Fluid Flow in Porous Media”, Vol. 1, Leoben, University of Leoben

[12] Anderson, W., "Wettability Literature Survey- Part 2: Wettability Measurement”, Society of Petroleum Engineers Journal of Petroleum Technology, Vol. 3811 (1986), 1246-1262

[13] http://www.spec2000.net/09-relperm.htm

[14] Aminian, K., "Basic Reservoir Engineering, Course Note", Part 1, Petroleum and Natural Gas Engineering Department, West Virginia University, 2014.

[15] http://www.aptifirst.com/rheometry/ctpt_cement_concrete_workability_test.htm

[16] Bear, J., "Dynamic of Fluids in Porous Media”, Dover Publication Inc., New York, 1988. 
[17] Green, D. W. and Willhite, P. G., "Enhanced Oil Recovery" Vol. vol. 6, Society of Petroleum Engineers, Richardson, Texas, 1998.

[18] Craft, B. C., Hawkins, M. F., Terry, R. E., “Applied Petroleum Reservoir Engineering”, Englewood Cliffs, N.J. : Prentice Hall, c1991.

[19] Donaldson, C. E., Chilingarian, G. V. and Yen, T. F., "Enhanced Oil Recovery, I Fundamentals and Analyses", Amsterdam; New York: Elsevier, 1985-1989

[20] Kong, X., and Ohadi M. M., "Application of Micro and Nano Technologies in the Oil and Gas IndustryAn Overview of the Recent Progress", SPE 138241.

[21] Ju, B., Shugao, D., Zhian L., Tiangao, Z., Xiantao, S., and Xiaofeng Q., “A Study of Wettability and Permeability Change Caused by Adsorption of Nanometer Structured Polysilicon on the Surface of Porous Media”, SPE 77938.

[22] Shah, R. D., “Application of Nanoparticles Saturated Injectant Gases for EOR of Heavy Oils”, SPE129539.

[23] Ogolo, N. A., and Olafuyi, O. A., "Enhanced Oil Recovery Using Nanoparticles”, SPE-160847.

[24] Rusheet D., S., “Application of Nanoparticle Saturated Injectant Gases for EOR of Heavy Oils”, SPE129539.

[25] Yu, H., Kotsmar, C., Yoon, K., Ingram, D., Johnston, K., Byrant, S., Huh, C., "Transport and Retention of Aqueous Dispersions of Paramagnetic Nanoparticles in Reservoir Rocks”, SPE- 129887.

[26] Villamizar, L. C., Lohateeraparp, P., Harwell, J. H., Reasasco, D. E., Shiau, B. J., "Interfacially Active SWNT/Silica Nanohybrid Used in Enhanced Oil Recovery”, SPE- 129901.

[27] Heydarian, A., Kharrat, R., and Hashemi, A., "The Impact of Sparkling Mechanism on Improving Oil Recovery in Nano-Particle Injection through Pseudo 3-Dimensional Micromodels", Journal of American Science, 2012.

[28] Yu, W., and Xie, H., “A Review on Nanofluids: Preparation, Stability Mechanisms, and Application”, Journal of Nanomaterials, 2012.

[29] Vinci Technologies Inc., "Keyphi Porosimeter and Permeameter User Guide”, France.

[30] Vinci Technologies Inc., "Formation Damage System, Model FDS-350 User Guide”, France. 
[31] Invensys Company, "Eurotherm Programmable Temperature/Process Controllers, Model 2416 User Guide", United Kingdom.

[32] Spectrum Chromatography, “CF-2 Fraction Collector User Guide”, Houston, Texas.

[33] Sartorius Mechatronics, “Sartorius CP Operating Instructions”, Goettingen, Germany.

[34] Onyekonwu, M., Ogolo, A., "Investigating the Use of Nanoparticels in Enhancing Oil Recovery", SPE-140744 